\title{
Uma Alternativa para Simplificação do Sincronismo de dados entre os Ambientes Operacionais e Analíticos
}

Leonardo Augusto Taniguti Mantovani

Orientador: Prof. Dr. João Eduardo Ferreira

Dissertação apresentada ao Instituto de Ciências Matemáticas e de Computação - ICMC-USP, como parte dos requisitos para obtenção do título de Mestre em Ciências de Computação e Matemática Computacional.

USP - São Carlos

Fevereiro de 2001 
A Comissão Julgadora:

Prof. Dr. João Eduardo Ferreira

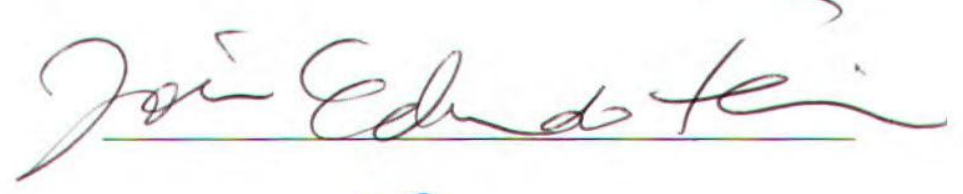

Profa. Dra. Renata Pontin de Mattos Fortes

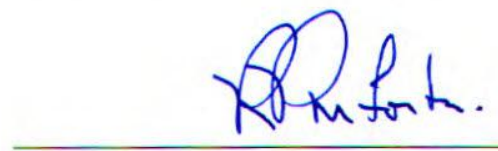

Prof. Dr. Marcelo Finger

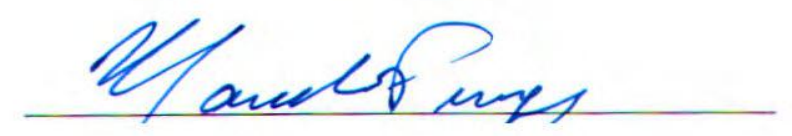


Aos meus pais, Gilberto e Maria por todo amor, compreensão para comigo e por sua moral, pessoas que sempre amarei e em quem sempre me espelharei.

Aos meus irmãos, Ricardo e Thais, por toda amizade, incentivo e carinho que sinto por ambos. 


\section{Agradecimentos}

Agradeço a Deus pela opprtunidade de realizar este trabalho sempre com muita saúde e disposição.

Ao Prof Dr. João Eduardo Ferreira por tudo que fez por mim, sua exemplar orientação e acima de tudo por sua amizade.

A Profa. Dra. Renata Pontin de Mattos Fortes por todo seu apoio e ajuda nos momentos em que se fizeram necessários.

A toda minha familia, primos, tios, avós, pelo excelente ambiente familiar em que sempre estive envolvido. Amo a todos.

A todos meus Professores, por tudo que aprendi, por todo conhecimento que me ensinaram, tanto em nível acadêmico como em nivel pessoal.

A todos meus amigos de Amparo, São Carlos, Rio Claro e São Paulo por todo apoio e amizade, pelos bons e maus momentos compartilhados. 


\section{Sumário}

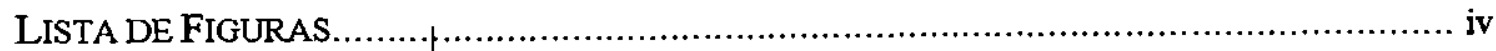

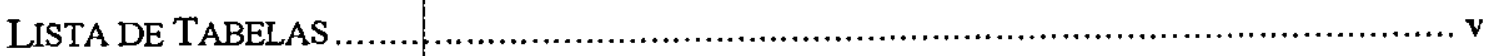

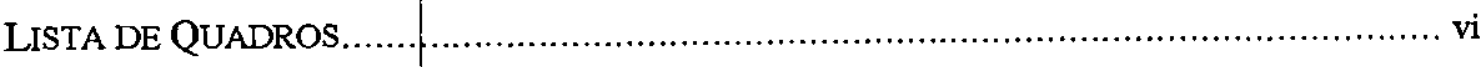

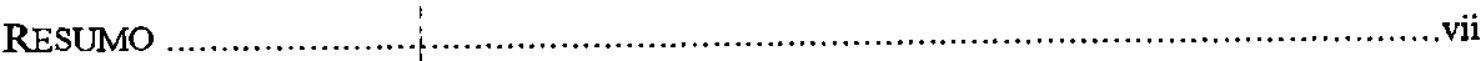

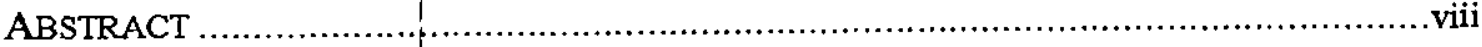

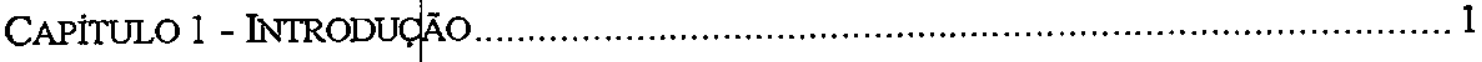

1.1 Caracterização do problema .............................................................. 1

1.2 Tópicos Abordados ............................................................................... 3

1.3 Data Warehouse, OLAP e Data Mining ..................................................... 4

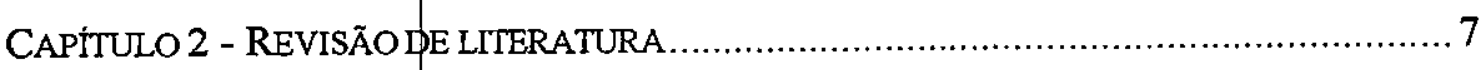

2.1 Arquitetura e o Processo no Data Warehouse ............................................ 7

2.2 Fases do Data Warehouse ................................................................ 9

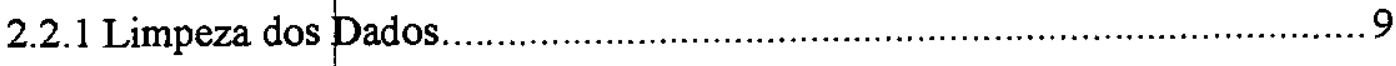

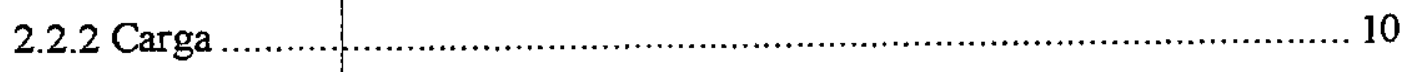

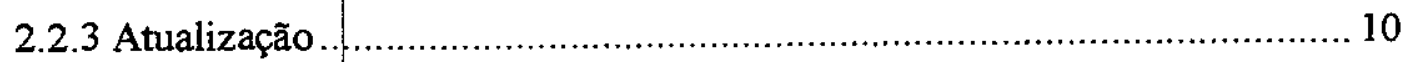

2.3 Modelo Conceitual e Metodologia de Projeto do Banco de Dados.................. 11

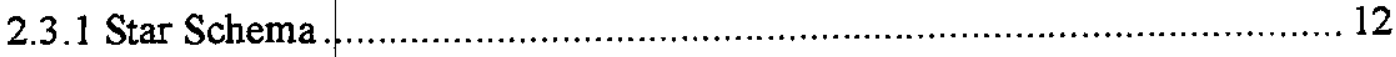

2.3.2 Star Schema Parcial...................................................................... 14

2.3.3 Constelações de fatos ................................................................ 15

2.3.4 Schema Dimension Partitioning .................................................. 16

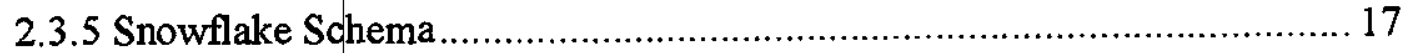

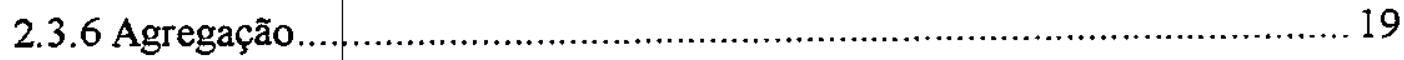

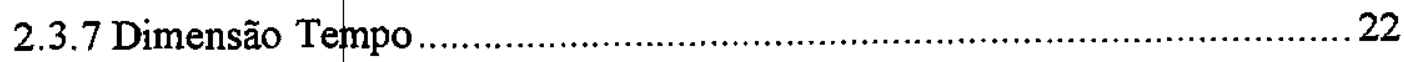

2.3.8 Hierarquia Unívoca e Ambígua .................................................... 23

2.3.9 Chaves primárias com significado semântico X Chaves Geradas .............. 23

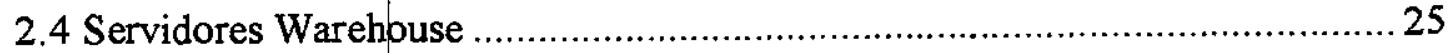

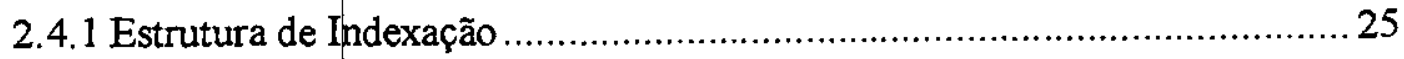

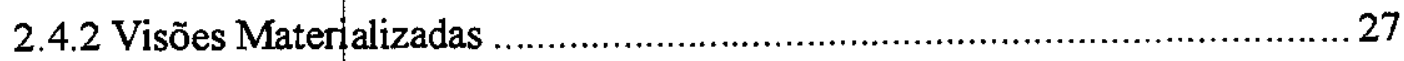

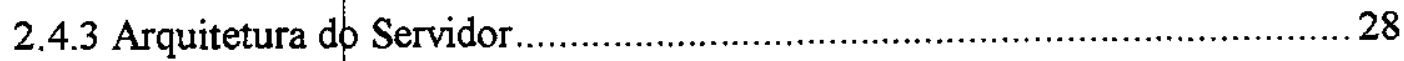

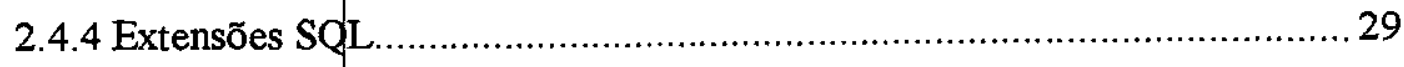

2.5 Metadados e Gerenciamento do Warehouse .............................................. 30 


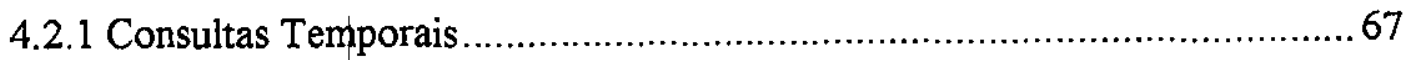

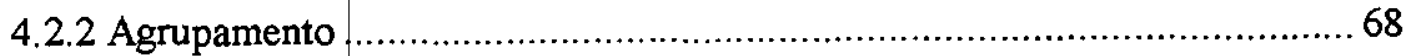

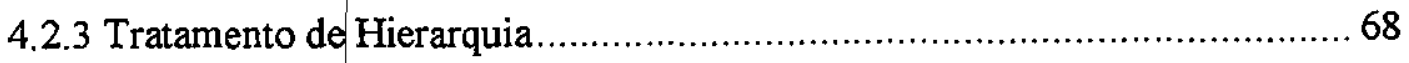

4.2.4 Consultas FH agregação completa................................................ 70

4.2.5 Consultas FH agregação parcial.................................................. 70

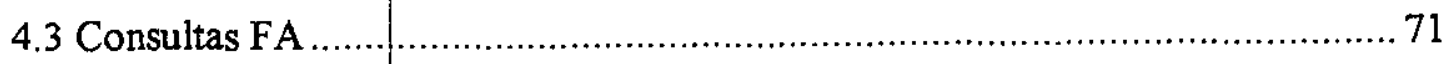

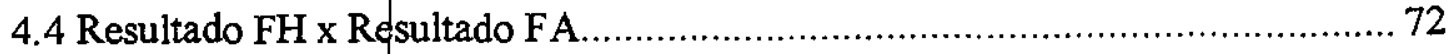

4.4.1 Índices Histórico-Analítico ..................................................... 72

4.5 Aspectos para Geração de Consultas ...................................................... 75

4.5.1 Alternativas para representação dos dados em DW ............................... 76

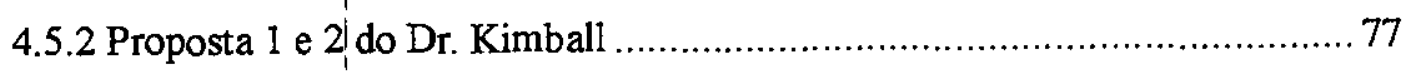

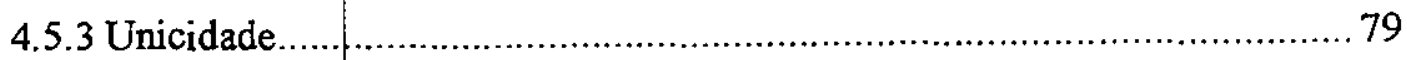

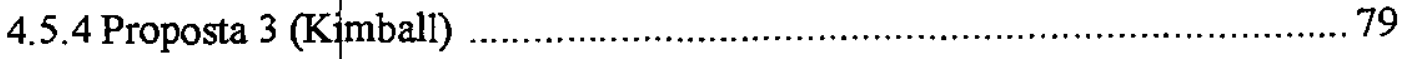

4.5.5 Proposta 4 - Data Warehouse Temporal .......................................... 82

4.6 Tratamento das Agregações de Composição / Especialização.......................... 91

4.6.1 Replicação de Chaves...................................................................... 91

4.6.2 Sem replicação de Chaves ......................................................... 92

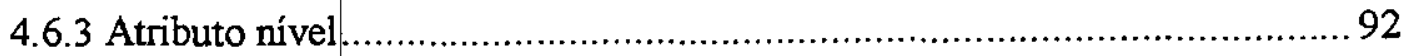

CAPÍTULO 5 - CONCLUSÃ

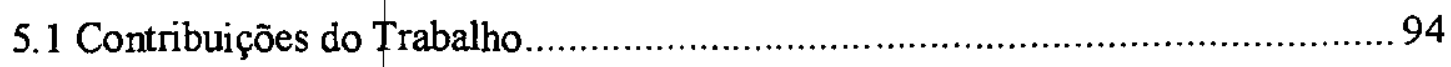

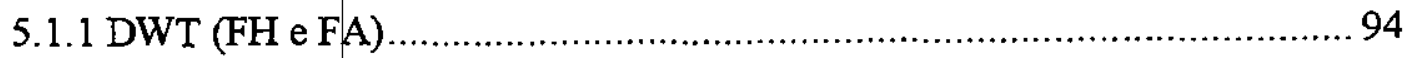

5.1.2 Monitor de Consultas ................................................................ 95

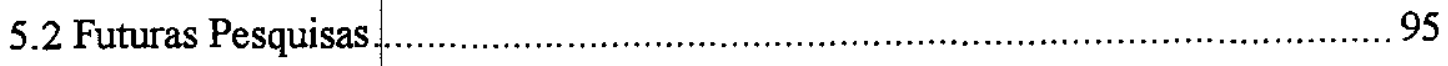

5.2.1 Métrica para classificação de transações................................................ 95

5.2.2 Alteração dos Algoritmos de Sincronismo............................................95

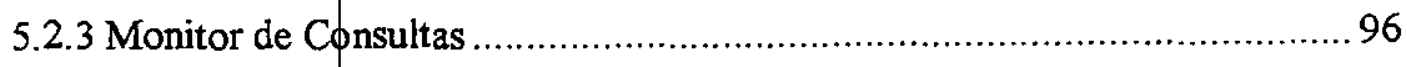

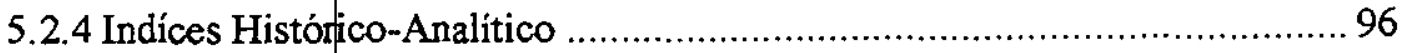

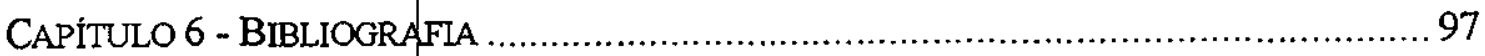

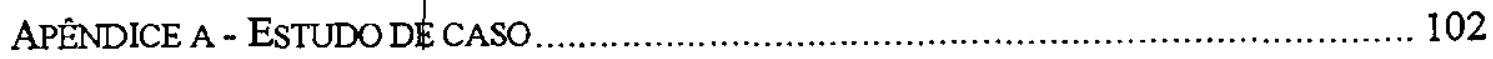




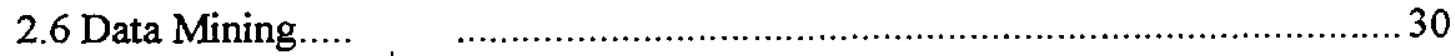

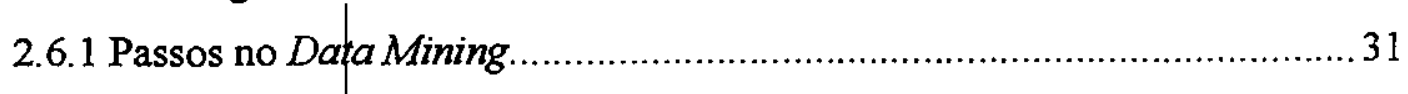

2.6.2 Características necessárias ao Data Mining ........................................ 32

2.7 Data Warehouse articulado ao Data Mining .............................................. 34

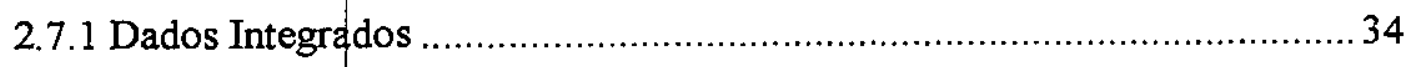

2.7.2 Dados Particularizados e Sumariados .......................................... 34

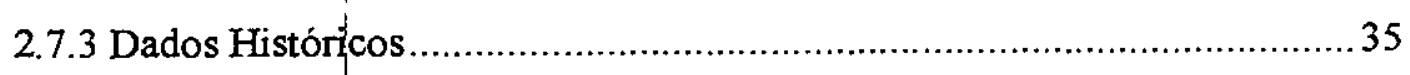

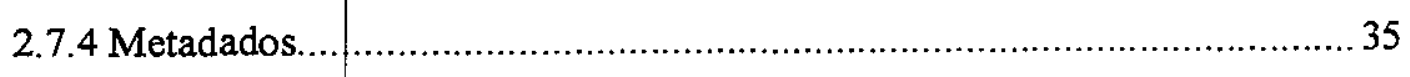

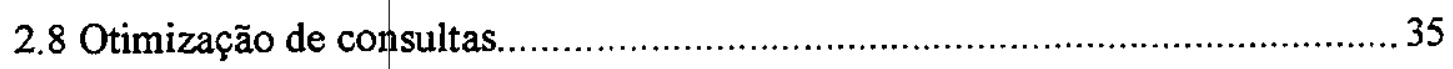

2.8.1 Plano de Avaliação de Consultas....................................................... 37

2.8.2 Aplicação precoce de seleções........................................................ 39

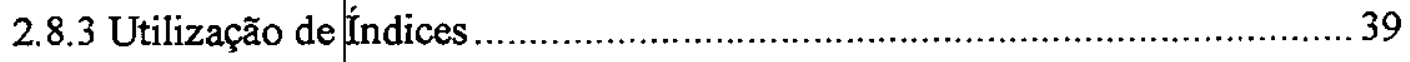

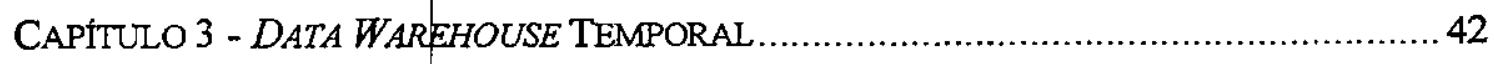

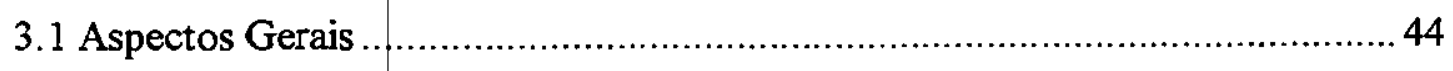

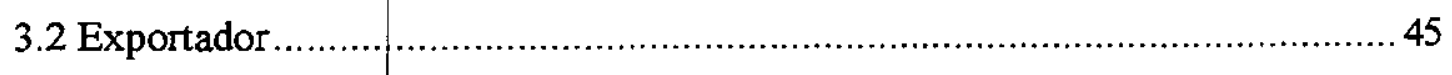

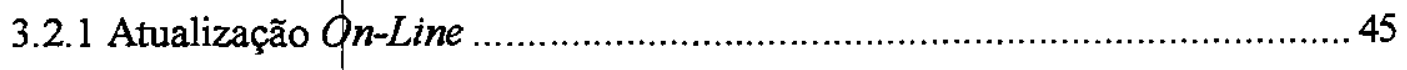

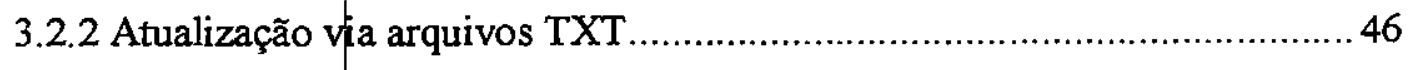

3.2.3 Atualização via tabelas temporárias.................................................. 46

3.2.4 Uma combinação das soluçõse apresentadas (configurável) ....................47

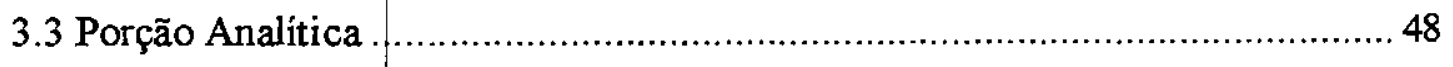

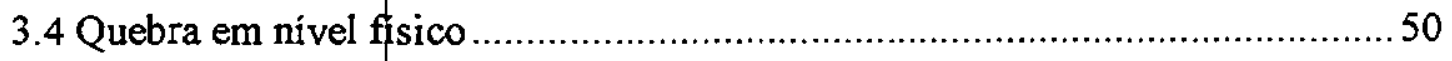

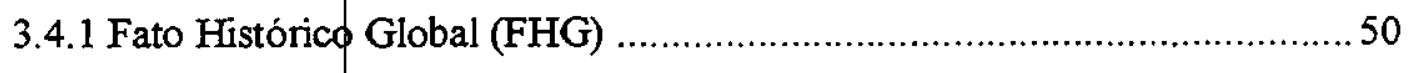

3.4.2 Fato Histórico Parcial-Dimensional-Independente (FHPDI) ...................51

3.4.3 Fato Histórico Parcial-Dimensional-Semi-Dependente (FHPDSd) ...........51

3.5 Quebra de FH por domínio - FHn .................................................. 55

3.6 Especialização / Composição ............................................................... 57

3.7 Tratamento de alterações ocorridas nas tabelas de dimensão .........................6 60

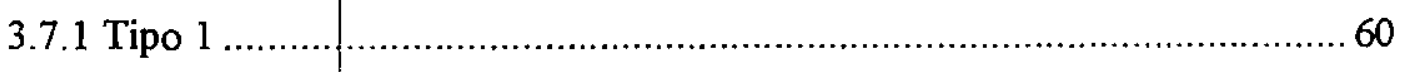

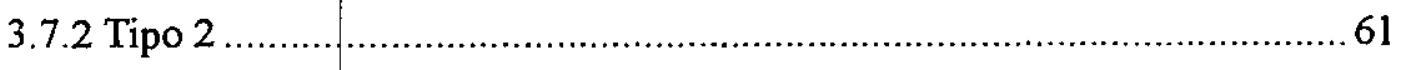

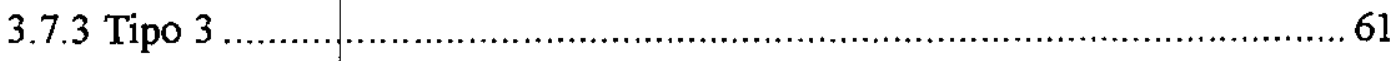

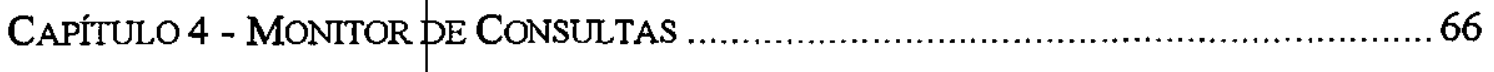

4.1 Considerações Gefais sobre Data Warehouse Temporal ................................6 66

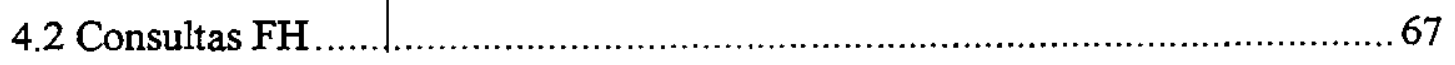




\section{Lista de Figuras}

FIGURA 2.1 - ARQUTETURA TÍPICA DE UM DATA WAREHOUSE ............................ 8

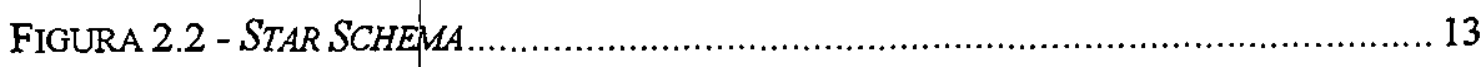

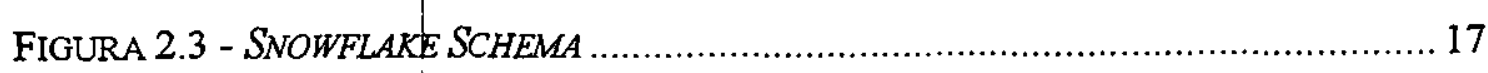

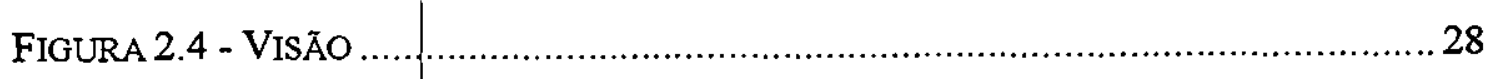

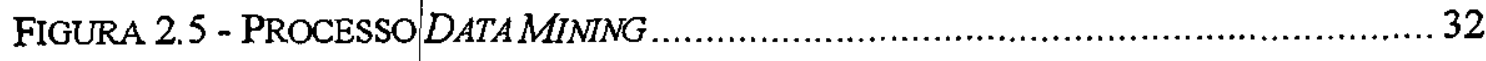

FIGURA 2.6 - PASSOS DE PROCESSAMENTO DE UMA CONSULTA DE ALTO NIVEL............. 36

FIGURA 2.7 - PLANO dE AVALIAÇÃO PARA A CONSULTA DADA ................................ 38

FIGURA 2.8 - PLANO DE EXECUÇÃO COM UTILIZAÇÃO DE ÍNDICES .......................... 40

FIGURA 3.1 - MODELAGEM DO SISTEMA.TRANSACIONAL E ANALITICO ..................... 44

FIGURA 3.2 - EXEMPLIFICAÇÃO DOS CONCEITOS DE FHG, FHPDI E FHPDSD .............53

FIGURA 3.3 - DIMENSÃ

FIGURA 3.4 - DIMENSÄ Q GEOGRAFIA - TRATAMENTO HISTÓRICO $\ldots \ldots \ldots \ldots \ldots \ldots \ldots \ldots \ldots 62$

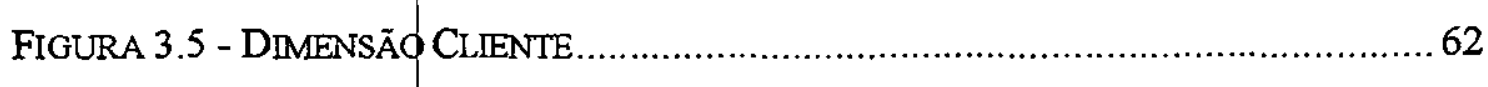

FIGURA 3.6 - TRATAMENTO HISTÓRICO DE DIMENSŌES - DATA DE ALTERAÇÃO ...........63

FIGURA 3.7 - TRATAMENTO HISTÓRICO DE DIMENSÕES - INTERVALO DE TEMPO ...........64

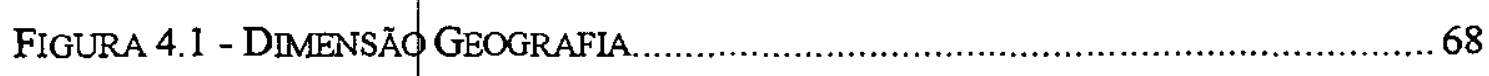

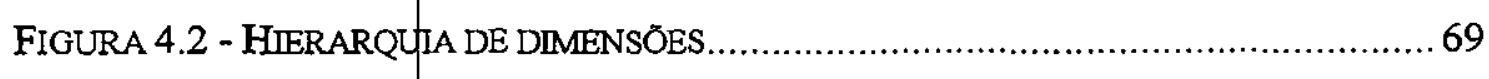

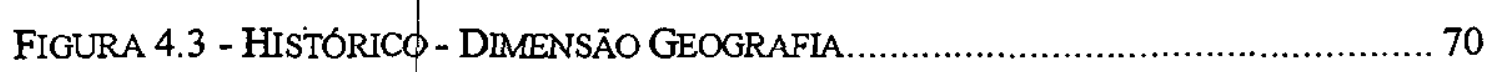

FIGURA 4.4 - MODELO DATA WAREHOUSE EXEMPLO ........................................ 77

FIGURA 4.5 - CRIAÇÃO DE TABELAS TEMPORÁRIAS PARA TRATAMENTO HISTÓRICO ...... 81

FIGURA 4.6 - TRATAMENTO DADO AO DATA WAREHOUSE HISTÓRICO ........................ 83

FIGURA 4.7 - HISTÓRIC $\varnothing$ ENTRE TABELA DE DIMENSÕES X TABELA DE FATOS ............85

FIGURA 4.8 - TRATAMENTO DE PERIODOS DE DATA ........................................... 86

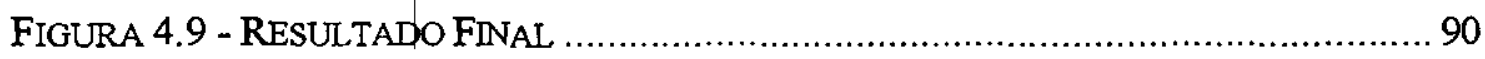




\section{Lista de Tabelas}

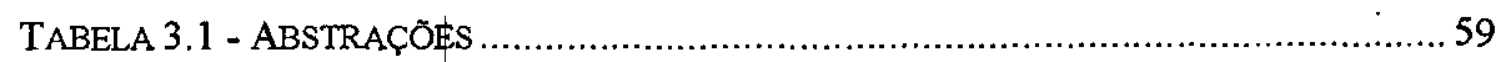

TABELA 4.1 - CONSULTA TIPICA NUM DATA WAREHOSUE .................................... 76 


\section{Lista de Quadros}

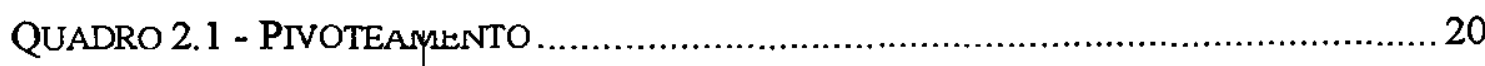

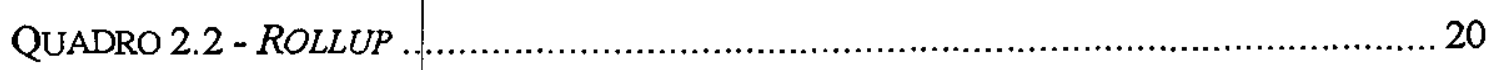

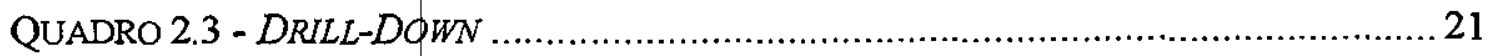

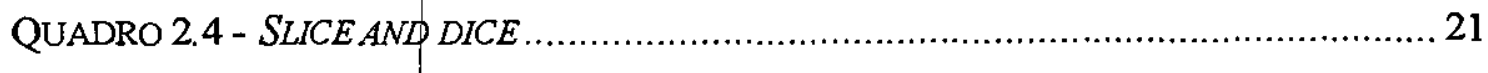

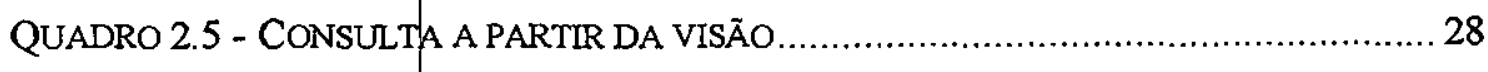

QUADRO 2.6 - CONSULTA DO QUAL SERÁ EXTRAIDA O PLANO DE EXECUÇÃO ............... 37

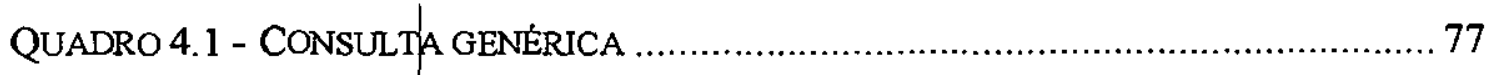

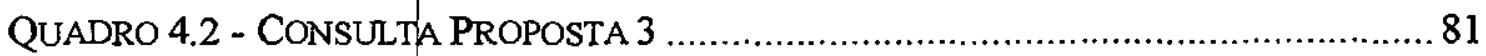

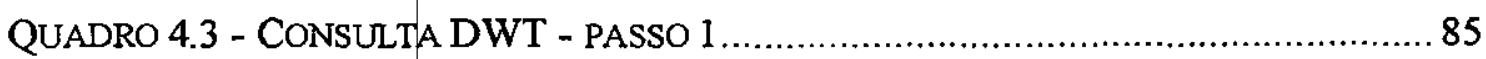

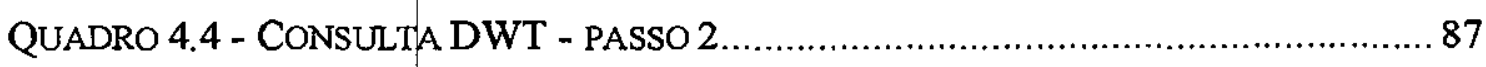

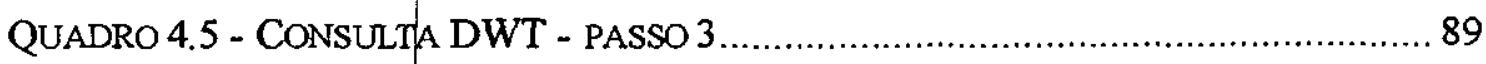

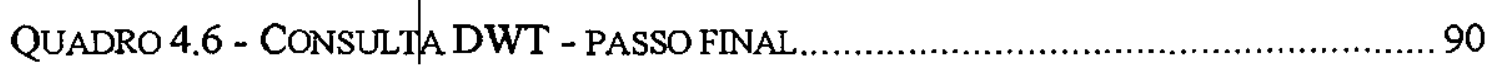




\section{Resumo}

A complexidade transacional envolvida na atualização de um Data Warehouse (DW) é considerável. Tal complexidade pode inviabilizar o projeto do DW.

Em alguns casos o ambiente operacional não consegue atender as requisições de consultas do DW. Isto acontece quando não existe agilidade para responder as consultas no ambiente operacional ou quando a soprecarga para atualização do DW é grande.

Este trabalho apresenta uma nova estrutura para armazenamento de dados denominada de Data Warehouse Temporal (DWT). Esta nova estrutura objetiva diminuir a complexidade da comunicação entre o ambiente operacional e analítico. Tal estrutura facilita as atualizações dos dados históricos dos ambientes operacionais para o Data Warehouse. 


\section{Abstract}

The transactional complexity involved in updates of the Data Warehouse is considerable. This transactional complexity may be induce many problems to Data Warehouse project.

Sometime the operational environment couldn't to attend the request of Data Warehouse queries. It is possible when the answer time of the operational environment isn't smart or the overload to update the Data Warehouse is big.

This work propose a new structure of Data Warehouse called Temporal Data Warehouse. The new structure purpose to reduce the communication between analytical and operational environment. Than, the updates of the historical operational data to Data Warehouse could be simplify. 


\section{Capítulo 1}

\section{Introdução}

Data Warehouse e on-line analytical processing (OLAP) são elementos de grande importância para sistemas de suporte a decisão (Chaudhuri \& Dayal, 1997). Atualmente todos os principais fabricantes de sistemas gerenciadores de Banco de Dados oferecem recursos nessas áreas. Suporte a decisão tem requisitos diferentes em relação ao Banco de Dados se comparados ao tradicional on-line transaction processing (OLTP). Minerar a informação e extrair conhecimento de grandes Bancos de Dados são tópicos chave de pesquisa para diferentes áreas, incluindo banco de dados. Pesquisadores das mais diferentes áreas têm demonstrado grande interesse em Data Mining (Chen et. al., 1996). Há uma relação simbiótica entre Data Mining e Data Warehouse (Inmon, 1996). Data Mining pode ser aplicado onde não exista Data Warehouse, mas o Data Warehouse aumenta as chances de sucesso de um Data Mining. Veremos nesse capítulo introdutório a caracterização do problema a ser abordado no projeto de mestrado em questão e um resumo sobre Data Warehouse, tecnologia OLAP e Data Mining e a maneira pela qual elas se encontram relacionadas

\subsection{Caracterização|ao Problema}

Atualmente dado o grande volume de informações já armazenadas ou com grande potencial de armazenamento, as aplicações para os sistemas de informação tem se ressentido de uma estrutura de armazenamento de dados histórica que suporte as necessidades de manipulação transacional e ao mesmo tempo forneçal condições para as necessidades de análise de gestão da informação. 
As soluções atualmente existentes separam esses dois aspectos operacionais ${ }^{1} \mathrm{e}$ analíticos ${ }^{2}$. As estruturas de dados são específicas para cada segmento e os gerenciadores de dados não estão preparados para suportar a heterogeneidade da estrutura de dados dessas informações, principalmente num ambiente com potencialidade para distribuição, clusterização e materialização dos dados em questão.

Dessa maneira o projeto de pesquisa em questão tem por objetivo: levantar as estruturas convencionais para armazenamento histórico tanto no ambiente operacional como no ambiente analítico; estabelecer diretrizes para a criação de uma metodologia que busque integrar as estruturas envolvidas de modo a facilitar a transição entre o ambiente operacional e analítico num contexto de armazenamento de dados distribuído e/ou centralizado. A complexidade transacional envolvida na manutenção / atualização de um Data Warehouse é grande (Zhuge et. al., 1998). Este trabalho tem como principal objetivo a diminuição da comunicação entre 0 ambiente operacional e o ambiente analítico, possibilitando com isso uma diminuição da complexidade transacional envolvida no processo.

O trabalho proposto se utilizará do estudo de caso da Secretaria da Fazenda do Estado de São Paulo. Através da análise deste estudo de caso objetiva-se validar diretrizes de apoio na modelagem de dados para concepção de Data Warehouse integrado aos ambientes operacionais.

1 operacionais - utilizado para feferenciar ambientes de transaçōes operacionais

2 analíticos - utilizado para referenciar ambientes de transações analíticas 


\subsection{Tópicos Abordlados}

No segundo capítulo será vísto a arquitetura e o processo do Data Warehouse. As fases em que o Data Warehouse se encontra dividido, os modelos conceituais Star Schema e SnowFlake Schema e os recursos que podem ser utilizados visando um melhor desempenho do mesmo. Em seguida veremos os principais aspectos do Data Mining e os passos em que se encontra dividido e suas características. Veremos a importância do Data Warehouse para a obtenção de um Data Mining eficiente apresentando as principais técnicas de classificação de Data Mining. Finalmente veremos um tópico que tratará de otimização de consultas SQL em ambientes relacionais visando com isso a obtenção de maior eficiência nas consultas realizadas ao Data Warehouse.

No terceiro capitulo serão apresentados novos aspectos de modelagem e conceitos para a concepção que chamamos neste trabalho de Data Warehouse Temporal. Suas vantagens e desvantagens em relação|ao modelo tradicional de Data Warehouse. As duas diferentes distribuições de dados para o DWT, quebra em nivel fisico e por domínio, visando um melhor desempenho do mesmo. Os diferentes tratamentos históricos das dimensões também serão tratados neste capítulo.

No capítulo quatro será visto como pode ser feita a implementação das diferentes soluções apresentadas no capítulo tfês. Propõe-se a criação de uma ferramenta que terá a capacidade de considerar os parâmetros de uma consulta para apoio a diferentes estruturas de consultas SQL para cada modelo fisico de dados armazenados no Data Warehouse. Para isso é necessário considerar uma série de parâmetros que serão vistos neste capítulo.

No capítulo cinco apresentamos a conclusão desta dissertação de mestrado, com suas contribuições e os próximos tópicos para futuras pesquisas.

A seguir apresentaremos, de forma resumida, alguns conceitos de grande importância para a apresentação desta dissertạ̧ão. 


\subsection{Data Warehouse, OLAP e Data Mining}

Data Warehouse é uma coleção de tecnologias de suporte a decisão, objetivando melhores tomadas de decisão e de uma maneira mais rápida. A tecnologia de Data Warehouse tem sido empregada com sucesso em muitas indústrias: manufatura, serviços financeiros, telecomunicações etc. Um Data Warehouse é integrado, incremental, seus dados são não voláteis. O Data Warehouse é usado primariamente para tomadas de decisão organizacionais. Tipicamente temos que o Data Warehouse é mantido separadamente do Banco de Dados Operacional. O Data Warehouse suporta OLAP (Processos Analíticos cujas respostas são dadas On-line), os requisitos funcionais e de desempenh $\phi$ são diferentes entre OLAP e OLTP. OLTP (Processos Transacionais que são realizados On-line) são aplicações tradicionalmente suportadas por Banco de Dados operacionais.

Aplicações OLTP são tipicamente tarefas de processamento de dados automatizados como transaçס̃es bancárias, operações do dia a dia de uma organização. Estas tarefas são estruturadas e repetitivas e consistem de transações pequenas, atômicas. Estas transações geralmente lêem ou alteram poucos registros acessados tipicamente pela sua chave primária. Banco de Dados operacionais tendem a ter centenas de megabytes em tamanho. Consistência e recuperação destes Banco de Dados são críticos. O Banco de Dados é projetado para refletir a semântica operacional das aplicações conhecidas ę em particular, para minimizar a ocorrência de conflitos.

O Data Warehouse, em contraste, é direcionado para suporte a decisão. Dados históricos, sumariados e consolidados são mais importantes do que os registros individuais, desde que contenha dados consolidados, muitas vezes de vários Bancos de Dados operacionais, sobre um longo período de tempo é natural que ele possua uma ordem de magnitude superior aos Banco de Dados operacionais. O Data Warehouse é projetado para ter de centenas de gigabytes a terabytes em tamanho. O Data Warehouse deve providenciar além do uso intensivo de consultas o uso de consultas complexas que podem acessar milhões de registros.

Para facilitar a análise e visualização o Data Warehouse é tipicamente modelado utilizando o modelo multidimensional. Estas dimensões podem ser hierárquicas: tempo pode estar na hierarquia dia-mês-bimestre-semestre-ano. Tipicamente operações OLAP (On Line Analytical 
Process) incluem rollup, drill-down, slice_and_dice e pivoteamento, que serão detalhados na sequência.

Dado que Banco de Dados operacionais são construídos visando suportar OLTP (On Line Transactional Process), quando tentamos executar complexas consultas OLAP sobre o Banco de Dados operacional temos que muitas vezes o desempenho é inaceitável. Além disso, suporte a decisão pode necessitar de dados que podem estar faltando no Banco de Dados operacional; devemos considerar ainda que para fazer previsões são necessários dados históricos. Entretanto, o Banco de Dados operacional não consegue armazenar dados históricos de maneira eficiente para a recuperação analítica. Suporte a decisão geralmente requer consolidação de dados de muitas fontes heterogêneas. As diferentes fontes contêm dados em diferentes formatos que precisam ser integrados. Finalmente, suporte a modelo de dados multidimensional e operações típicas de OLAP necessitam de uma organização especial dos dados, métodos de acesso, e métodos de implementação, que não são geralmente providos por Sistemas Gerenciadores de Banco de Dados (SGBDs) comerciais objetivando OLTP.

O Data Warehouse geralmente armazena dados históricos, dados que são obtidos com o passar do tempo. Porém devemos destacar que a abordagem tradicional de um Data Warehouse não possui função de um bancol de dados histórico. Exemplo: suponha que desejamos analisar a quantidade e o valor de vendas de um determinado produto de uma rede de supermercados. Neste caso iremos armazenar dados históricos pois teremos dados referentes as vendas de um período (de um a vários meses). Geralmente quanto maior for o número de meses armazenados na base de dados a maior será a chance de obtermos informações importantes do Data Warehouse. Isto ocorre pois com uma maior quantidade de dados a chance de se encontrar um padrão relacionado as vendas de determinado pfoduto são maiores, as peridiocidades podem ser mais facilmente identificadas.

Como foi dito o Data Warehouse típico (tradicional) não tem função de base de dados histórica. Pode não ser de interesse saber o nome de determinado produto a dois anos atrás, mas o que se deseja analisar são as alterações provocadas nas vendas relacionada a mudança de nome do produto. 
Data Warehouse pode ser implementado estendendo-se os Sistemas Gerenciadores de Banco de Dados Relacionais, chamados servidores relacionais OLAP (ROLAP), como exemplo podemos citar o Informix Adaptive Server Enterprise. Estes servidores assumem que os dados estão armazenados num Banco de Dados relacional e que oferecem suporte a extensões SQL, acessos especiais e métodos de implementação para implantação do modelo de dados multidimensional e suas operações. Em contraste, servidores multidimensionais OLAP (MOLAP) são servidores que armazenam diretamente dados multidimensionais em estruturas de dados especiais e implementam as operações OLAP sobre estas estruturas de dados especiais. Como exemplos de servidores MOLAP podemos citar o IQ da Sybase.

Data Mining que é também referenciado como KDD (knowledge discovery in databases descoberta de conhecimento em banco de dados) é um processo implícito de extração não trivial de informações úteis (como regras de conhecimento, regularidades) a partir de dados que podem estar armazenados num banco de dados. Descoberta de conhecimento pode ser extraído de um conjunto relevante de dados e ser investigados de diferentes ângulos. Minerar informação e extrair conhecimento de grandes bancos de dados tem sido reconhecido como uma área de pesquisa muito forte. A descoberta do conhecimento pode ser aplicada ao gerenciamento de informação, processamento de consultas, tomadas de decisão e muitas outras aplicações. 


\section{Capítulo 2}

\section{Revisão de Literatura}

Nós iremos descrever uma arquitetura típica de Data Warehouse e o processo de projetar e operar um Data Warehouse. Veremos tecnologias relevantes para carregar e atualizar dados num Data Warehouse, servidores Data Warehouse e ferramentas de gerenciamento do Data Warehouse.

Recentemente a capacidade de gerar e colecionar dados tem aumentado (Chauduri \& Dayal, 1997). O uso de código de barras para produtos comerciais, a computação de transações governamentais e de negócios, os avanços nas ferramentas para coleção de dados têm provido uma quantidade muito grande de dados. Este crescimento explosivo na quantidade de informação e dos Bancos de dados tem gerado uma necessidade de novas técnicas e ferramentas que podem transformar os dados em informação útil e conhecimento. Conseqüentemente, Data Mining e a estrutura de armazenamento para um grande volume de dados tem-se tornado uma área de grande crescimento.

Pesquisadores de diferentes campos incluindo sistemas de banco de dados, sistemas baseados no conhecimento, inteligência artificial, aprendizado de máquina, estatística, visualização dos dados têm mostrado grande interesse em Data Mining.

\subsection{Arquitetura e o Processo no Data Warehouse}

Podemos observar que são necessárias ferramentas capazes de extrair dados de múltiplos Banco de Dados operacionais e de fontes externas; de limpar, transformar e integrar estes dados; de carregar dados para o Data Warehouse; e de periodicamente atualizar o Warehouse para refletir alterações nas fontes e para purificar dados do Warehouse. Em adição ao Warehouse principal, pode haver muitos Data Mart departamentais (Inmon, 1996). Dados num Warehouse e no Data Mart são armazenados e gerenciados por um ou mais servidores de Warehouse, que apresentam visões multidimensionais dos dados para uma variedade de ferramentas de front end. Finalmente, 
temos um repositório para armazenar e gerenciar metadados e ferramentas para monitorar e administrar o sistema Warehouse.

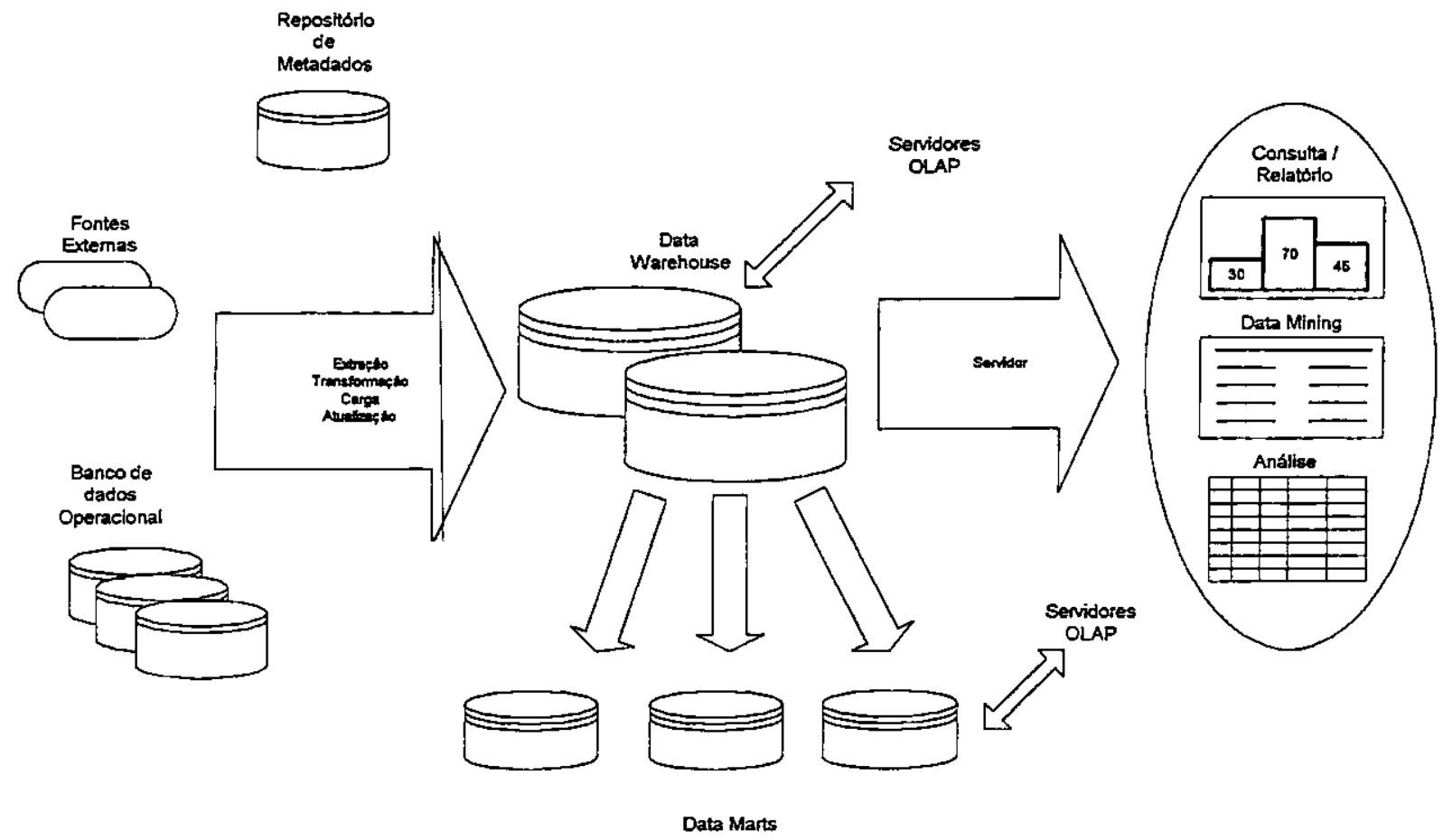

Figura 2.1 - Arquitetura típica de um Data Warehouse

O Warehouse pode ser distribuído para balanceamento de carga, escalabilidade e maior disponibilidade (Chaudhuri \& Dayal, 1997). Numa arquitetura distribuída o repositório de metadados é freqüentemente replicado em cada fragmento do Warehouse e todo o Warehouse é administrado centralmente. Uma arquitetura alternativa é uma federação de Warehouse ou Data Mart, cada qual com seu próprio repositório e administração descentralizada.

Os passos para um projeto convencional de Data Warehouse são:

- Definir a arquitetura, selecionar os servidores de banco de dados, servidores OLAP e ferramentas a serem utilizadas;

- Integrar os servidores, ferramentas para os clientes;

- Projetar o esquema e as visões do Warehouse;

- Definir a organização física do Warehouse: particionamento, métodos de acesso, posição dos dados; 
- Conectar as fontes usando gateways (possibilitam a comunicação entre equipamentos de diferentes fabricantes), drivers ODBC;

- Projetar e implementar scripts para extração, limpeza, transformação, carga e atualização dos dados;

- Povoar o repositório com o esquema e definição das visões, scripts e outros metadados;

- Projetar e implementar aplicações para o usuário final.

\subsection{Fases do Data Warehouse}

A primeira fase é a extração de dados. A extração de dados de fontes externas geralmente é implementado via gateways e interfaces padrão. As demais fases consistem de: Limpeza dos Dados, Carga e Atualização (Orli, 1996).

\subsubsection{Limpeza dos Dados}

Como o Data Warehouse é utilizado para suporte a decisões é de vital importância que os dados estejam corretos. Entretanto, devido ao grande volume de dados vindos de múltiplas fontes, a probabilidade de erros e anomalias nos dados é grande. Portanto faz-se necessário a limpeza dos dados. Alguns exemplos onde a limpeza dos dados se faz necessária: inconsistência no tamanho dos campos, entradas erradas, violação de integridade.

Existem três atividades para limpeza dos dados:

- Migração dos Dados - permitem a transformação de regras a serem especificadas, por exemplo, "troque a palavra gênero por sexo";

- Purificação dos dados - usam o conhecimento específico do domínio para purificar os dados;

- Auditoria dos dados - é possível descobrir regras e relacionamentos pela leitura minuciosa dos dados. Podem ser consideradas como ferramentas variantes de Data Mining. 


\subsubsection{Carga}

Depois de extrair, limpar e transformar os dados, os mesmos devem ser carregados para o Data Warehouse. Pré-processamento adicional ainda pode ser requerido: checagem de integridade, ordenação, soma, agregação e outras computações para construir as tabelas derivadas armazenadas no Warehouse. Tipicamente utilitários de carga em lote são utilizados para esta fase. Para popular o Warehouse, um utilitário de carga deve permitir que o administrador do sistema monitore o estado, cancele e resuma a carga. Além disso também será capaz de reiniciar a carga sem que haja perda de integtidade.

O utilitário de carga irá trabalhar com grande volume de dados. O tempo disponivel para que o Warehouse possa ser atualizado é pequeno, geralmente a noite e de madrugada. Logo o paralelismo deve ser explorado. Note que a carga completa da base, mesmo usando paralelismo, é muito longa. É mais natural que utilizemos cargas incrementais durante a fase para reduzir o volume de dados que devem ser incorporados ao Data Warehouse.

\subsubsection{Atualização}

Atualizar o Data Warehouse consiste em propagar alterações das fontes de dados para a base de dados e dados armazenados no Data Warehouse. Há duas considerações a se fazer: quando e como atualizar. Geralmente $\mathrm{o}$ Data Warehouse é atualizado de periodicamente. Somente quando consultas OLAPs requerem dados correntes é que se faz necessário propagar todas alterações. Soluções que envolvem visões materializadas são utilizadas para atender tais necessidades.

Extrair arquivos fonte ou do Banco de Dados é muito custoso. Sistemas de Banco de Dados provêm servidores de replicação que suportam técnicas incrementais para propagar as alterações em uma ou mais réplicas. Assim podemos utilizar servidores de replicação para atualizações incrementais do Warehouse.

O ciclo de atualização deve ser escolhido apropriadamente para que o volume de dados não sobrecarregue o utilitário de carga incremental. O problema para construir mecanismos que alterem dados de maneira correta tem sido o foco importante de pesquisa. Para Data Warehouse, as classes mais significantes de dados derivados são tabelas sumariadas e índices. 


\subsection{Modelo Conceitual e Metodologia de Projeto do Banco de Dados}

O modelo conceitual mais popular para Data Warehouse é o modelo de visão multidimensional dos dados (Hammer et. al, 1995). No modelo de visão multidimensional dos dados, há um conjunto de medidas numéricas que são o objeto da análise. Cada medida numérica depende de um conjunto de dimensões, que provêm o contexto para a medida. Na visão multidimensional a medida é um valor no espaço multidimensional. Cada dimensão é descrita por um conjunto de atributos. Cada dimensão pode representar um parâmetro da pesquisa que se deseja realizar sobre os dados. Os atributos de una dimensão podem estar relacionados entre si por uma hierarquia.

Uma característica dos modelos conceituais para OLAP é a agregação de medidas por uma ou mais dimensões com uma operação chave (Gupta et. al., 1995). Outra operação popular inclui a comparação entre duas medidas agregadas pela mesma dimensão. O Tempo é uma dimensão que tem grande importância para suporte a decisão e deve ser tratada de maneira especial.

Para um melhor entendimento dos conceitos acima vamos a um exemplo:

Consideremos uma rede de supermercados que deseja avaliar suas vendas e compras. A análise deve ser feita baseada em períodos de tempo, localização fisica de cada supermercado, tamanho de cada supermercado e classe econômica do público alvo. Desta maneira obtemos as seguintes dimensões: Tempo, Geografia, Tamanho e Classe.

Aonde em Tempo podemos ter os atributos: dia, mês, semestre e ano. Em Geografia temos os atributos: Bairro, Cidade, Estado e País. A dimensão Tamanho teria somente o atributo tamanho aonde poderíamos ter os valores associados: Pequeno, Médio e Grande. A dimensão Classe teria somente o atributo classe aonde poderíamos ter os valores: A, B, C, D e E. Desta maneira obtemos todas as dimensões do modelo. Observe que a dimensão Tempo e Geografia apresentam agregação de atributos. Dada uma cidade sabemos ao estado a que pertence. $O$ atributo cidade está associado ao atributo estado, encontra-se agregado ao atributo estado.

A consulta: deseja-se conhecer o valor ganho (venda de produtos) para supermercados que atendem a classe B e pertencem ao estado de SP. Esta consulta irá realizar primeiramente uma 
agregação entre as dimensões Classe e Geografia para que se obtenha o conjunto de dados desejados (classe=B e estado=SP). A seguir é feita a soma sobre a venda de cada um dos produtos que atendem a seleção. Desta maneira temos que a medida venda de produto foi agregada baseada nas dimensões Classe e Geografia aonde a operação chave foi a soma.

O modelo de dados multidimensional descrito acima é implementado diretamente por servidores MOLAP. Entretanto, quando um servidor ROLAP é usado, o modelo multidimensional e suas operações têm que ser mapeadas para relacionamentos e consultas SQL (Colliat, 1996).

Descreveremos agora o projeto de esquemas de Banco de Dados relacionais que refletem as visões multidimensionais dos dados.

\subsubsection{Star Schema}

A maioria dos Data Warehouses usam o esquema estrela (popularmente conhecido como star schema, nomenclatura esta que começaremos a utilizar devido a sua popularização) para representar o modelo de dados multidimensional (Chaudhuri \& Dayal, 1997; Ozsu \& Valduriez, 1999).

O Data Warehouse é constituído de dois elementos básicos: objetos de análise que são representados pelos fatos e os parâmetros de seleção que irão atuar sobre o objeto de análise que são denominados dimensões.

Neste modelo o banco de dados consiste de uma tabela de fatos e de tabelas de dimensão. Todas as tuplas na tabela de fatos contêm: ligações para cada uma das dimensões que provêm coordenadas multidimensionais e medidas numéricas para estas coordenadas. Cada tabela de dimensão consiste de colunas que correspondem aos atributos da dimensão. A dimensão tempo geralmente está sempre presente no Data Warehouse. As dimensões são pouco mutáveis e com uma quantidade de informações bem inferior a tabela de fatos. A figura 2.2 mostra um exemplo de um star schema. 


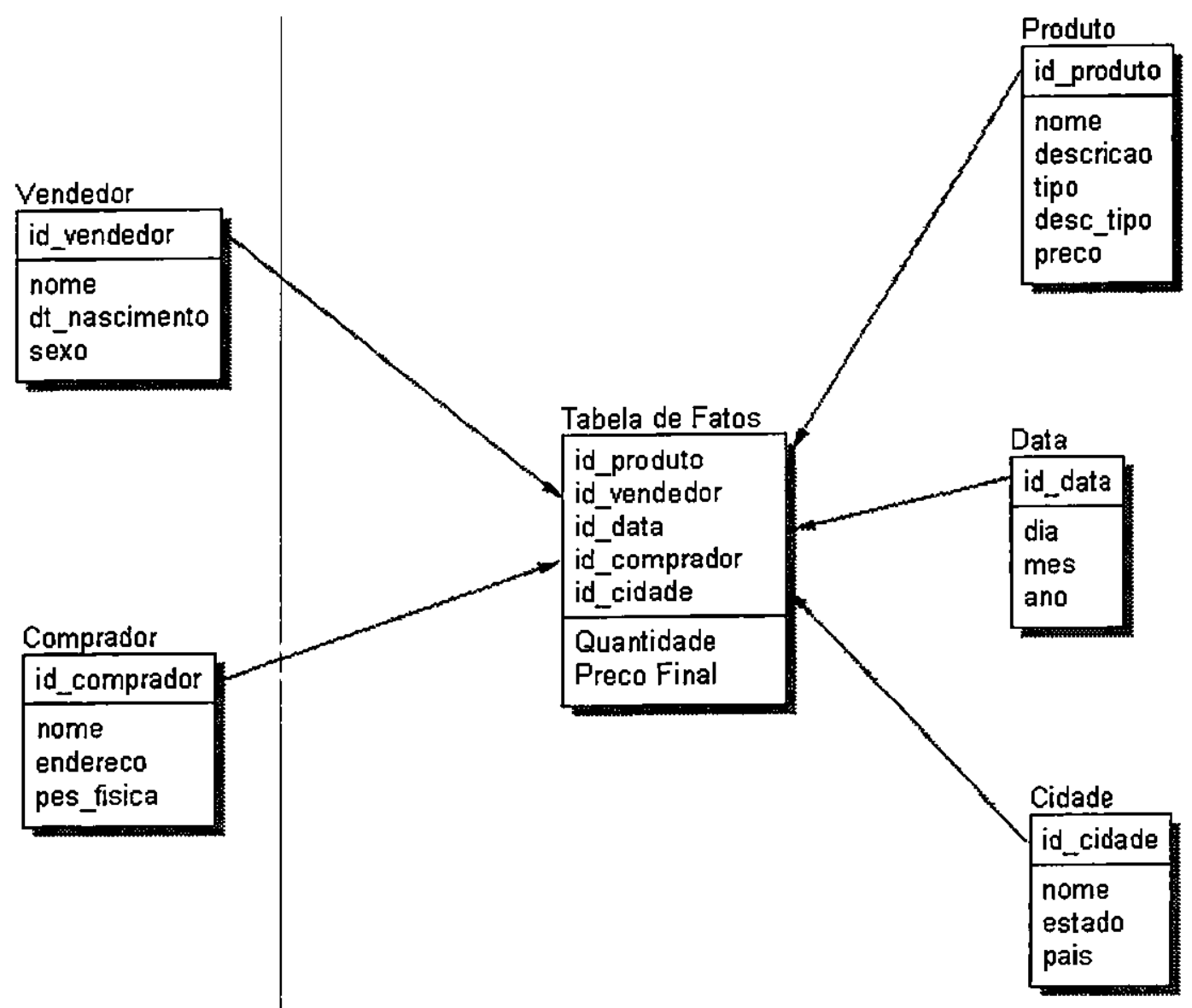

Figura 2.2 - Star schema

Neste exemplo temos cinco dimensões, Vendedor, Produto, Comprador, Cidade e Data. A tabela de fatos possui $5 \mathrm{ids}$, referentes a cada uma das dimensões além de dois fatos, representados pelos atributos Quantidade e Preco_Final. Neste exemplo foi utilizado o parâmetro id_xxxx para fazer a ligação entre a tabela de fatos e as dimensões correspondentes, mas poderiam ser utilizados também outros atributos chaves. Em breve discutiremos se é mais vantajoso a utilização de um atributo chave relacionado a o sistema ou a criação de um atributo chave, sem qualquer significado semântico. 


\subsubsection{Star Schema Parcial}

Variação do Star Schema.

Formado por múltiplas tabelas de fatos e múltiplas tabelas de dimensão, separadas tanto lógica quanto fisicamente por níveis de sumarização. Criam-se múltiplas estrelas, cada uma representando uma combinação das dimensões em seus diferentes níveis existentes no modelo global. É importante notar que não existem ligações lógicas entre as várias tabelas de fatos ou dimensões.

Além disso existem fatos que podem existir em algumas estrelas e outras não (de acordo com as dimensões que a compõem e o nivel em que a consideramos). Ex.: suponha uma tabela de fatos com as dimensões produto no nível produto unitário. Em nossa tabela de fatos poderíamos Ter o fato preço unitário (em uma unidade financeira mais estável, dólar, por exemplo) e quantidade de produtos vendidos. Podemos Ter uma consulta onde desejamos saber a quantidade de produtos vendidos cujo preço unitário é superior a um valor $X$. Este valor não deve se encontrar na dimensão pois o valor do produto pode variar de acordo com a época e promoções realizadas e a pesquisa deseja saber o valor pago na época pelo consumidor e não o valor atual do produto. Outra tabela de fatos poderia encontrar-se associada ao produto no nível gênero do produto (alimentício, vestuário, eletrodoméstico). Neste caso não faz sentido falar em preço unitário pois produtos diferentes são do mesmo gênero.

Uma das vantagens é que temos um maior controle da manutenção do Data Warehouse (tempo de carga, backup): isto ocorre devido ao particionamento do Data Warehouse, onde cada uma das partes é menor do que todo o Data Warehouse e por isso mais facilmente gerenciáveis. Além disso, pode-se criar uma política para atualização de cada estrela em períodos diferentes do mês e com diferentes freqüências, de acordo com a necessidade.

Outra vantagem é que temos uma melhor performance, como existem várias estrelas encontrar aquela que apresente todas as dimensões desejadas. Existem algoritmos no mercado que nos dizem quais são as estrelas a serem construidas baseadas na freqüência de consultas e na quantidade de dados que cada estrela irá possuir. 
Além disso, temos uma redução do sparsity, eliminando colunas que não tenham significado em determinados niveis de sumarização.

Por outro lado temos um aumento de manutenção, já que possuímos muitas estrelas e para cada uma delas é necessário uma definição dos metadados. Imagine a criação ou exclusão de um nível intermediário de determinada tabela de dimensão, pode ser que seja necessária a atualização de muitas estrelas, causando um aumento na manutenção.

Deve-se conhecer muito bem as consultas para se determinar quais estrelas devem ou não ser construídas. Construir estrelas abrangendo todas as possibilidades é praticamente impossivel, visto que as possibilidades de combinação são enormes. Caso construa-se estrelas erradas, todo 0 esforço será perdido pois a grande parte das consultas terão que olhar a mesma estrela (àquela que contém todas as dimensões em seus níveis mais baixos) degradando e muito a performance.

\subsubsection{Constelações de fatos}

Variação do Star Schema Parcial. A diferença é que neste modelo as dimensões não são replicadas, economizando espaço em disco e tempo para atualização / manutenção das dimensões.

Uma única tabela por dimensão ligada a várias tabelas de fatos. Cada tabela de fatos poderá estar ligada a mesma dimensão, porém em níveis diferentes. Enquanto que a tabela de fatos A está ligada a dimensão Localidade pela hierarquia de Cidade a tabela de fatos $\mathrm{B}$ está ligada pela hierarquia Estado e a tabela de fatos $\mathrm{C}$ está ligada pela hierarquia Região do País.

Da mesma maneira que no Star Schema Parcial deve-se conhecer muito bem as consultas para se determinar quais estrelas associadas a quais níveis de hierarquia deve-se ou não construir. Se a hierarquia for muito extensa é inviável construir estrela para cada uma das hierarquias existentes. Além disso, precisamos verificar se o espaço que dispomos em disco é suficiente para suportar todas estas estrelas e de que maneira a utilização deste espaço degrada ou não nossas consultas. 
Suponha uma concessionáría, onde se vendem produtos e serviços. Poderiamos construir duas tabelas de fatos, uma referente a produtos e outra a serviços. Devemos fazer isso, pois os fatos correspondentes a cada uma das opções são diferentes. Enquanto que em produtos temos os fatos Quantidade, Preco_Total em serviços poderíamos Ter Horas e Preco_Servico. Além disso, teríamos dimensões compartilhadas como Atendente, Cliente como teríamos também dimensões exclusivas como Produto (referente a dimensão produto) e Servico (referente a dimensão serviço).

\subsubsection{Schema Dimension Partitioning}

Varição do Star Schema combinando princípios do Star Schema Parcial.

Neste esquema teríamos uma tabela de fatos ligada a múltiplas tabelas de dimensão, particionadas por niveis de sumarizaçăo. Como exemplo teríamos as dimensões Localidade_cidade e Localidade_região, ambas com o atributo id_cidade (que se encontra também na tabela de fatos). Desta maneira se desejamos realizar uma consulta por cidade consideraríamos a dimensão Localidade_cidade, se desejamos realizar a consulta por região consideraríamos a dimensão Localidade_região.

Desta maneira nós eliminamos a necessidade de se percorrer todas as hierarquias de Localidade para determinar quais Cidades pertencem a quais Regiões.

A principal desvantagem desta abordagem é relacionado as consultas onde deseja-se realizar pesquisas a niveis mais altos da hierarquia. Como os dados encontram-se armazenados na tabela de fatos ao nível mais baixo da hierarquia, uma consulta a níveis mais altos pode se tornar ineficiente. 


\subsubsection{Snowflake Schema}

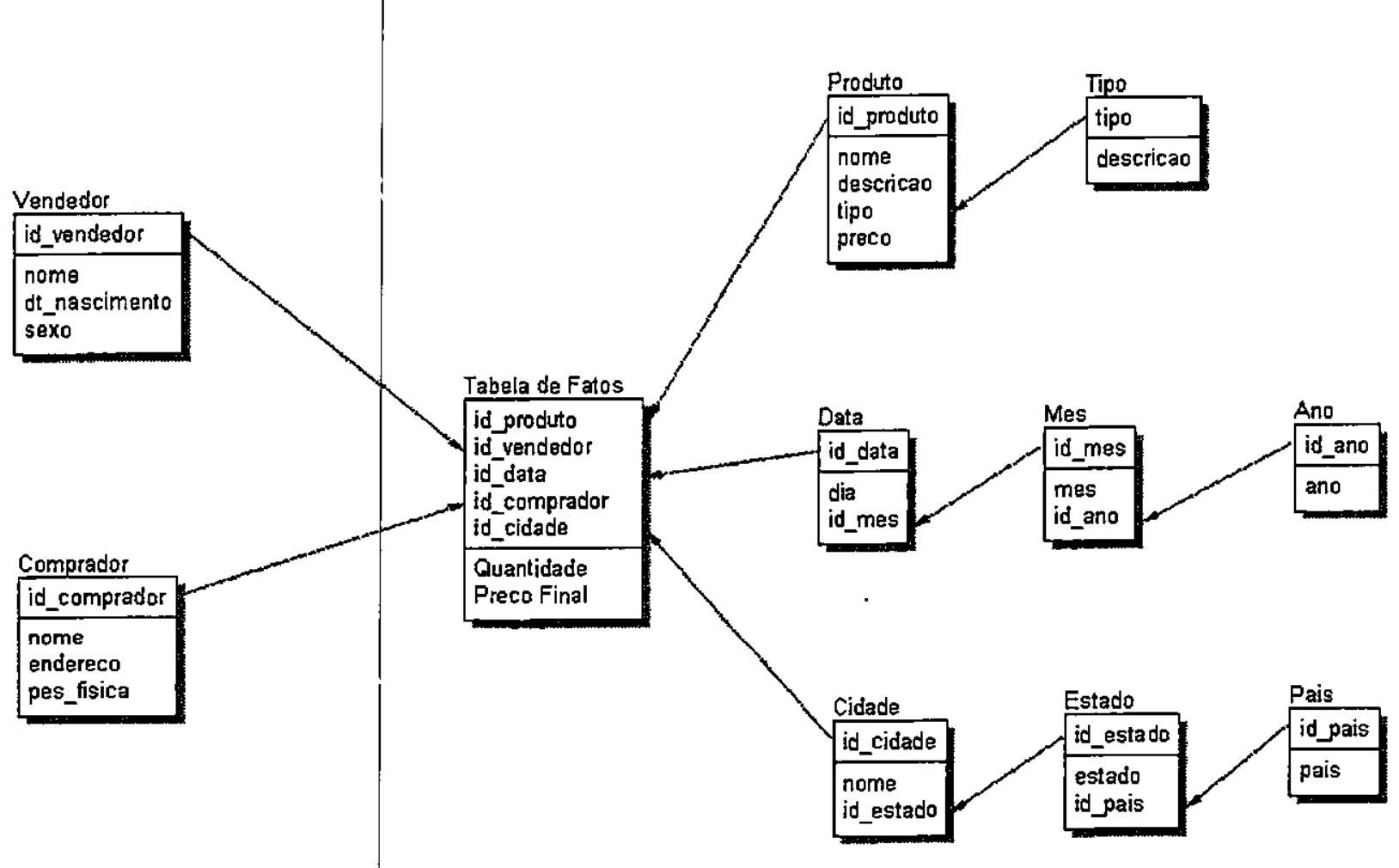

Figura 2.3 - Snowflake Schema

Star Schema normalizado. Não existe o atributo nível para essa abordagem. A diferença encontrase nas tabelas de dimensão onde as mesmas possuem suporte a níveis de hierarquia.

Star schemas não provêm explicitamente suporte para hierarquias de atributos. Snowflake schemas provêm um refinamento do star schema onde a hierarquia de dimensão é explicitamente representada pela normalização de tabelas de dimensão, como mostrado na figura 2.3. Isto nos conduz a vantagens na manutenção de tabelas de dimensão. Entretanto, a estrutura desnormalizadas das tabelas de dimensão no star schema é mais apropriado para caminhar pelas dimensões. 


\subsubsection{Snowflake Schema Lookup}

Tem como característica uma tabela principal por dimensão que se encontra ligada a tabela de fatos e a uma tabela de descrição (lookup). Desta maneira temos que o nivel máximo de agregação é 2, ou seja, a tapela de dimensão principal e a sua tabela lookup associada.

Tem como principal vantagem a integridade dos dados, já que nomes e descrições são mantidos em um único local (tabela de lookup). Além disso, reduz o tamanho das tabelas de dimensão eliminando sua redundância.

\subsubsection{Snowflake Schema Chain}

Tem como principal característica o encadeamento das dimensões. A tabela de fatos encontra-se associada a dimensão pela sua tabela principal (nível mais baixo da hierarquia). A tabela principal contém a chave para o próximo nivel da hierarquia da dimensão e assim sucessivamente.

Tem como principal vantagem a integridade. Como principal desvantagem podemos citar a baixa performance quando o número de níveis é grande e a quantidade de dados por nível também for considerável pois podem ser necessários múltiplas junções para a criação de um relatório (suponha um relatório sumarizado por cidade, estado, região e país).

\subsubsection{Snowflake Schema Attribute}

Construção de uma dimensão com vários grupos de atributos que não estão associados a nenhuma dimensão (ou que são a própria dimensão). Desta maneira reduz-se o número de dimensões do Banco de Dados, simplificando-se a obtenção de determinada consulta. Ex.: suponha a existência das dimensões cor, forma e tamanho. A dimensão cor possui 5 entradas, forma possui 3 entradas e tamanho 6 entradas. São todas dimensões pequenas então porque não uni-las em uma única dimensão. Esta nova dimensão teria 90 atributos $(5 \times 3 \times 6)$, ou seja, continuaria pequena e desta maneira conseguimos reduzir de três para apenas um atributo na tabela de Fatos. 


\subsubsection{Agregação}

Além das tabelas de dimensão, o Data Warehouse armazena tabelas sumariadas contendo dados pré-agregados (Kimball, 1\$96; Gupta et. al, 1995). Nos casos mais simples, os dados préagregados correspondem à agregação da tabela de fatos com uma ou mais dimensões selecionadas. Dados pré-agregados podem ser representados no banco de dados de diferentes maneiras. Podemos representar uma tabela sumariada de dados pré-agregados por uma tabela de fatos separada que compartilha as dimensōes ou encolhendo tabelas de dimensão deixando somente os atributos que fazem sentido para a tabela sumariada. Alternativamente, podemos representar a tabela sumariada codificando as tuplas agregadas na mesma tabela de fatos e nas mesmas tabelas de dimensão sem adicionarmos novas tabelas. Isto deve ser feito pela adição de um novo campo (nivel) para cada dimensão e utilizando valores nulos quando os mesmos não tiverem sentido para aquele nivel de agregação. Podemos codificar o dia, o mês e o ano na dimensão Data como se segue: $(1,18,03,1976)$ representando $18 / 03 / 1976$, tendo nível $1,(2$, NULL, 03, 1976) representando o mês de março de 1976, nível 2 e (3, NULL, NULL, 1976) representando o ano de 1976, nível 3. O método anterior, enquanto que por um lado reduz o número de tabelas apresenta com certa freqüência erros operacionais já que o campo nível precisa ser muito bem interpretado.

\subsubsection{Operaçōes Tipicas em Data Warehouse}

Tipicamente operações OLAP incluem:

- pivoteamento: orienta a visão multidimensional dos dados, dados as dimensões escolhidas (a e $\mathrm{b}$, por exemplo) temos que cada ponto $(\mathrm{x}, \mathrm{y})$ corresponde ao valor agregado ao par para as dimensões escolhidas. Consiste na operação de agregação das dimensões desejadas para que se possa obter o subconjunto desejado de dados. Cada elemento pertencente a este subconjunto de dados é agregado aos demais por uma função (soma, média).

- rollup: aumenta o nível de agregação - diminui o detalhe sobre uma ou mais hierarquia de dimensões;

- drill-down: decresce o nível de agregação - aumenta o detalhe sobre uma ou mais hierarquia de dimensões; 
- slice_and_dice: seleção e projeção - corresponde a reduzir/trocar a dimensão do dado, isto é, tomando a projeção do dado num subconjunto de dimensões para o valor selecionado de outras dimensões.

Como exemplo vamos supor a existência do modelo representado pela figura 2.2. Suponha agora que desejamos conhecer a quantidade de cada um dos produtos vendidos em nosso sistema por mês. Para isso devemos pivotear as seguintes dimensões: Tabela de Fatos (Fatos), Produto e Data. Onde teríamos o seguinte comando SQL:

Desta maneira conseguiremos obter a resposta para o nosso problema.

Outras operações relacionadas com o pivoteamento são rollup e drill-down. Se fizermos o rollup sobre a consulta anterior estaremos aumentando o nível de agregação, ou seja, passaremos a analisar a venda de produtos por ano (próximo nível de agregação em relação ao mês). Drilldown é o processo inverso de rollup, ou seja, decresceríamos o nível de agregação, passando a analisar as vendas de prođutos por dia e não mais por mês. Note que para as operações de rollup e drill-down é necessário que haja uma hierarquia. Em nosso exemplo tais operações são permitidas para as dimensões de Produto, Data e Cidade. Os respectivos comandos SQL para rollup e drill-down seriam:

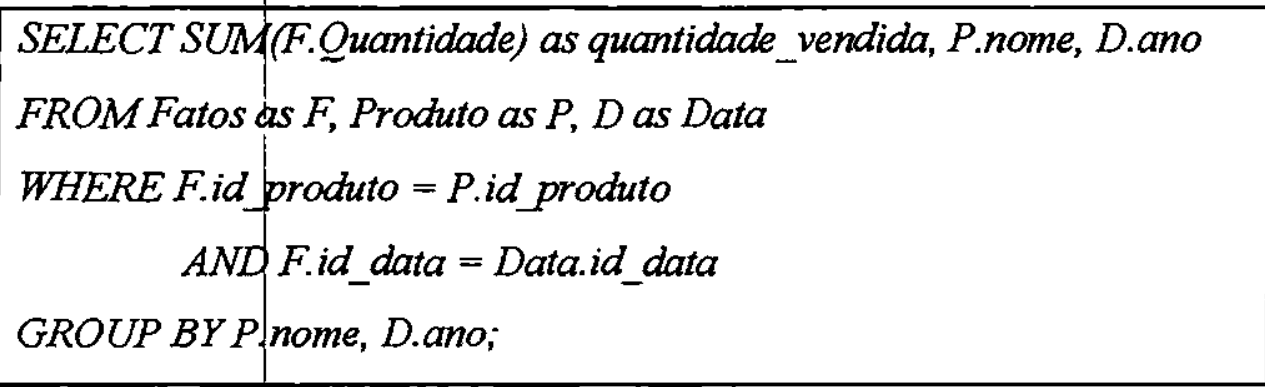

Quadro 2.2 - Rollup 


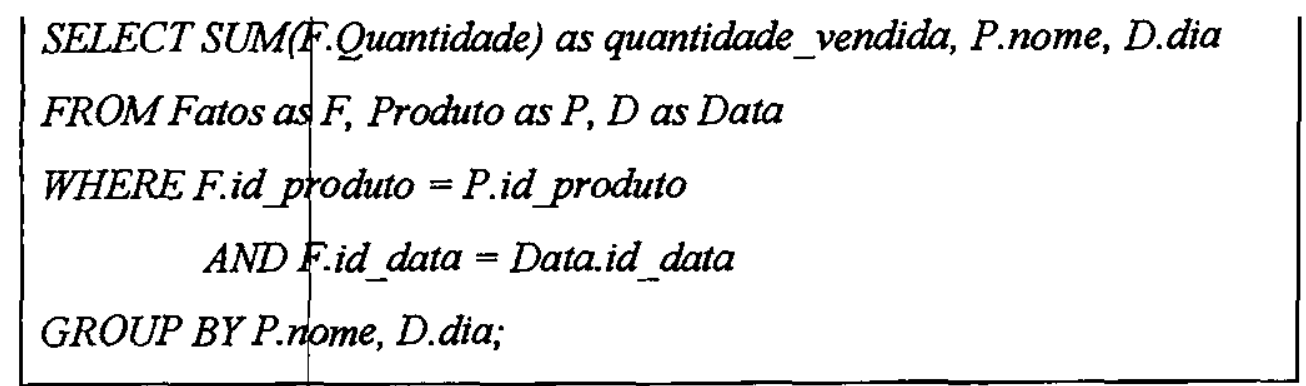

\section{Qaudro 2.3 - Drill-down}

Suponha que após tal análise (quadro 1) desejássemos saber a quantidade de produtos vendidos de determinado produto (tênis Bical, por exemplo) para cada cidade durante todo o período. Neste caso estaríamos realizando uma operação de slice_and_dice. Neste caso necessitaríamos da tabela de Fatos e das dimensões de Região e Produto. O comando SQL correspondente ficaria:

Note que o quadro 4 não se utiliza das dimensões de Data e Vendedor, ao contrário do quadro 1, porém se utiliza da dimensão Cidade que não foi utilizada pelo quadro 1. Vemos ainda que o quadro 4 seleciona determinado valor para a dimensão de Produto ("Tênis Bical").

O atributo nível na dimensão é útil principalmente para atender as funções de drill down e roll up. Dado que estamos no nível $\mathrm{X}$, então se realizarmos uma operação de drill down iremos ir para o nível $\mathrm{X}+1$, quando o mesmo existir, caso realize-se uma operação de roll up iremos para o nível $\mathrm{X}-1$, quando este existir. 


\subsubsection{Drill Trhu}

Consiste do processo de se obter informações do Data Warehouse como também do Banco de Dados Histórico e/ou Atual.

Esta operação é de grande importância para grande parte dos sistemas e muitas vezes apresenta desempenho abaixo do desejado. Isto ocorre pois o Data Warehouse encontra-se bem dissociado dos dados que se encontram armazenados numa base de dados relacional (histórico ou não). Isto se dá devido a estruturação do Data Warehouse que é bem diferente da estruturação tradicional (OLTP), como já foi visto.

Um exemplo de uma operação de Drill Trhu: Dada uma consulta onde se deseja saber quais contribuintes do Estado de São Paulo possuem ao Regime de Apuração Microempresa e que tiveram recolhimento anual de ICMS de 1999 superior a R\$120.000,00. No Data Warehouse típico conseguimos identificar quais contribuintes atendem a consulta desejada. Suponha agora que se deseja enviar uma carta para todos estes contribuintes para que os mesmos compareçam ao Posto Fiscal de sua Jurisdiçăo para esclarecimentos. Os dados referentes a endereço dificilemente estarão no Data Warehouse. Este dado encontra-se na Base de Dados Operacional. Usualmente devido a pouca integração entre estes dois ambientes a consulta teria que ser feita em quatro passos. Primeiramente identifica-se os contribuintes que atendem a consulta desejada. Exportamse os dados do Data Warehouse para um arquivo. Importa-se este arquivo para a base de dados corrente. Faz-se a consulta ao endereço de cada uma das empresas desejadas. Os passos relativos a exportação e importação poderiam ser substituídos por um programa que fizesse a ligação entre os dois ambientes, o DW e a Base de Dados Corrente.

\subsubsection{Dimensão Tempo}

A dimensão Tempo é de grande importância para o Data Warehouse. Muitos autores realizaram extensões relacionadas a esta dimensão. $O$ atributo resolução na Dimensão Tempo equivale ao atributo nivel das outras dimensões. Acrescenta-se o atributo corrente que indica se determinada data/periodo encontra-se presente na tabela de fatos além de uma coluna seqüência que contém um número seqüencial iniciado em 1 e que serve para indicar a ordem relativa da data. Assim para 
abordagem é que ela nos da maior flexibilidade. Ex.: suponha que estejamos utilizando como chave primária o nome de determinado produto (chocolate Lolo) porém tal produto muda de nome (Milkbar). O produto é o mesmo, queremos que em nosso Data Warehouse ele seja tratado da mesma forma. Se utilizarmos o nome como chave teríamos dois produtos diferentes que existem em tempos disjuntos. Com uma chave genérica tal problema não ocorreria. Se por algum motivo fosse desejado que tais produtos fossem tratados de maneira diferente bastaria gerar uma nova chave para o chocolate Milkbar. Ele deve ser tratado como sendo um mesmo produto pois assim fica mais fácil verificar se o novo nome e a nova campanha publicitária estão fazendo o efeito desejado.

Porém o maior problema encontrado para a geração de chave primária encontra-se em como gerar e manter esta chave. O procedimento ideal é que tais chaves fossem incorporadas aos sistemas operacionais e históricos responsáveis pela realização de carga do Data Warehouse. Muitas vezes, porém isso não é possível ou é totalmente inviável. Uma importante observação que deve ser feita é com relação a granulalidade e a alterabilidade da tabela de dimensão que veremos a seguir. O importante aqui é destacarmos que se estamos iniciando um projeto do marco zero (operacional, histórico) é importante que pensemos que um dia tal base pode ser utilizada para análise (DW) l̦go devemos criar um modelo que esteja preparado para a criação de um Warehouse, ou seja, com chaves geradas que são mais eficientes para o SGBD escolhido.

Outra importante observação que devemos fazer é a de que muitas vezes cada serviço prestado não corresponde a uma entrada no Data Warehouse. Por exempio, cada venda que se realiza numa loja não corresponde necessariamente a uma entrada no Data Warehouse. O processo para se dar carga no Data Warehouse pode ser determinado como sendo o seguinte: no final do dia sumariza-se a venda do mesmo produto e lança-se no Data Warehouse. Se uma pessoa A comprou 2 produtos $\mathrm{X}$, a pessoa $\mathrm{B}$ comprou 3 produtos $\mathrm{X}$ e a pessoa $\mathrm{C}$ comprou 1 produto $\mathrm{X}$ no mesmo dia, teríamos no Data Warehouse uma única linha referente a venda do produto $\mathrm{X}$ neste dia, com quantidade igual a 6. 


\subsection{Servidores Warehouse}

O Data Warehouse contém grande volume de dados. Para responder as consultas eficientemente métodos de acesso eficientes e técnicas para processamento das consultas são necessários. Para isso o Data Warehouse usa estruturas redundantes como índices e visões materializadas. A escolha de quais índices devem ser construídos e quais visões devem ser materializadas é uma decisão muito importante. $\phi$ próximo desafio é usar efetivamente os índices existentes e as visões materializadas para responder as consultas. Índices podem ser muito eficientes para consultas seletivas aos dados, mas para consultas intensivas precisa-se usar varreduras seqüenciais. Portanto, é muito importante aumentar a eficiência de varredura dos dados. Finalmente, o paralelismo precisa ser explorado para reduzir o tempo de resposta das consultas.

\subsubsection{Estrutura de Indexação}

Podemos utilizar algumas de técnicas de processamento que aplicam índices. A seleção a partir de múltiplas condições pode ser aplicada através da interseção de índices (Harinayan et. al., 1996; Chaudhuri \& Dayal, 1997). Outra operação útil é a união de índices. Estas operações podem reduzir significantemente e em alguns casos eliminar a necessidade de acesso as tabelas da base de dados.

Servidores Warehouse podem usar índices bitmap, que suportam eficientemente operações de indexação. Considere uma folha na estrutura de índices correspondente ao domínio do valor d. A folha tradicionalmente contém uma lista dos identificadores (ids) dos registros (RID) que contém o valor d. Entretanto, índices bitmap usam uma representação alternativa da lista RID. Ela é representada como um vetor de bits que tem um bit para cada registro, que é ativado quando o valor daquele registro é d. Esta representação realiza rapidamente a interseção, união, agregação e junção de índices. Esta representação é extremamente útil para domínios de baixa cardinalidade (sexo, por exemplo) mas se utilizarmos a compressão de bitmaps ela também se torna efetiva para domínios de maiores cardinalidades. Uma questão importante é decidir quais atributos devem ser indexados. 
A natureza do star schema sugere a criação de índices para a junção de tabelas. Por exemplo, suponha a existência de uma dimensão Estado. Pode haver um índice de junção sobre Estado que mantém, para cada estado, uma lista de RDs das tuplas da tabela de fatos que correspondem àquele Estado. Índices de junção podem usar representações bitmap para a lista de RID para maior eficiência.

Ex: Suponha a dimensão Sexo com os valores: Masculino e Feminino. Na tabela de fatos temos que os registros de posição fisica $1,2,4,7,10,13,14,15$ e 20 pertencem ao sexo Masculino e os restantes ao sexo Feminind. Considre agora a Dimensão Geografia aonde os registros de posição física $1,4,9,14,17,18$ e 20 representam o Estado de São Paulo.

$\mathrm{Na}$ abordagem com RIDs teríamos no nó folha sexo feminino a seguinte lista: $1,2,4,7,10,13$, 14, 15 e 20. No nó folha Estado São Paulo a seguinte lista: 1, 4, 9, 14, 17, 18 e 20. Para obtermos os registros fisicos que satisfazem a condição sexo feminino do Estado de São Paulo teríamos que realizar a junção destas duas listas para se obter o resultado. Para grandes quantidades de tuplas na tabela de fatos teríamos duas grandes listas o que torna o processo de junção das mesmas ineficiente.

$\mathrm{Na}$ abordagem de índices bitmap teríamos:

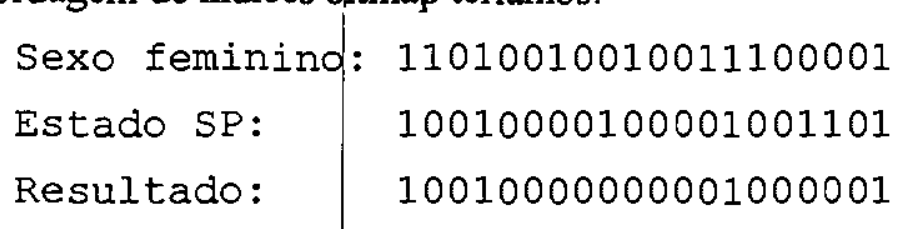

Temos que a obtenção do vetor resultante é bem eficiente já que a operação realizada é rapidamente feita pelo computador. Observe que quanto maior forem as dimensões envolvidas na seleção maior será a diferença no tempo de execução das duas abordagens vistas. Enquanto temos que para a abordagem de RIDs a adição de uma dimensão aumenta consideravelmente o tempo de execução da seleção temos que para a abordagem de bitmaps este acréscimo é mínimo. 


\subsubsection{Visões Materializadas}

Visões consistem de junções de tabelas de fatos com um subconjunto de tabelas de dimensão com a agregação de uma ou mais medidas agrupadas por um conjunto de atributos das tabelas de dimensão.

Dada uma consulta que possa ser respondida por uma visão materializada esta consulta deve se utilizar de tal visão, pois o tempo de resposta será inferior caso a consulta se utilizasse da tabela de fatos. Isto ocorre pois o número de tuplas nas visões materializadas tendem a ser bem inferiores ao da tabela de fatos, uma vez que os dados estão pré-agregados. Além disso diminui-se o "tráfego" na tabela de fatos, transferindo parte do "tráfego" para as visões materializadas.

Algumas consultas sobre o Data Warehouse requerem dados sumariados e, para tanto, usam agregados. A materialização de dados sumariados podem ajudar a acelerar algumas consultas comuns (Rossoupoulos, 1998; Blakeley, 1986; Zhuge et. al., 1995).

Os principais desafios de visões materializadas são:

- Identificar as visões a serem materializadas;

- Explorar as visões materializadas para responder a consultas;

- Alterar eficientemente as visões materializadas durante o processo de carga e o processo de atualização.

A seleção das visões a serem materializadas deve considerar: as características da carga de trabalho, os custos para alterações incrementais e os limites de requisitos de armazenamento.

Uma estratégia simples para usar visões materializadas é usar a seleção na visão materializada, ou rollup na visão materializada agrupando e agregando em colunas adicionais. Por exemplo, assuma que uma visão materializada contém o total de vendas por mês para cada produto. Esta visão pode ser usada para responder a uma consulta para obter o total de vendas para o produto "Suco de Laranja" por ano. Primeiramente aplicamos seleção e então rollup para a dimensão Data. Note que a função Soma pode ser rolled up, mas algumas outras funções estatísticas não podem ser. 
Primeiramente teríamos que a estrutura da visão materializada acima seria:

\begin{tabular}{|l|}
\hline \multicolumn{1}{|c|}{ Visao } \\
\hline id_produto \\
id_mes \\
total_vendas \\
\hline
\end{tabular}

Figura $2.4-$ Visão

O SQL ficaria:

SELECT SUM(total_vendas), Tempo.id_ano FROM
Visao as Y, Produto as P, Tempo as $T$
WHERE Visao.id_produto = Produto.id_produto
AND Produto.nome $=$ 'Suco de Laranja'
AND Visko.id_mes = Tempo.id_mes
GROUP BY Tempo.id_ano
Quadro 2.5 -Consulta a partir da Visão

A importante observação a ser feita aqui é que a visão não serve somente para atender a consulta para o qual ela foi preparada para atender, mas para todas as consultas que consigam obter 0 resultado desejado a partir da visão materializada.

A visão materializada em questão foi preparada para responder a perguntas que envolvessem Produto, Mês e somatória do total de vendas. Porém ela foi útil para responder a perguntas envolvendo Produto, Ano e somatória do total de vendas, isto porque Ano encontra-se um nível acima de Mês no nível hierárquico da dimensão Tempo.

\subsubsection{Arquitetura do Servidor}

Servidores relacionais tradicionais não oferecem uso inteligente dos índices e outros requisitos para fornecer suporte a visões multidimensionais dos dados. Entretanto, todos os principais fabricantes de SGBDs relacionais têm trabalhado arduamente para fornecer suporte a esses requisitos adicionais. Além disso, existem três outras categorias de servidores que foram desenvolvidos especificamente para suporte a decisão. 
- Servidores SQL especializados: Provêm uma linguagem de consulta avançada e suporte de processamento de consaltas SQL sobre os star schemas e snowflake schemas em ambientes somente de leitura;

- Servidores ROLAP: Uma extensão dos servidores relacionais tradicionais com suporte eficiente as consultas OLAP multidimensionais. Servidor intermediário localizado entre o servidor relacional e ferramentas de front end do cliente. Eles identificam as visões que devem ser materializadas e reescrevem consultas do usuário em termos das visões materializadas apropriadas. Provêm serviços adicionais como organização das consultas e associação de recursos. O principal valor de servidores ROLAP é que eles exploram a escalabilidade e as características transacionais dos sistemas relacionais. Entretanto uma perda de desempenho pode ser causada devido às diferenças entre o estilo de consulta de OLAP e dos servidores relacionais;

- Servidores MOLAP: Estes servidores dão suporte diretamente a visão multidimensional dos dados. É possível mapear diretamente consultas multidimensionais a partir da camada de armazenamento. Algumas das técnicas que são aplicadas sobre Banco de Dados estatísticos são relevantes também para servidores MOLAP.

\subsubsection{Extensões SQL}

Algumas extensões ao SQL que facilitam o processamento de consultas OLAP têm sido propostas ou implementadas em servidores relacionais estendidos (Chaudhuri \& Dayal, 1997; Chaudhuri, 1998). Algumas destas extensões são:

- Extensão da familia de funções agregadas: incluem suporte a posicionamento (por exemplo, os 5 produtos que mais venderam) e percentagem como também suporte a uma grande variedade de funções usadas em análise financeira;

- Resultados Parciais: Os relatórios produzidos para análise de negócio freqüentemente requerem o cálculo de características agregadas como, por exemplo, a mudança da média. É importante estar apto a fornecer pontos de parada e totais parciais;

- Múltiplos Agrupamentos: Ferramentas de front end necessitam agrupar diferentes conjuntos de atributos. Isto pode ser simulado por um conjunto de comandos SQL que requerem que os dados sejam varridos múltiplas vezes, mas esta solução pode ser ineficiente. Recentemente novos operadores têm sido propostos para solucionar este problema; 
- Comparações: SQL apresenta deficiências para realizar comparações muito comuns no mundo dos negócios. Isto porque a execução de uma comparação pode necessitar de múltiplas varreduras seqüenciais.

\subsection{Metadados e Gerenciamento do Data Warehouse}

Como o Data Warehouse reflete o modelo de negócio de uma corporação, um elemento essencial da arquitetura do Warehouse é o gerenciamento do metadado.

Metadados Administrativos incluem toda a informação necessária para montar e usar um Warehouse: descrição dos bancos de dados fonte, ferramentas de front end e de back end, definições do esquema Warehouse, dados derivados, dimensões e hierarquias, consultas e relatórios pré-definidos; organização física como as partições de dados; extração, limpeza de dados e regras de transformação; atualização dos dados e políticas de purificação; perfil do usuário, políticas de acesso de controle.

Metadados de Negócio incluem termos e definições de negócio, o proprietário do dado, políticas de carga.

Metadados Operacionais incluem informação que é colecionada durante a operação do Warehouse: a origem e os relacionamentos dos dados originários de uma migração ou transformação; monitoramento da informação como relatórios de erros, auditoria.

Um repositório de metadados é usado para armazenar e gerenciar todos os metadados associados ao Warehouse. O repositófio habilita o compartilhamento dos metadados entre ferramentas e processos para projetar, construir, usar, operar e administrar um Warehouse.

\subsection{Data Mining}

Data Mining é o processo que consiste na mineração de dados visando a descoberta de conhecimento a partir destes dados (Chen et. al, 1996; Fayad \& Shapiro, 1996). Minerar dados consiste na análise dos dados. O dado é analisado dentro de diferentes contextos na tentativa de 
se obter padrões ou anomalias dos dados. A figura 2.4 apresenta os passos necessários ao processo de Data Mining.

\subsubsection{Passos no Data Mining}

1. Criação de um Banco de Dados alvo: seleciona um conjunto de dados ou dar ênfase para um subconjunto de variáveis ou exemplo de dados nos quais a "descoberta" será realizada.

2 . Pré-processamento: realiza operações básicas como remover ruídos ou subcamadas coletando informação necessária para modelar, decidindo estratégias para manusear campos perdidos e decidindo também assuntos do SGBD como tipos de dados, esquema e mapeamento de valores perdidos ou desconhecidos

3. Transformação: encontra formas práticas para representação dos dados, utilizando métodos de transformação para reduzir o número efetivo de variáveis que deve ser levado em consideração, encontrando representações invariantes para os dados.

4. Extração: Determina o tipo de conhecimento a ser minerado e envolve a procura de modelos de interesse numa forma particular de representação ou num conjunto de tais representações, incluindo regras de classificação ou árvores, regressão, agrupamento, modelos de sequência, dependência e análise linear.

5. Interpretação e Avaliaçã̃o: Consiste na interpretação do modelo descoberto e possivel retorno a algum passo anterior como também uma possível visualização do modelo extraído, removendo modelos redundantes ou irrelevantes e traduzindo os modelos úteis de maneira tal que o usuário consiga entender.

6. Utilização do descobrimento obtido: incorpora o conhecimento adquirido ao sistema, ações baseadas no conhecimento adquirido são tomadas visando uma melhora de desempenho, redução de custos, geração de relatórios / documentos para grupos interessados. 


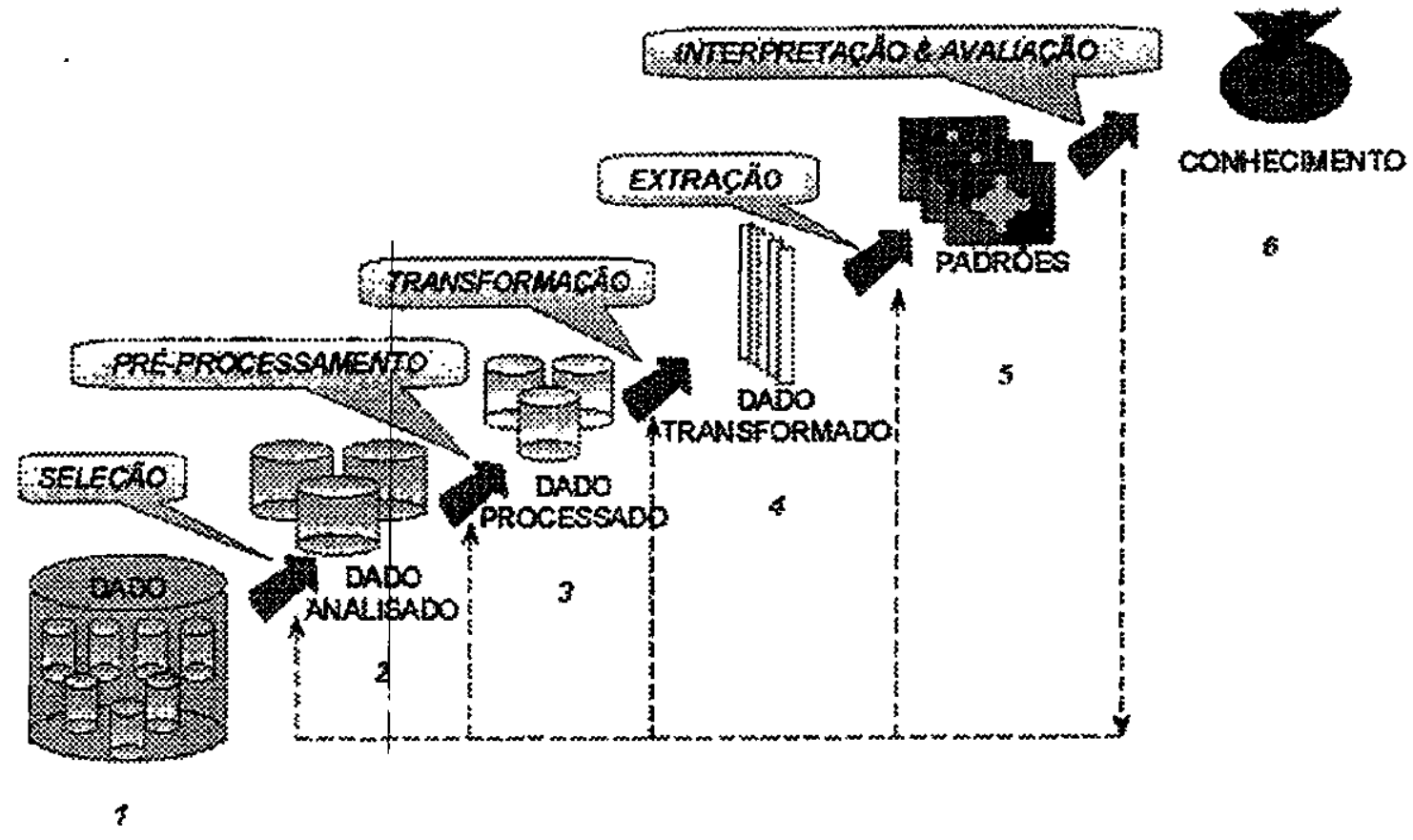

Figura 2.5 - Processo Data Mining

\subsubsection{Caracteristicas necessárias ao Data Mining}

1. Capacidade de manusear diferentes tipos de dados

Como existem muitos tipos de dados usado em diferentes aplicações, é esperado que o sistema de Data Mining consiga manipular estes diferentes tipos de dados existentes (dados espaciais, temporais, multimídia, hipertexto etc.). Entretanto, devido à grande variedade de dados não é de se esperar que o sistema de Data Mining manuseie todos os tipos de dados. Sistemas Data Mining devem ser construídos para mineração do conhecimento para tipos de dados específicos.

2. Eficiência e Escalabilidade de algoritmos Data Mining

Para extrair efetivamente informações de uma grande quantidade de dados, os algoritmos de Data Mining devem ser eficientes e escaláveis. Ou seja, o tempo de execução de determinado algoritmo deve ser previsível e aceitáyel para uma grande quantidade de dados. 
3. Utilidade, segurança e expressividade dos resultados.

As imperfeições devem ser expressas por medidas de incerteza. Dados excepcionais e ruídos devem ser tratados em sistemas de Data Mining. Isto inclui a necessidade de um estudo sistemático da qualidade dos resultados através da estatística, análise e simulação de modelos e ferramentas.

4. Expressar de diferentes maneiras as requisições e resultados do Data Mining

Diferentes tipos de conhecimento podem ser descobertos a partir de uma grande quantidade de dados. É desejável que o conhecimento descoberto possa ser examinado de diferentes visões e que possa ser apresentado de diferentes formas. Esta necessidade nos força a expressar as requisições ao Data Mining e o conhecimento descoberto em linguagens de alto nível ou interfaces gráficas de maneira que os usuários finais consigam especificar uma tarefa e entender o conhecimento descoberto.

5. Mineração interativa do conhecimento em múltiplos níveis de abstração

É dificil predizer o que exatamente pode ser descoberto a partir de um conjunto de dados. Descobrimento interativo deve ser encorajado, permitindo que o usuário refine interativamente uma requisição ao Data Mining, mude dinamicamente o foco dos dados, intensifique progressivamente um processo Data Mining e visualize flexivelmente os dados e os resultados do Data Mining em múltiplos níveis de abstração e de diferentes ângulos.

6. Minerar informações de diferentes fontes de dados

O Data Mining deve ter a capacidade de minerar conhecimento de diferentes fontes de dados, que podem estar formatados ou não, que podem apresentar uma diversidade semântica muito grande.

7. Segurança e privacidade dos dados 
Quando os dados podem set visualizados de diferentes ângulos e de diferentes níveis de abstração é necessário garantir a segurança a privacidade dos dados. É importante estudar quando um Data Mining pode estar sujeito ó não a uma invasão de privacidade, e quais medidas de segurança devem ser desenvolvidas pała prevenir a exposição de informações importantes.

Note que alguns desses requisitos podem entrar em conflito. Por exemplo, segurança de dados entra em conflito com requisitos de mineração interativa.

\subsection{Data Warehouse articulado ao Data Mining}

Data Warehouse deve estaf articulado com Data Mining (Inmon, 1996). Isto ocorre devido as características do Data Warehouse, que incluem:

- Dados integrados;

- Dados particularizados e sumariados;

- Dados históricos;

- Metadados.

\subsubsection{Dados Integrados}

Permite que o minerador facilmente e rapidamente olhe o panorama dos dados. Sem dados integrados, o minerador gastaria uma quantidade de tempo muito grande limpando e integrando os dados antes de iniciar o processo. Chaves teriam que ser reconstruidas, valores codificados, estruturas de dados padronizadas. Data Warehouse é integrado e todas essas tarefas (e algumas mais) fazem com que o minerador possa concentrar seu trabalho na mineração dos dados, sem se importar com limpeza e integração dos dados.

\subsubsection{Dados Particularizados e Sumariados}

Dados particularizados são necessários quando o minerador deseja examinar os dados em sua forma mais granular. Muitos niveis de baixo grau de detalhe escondem importantes características que podem úteis. Dados sumariados garantem que se uma análise prévia já foi feita, o minerador 
não precisa repetir todo o trabalho novamente. Esta capacidade faz com que o minerador não gaste quantias enormes de tempo fazendo trabalho desnecessário.

\subsubsection{Dados Históricos}

É útil ao minerador, pois importantes características da informação estão escondidas nos dados históricos. Um minerador que trabalha somente com dados correntes não está apto a detectar características ao longo do tèmpo. Informações históricas são essenciais para o entendimento da sazonalidade do negócio e para ciclos grandes do negócio a que toda corporação está sujeita.

\subsubsection{Metadados}

Servidores metadados fornecem ao minerador informações que descrevem o contexto da informação. Quando a informação está sendo examinada o contexto torna-se tão relevante quanto o conteúdo. Torna-se muito difícil para o minerador de dados trabalhar quando não há explicação para o significado dos dados.

\subsection{Otimização de consultas}

Discutiremos agora técnicas usadas por SGBD para processar, otimizar e executar consultas de alto nivel. Primeiramente uma consulta deve passar pelas fases de varredura (scanning), parseamento (parsing) e validação (validating) (Ozsu \& Valduriez, 1999; Ramakrishnan, 1997). A varredura identifica os componentes da linguagem, o parser checa a sintaxe da consulta para determinar se ela esta de acordo com as regras gramaticais da linguagem de consulta. A consulta deve então ser validada, checando que todos os atributos e tabelas são válidos e semanticamente significativos. A seguir a consulta é direcionada ao otimizador de consultas, que é responsável por identificar um plano eficiente de execução para a consulta desejada. O otimizador gera planos alternativos (Gerador de Planos) e escolhe o plano com menor custo estimado, tarefa esta que é realizada pelo "Estimador" de custo do plano que tem como base as informações do sistema de catálogos. Em seguida o gerador de código gera o código para execução do plano. O processador em tempo de execução do banco de dados tem a tarefa de executar o código da consulta e produzir o resultado da mesma. Se um erro em tempo de execução ocorrer cabe a ele a detecção 
e a geração da mensagem de erro apropriada. Apresentamos na figura 2.5 os passos de processamento de uma consulta de alto nível, como SQL, por exemplo.

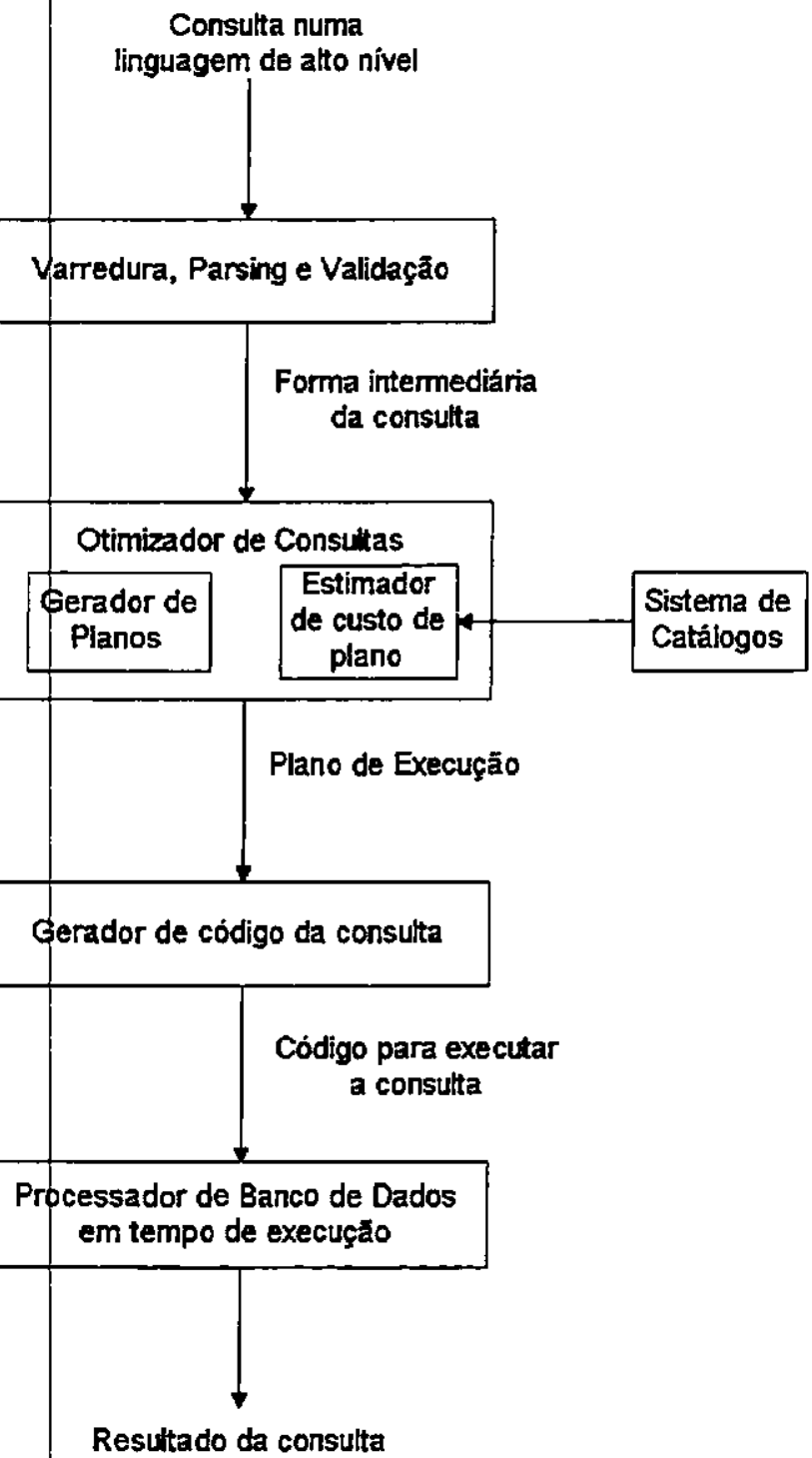

Figura 2.6 - Passos de processamento de uma consulta de aito nível

O principal objetivo de otimizadores de consultas é encontrar um bom plano de avaliação para uma dada consulta. Para tanto temos dois passos básicos:

4 Enumerar planos alternativos para avaliação das consultas; tipicamente devemos considerar um subconjunto de todos os planos possíveis pois o número de planos possíveis é muito grande. 
4 Estimar o custo dos planos enumerados e escolher àquele com menor custo estimado.

\subsubsection{Plano de avaliação de consultas}

Um plano de avaliação de consultas (ou simplesmente plano) consiste de uma árvore que é uma extensão a álgebra relacional onde cada nó indica o métodos de acesso para cada relação e o método de implementação para cada operador relacional.

Considere o seguinte esquema:

Vendedor(id IVendedor, nome, dt_nascimento, sexo)

Produto(id_produto, nome, descricao, tipo, desc_tipo, preco)

Compra (id vendedor, id produto data, quantidade)

Considere agora a seguinte consulta:

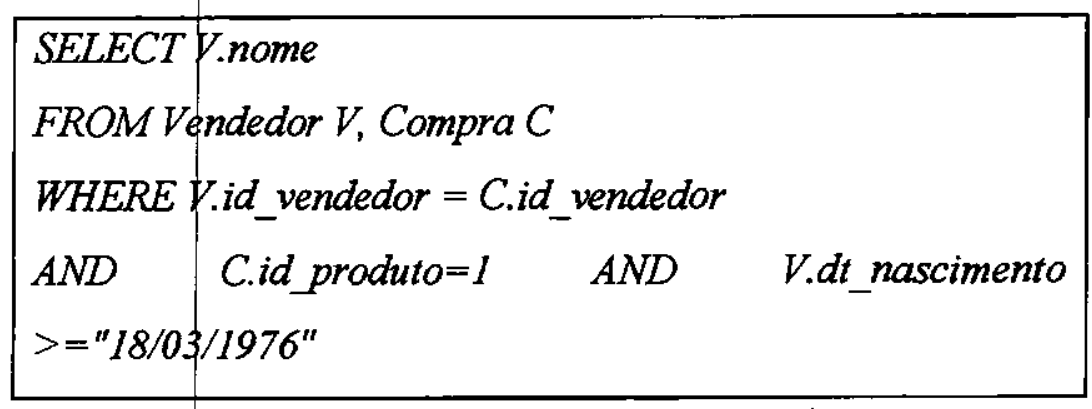

Quadro 2.6 - Consulta do qual será extraída o plano de execução

Para obter um plano de avaliação completo devemos decidir um método de implementação para cada operador algébrico envolvido. Por exemplo, podemos usar laços aninhados orientados ao tamanho da página para a operação de junção entre Compra e Vendedor e aplicar seleções e projeções para cada tupla no resultado produzido pela junção. 


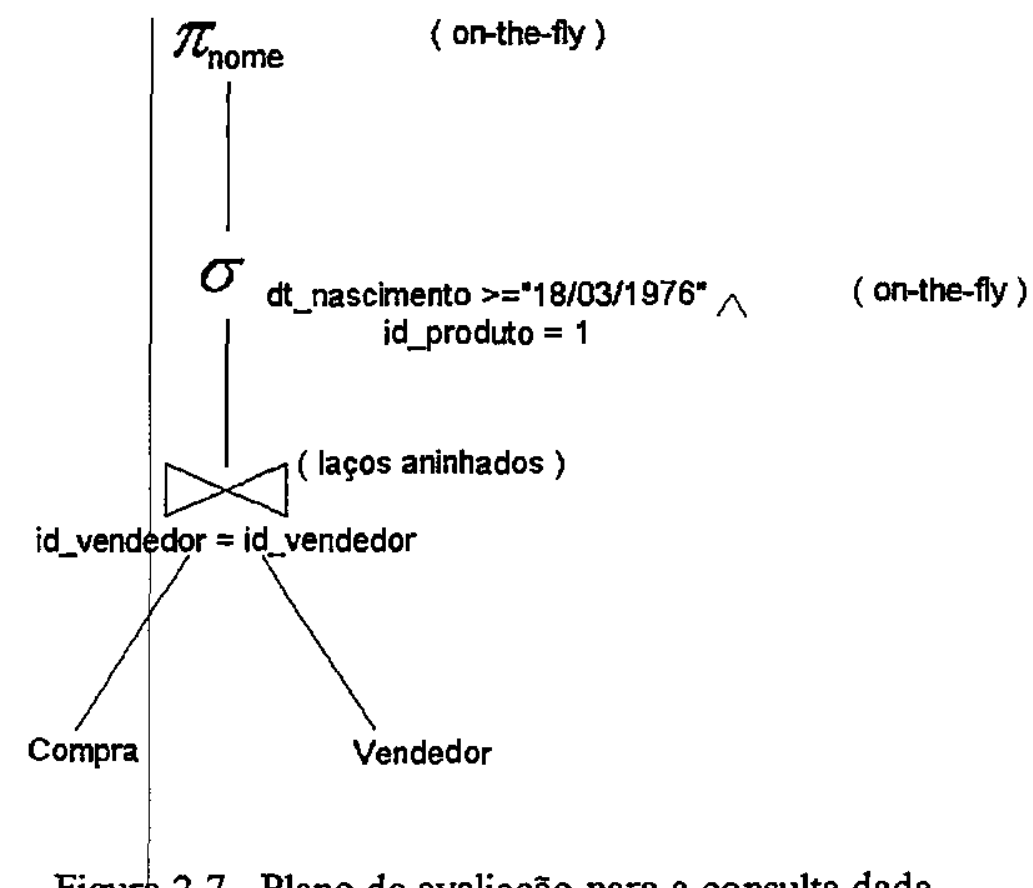

Figura 2.7 - Plano de avaliação para a consulta dada

A Figura 2.7 apresenta o plano de avaliação para a consulta anterior, juntamente com os métodos de implementação associados a cada operador algébrico envolvido.

Note que quando uma consullta é composta de muitos operadores, o resultado de um operador é, algumas vezes, direcionado para outro operador sem a criação de uma relação temporária para armazenar os resultados intermediários. Na figura 2.7 a junção entre Compra e Vendedor é direcionada para as seleçõęs e projeções que se seguem. O direcionamento da saida de um operador para o próximo operador economiza um custo que pode ser muito significante. Se a saída é salva em uma relação temporária dizemos que as tuplas são materializadas.

Consultas SQL são otimizadas pela decomposição em coleções de unidades menores chamadas blocos. Um otimizador concentra seus esforços na otimização de um bloco de cada vez. Um bloco consiste de uma consulta SQL sem aninhamento e exatamente uma clausula SELECT e uma clausula FROM; e no máximo uma cláusula WHERE, uma clausula GROUP BY e uma clausula HAVING.

Considerando e exemplo da figura 2.5 veremos agora planos alternativos para calcular a consulta desejada. 


\subsubsection{Aplicação precoce de seleções}

Uma junção é uma operação muito dispendiosa, e uma boa heuristica é reduzir o tamanho das relações a serem "juntadas" tanto quanto possivel. Uma abordagem é a de aplicação precoce de seleções. Como exemplo, a seleção id_produto $=1$ envolve somente os atributos de Compra e pode ser aplicado para Compra antes da junção. Similarmente, a seleção di_nascimento $>=" 18 / 03 / 1976$ " pode ser aplicada para Vendedor antes da junção. Tais dados devem ser armazenados em tabelas temporárias ( $T a b V$ e $T a b C$, por exemplo) onde as mesmas sofrerão então a operação de junção.

\subsubsection{Utilização de Índiçes}

Suponha que as tabelas de Vendedor e Compra possuam índices para id_vendedor e id_produto. Desta maneira podemos utilizar tais índices na tentativa de melhorarmos o desempenho da consulta. O plano de avalią̧ão para a consulta com a utilização de índices é mostrado na figura 2.8 . 


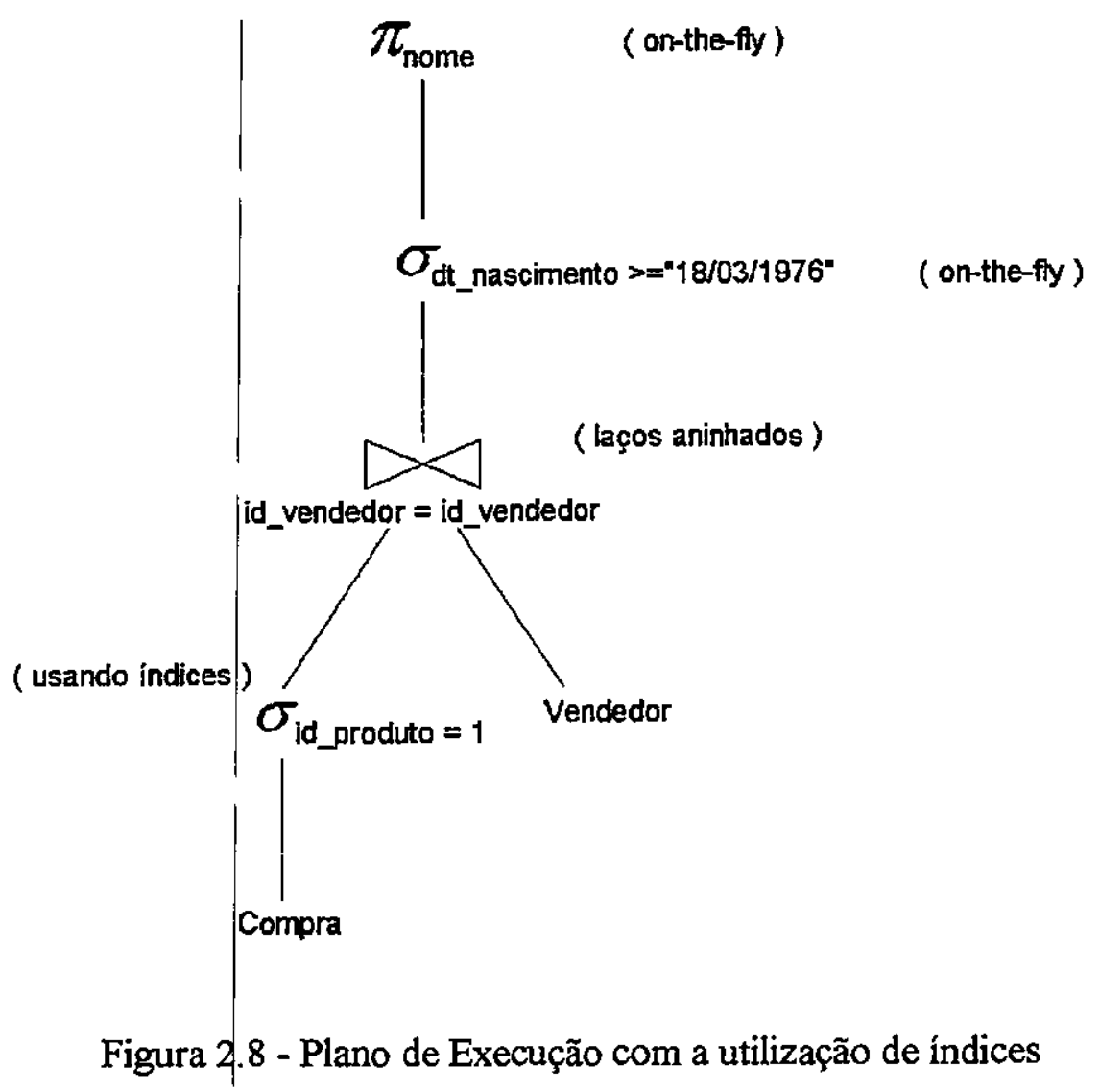

Para cada plano enumerado temos que estimar seu custo. Há duas partes para estimar o custo de um plano de avaliação para um bloco:

4 Para cada nó na árvore, devemos estimar o custo de desempenho para a operação correspondente. Custos são afetados significativamente pelo uso do direcionamento ou de relações temporárias.

4 Para cada nó na árvore, devemos estimar o tamanho do resultado e quando os mesmos estão ordenados ou não. O resultado é a entrada para a operação que corresponde ao pai do nó corrente, e o tamanho e ordenação irão afetar a estimativa de tamanho, custo e ordenação do nó pai.

A estimativa utilizada por um SGBD é baseada nas estatísticas das instâncias da relação, que estão disponíveis no sistema de catálogos. Tais estimativas não são totalmente precisas, logo não 
devemos esperar que o otimizador encontre o melhor plano mas que descarte planos ruins e encontre um bom plano de execução.

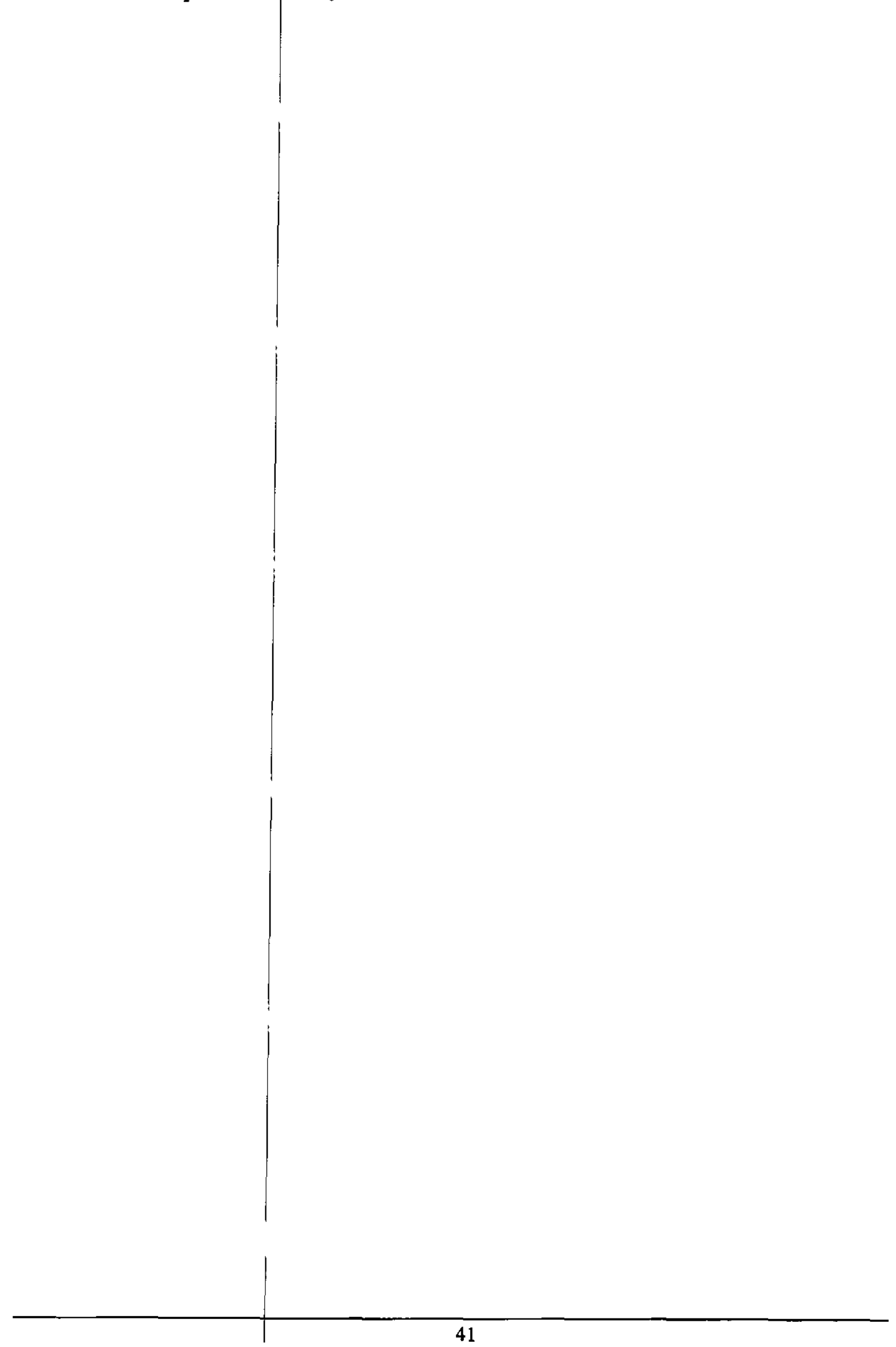




\section{Capítulo 3}

\section{Data Warehouse Temporal}

Uma das maiores dificuldades para se construir um Data Warehouse onde se deseja analisar um conjunto de dados pré-existentes é o da extração e a passagem de tais dados para a estrutura do Data Warehouse. Muitas vezes o projeto de Data Warehouse é inviabilizado, pois não se consegue realizar esta extração de dados em tempo hábil, ou por ela ser realizada de maneira a não garantir a integridade dos dados fazendo que com que as análises não sejam confiáveis.

o Data Warehouse é povoado por fatos que ocorreram num determinado instante do tempo, onde este fato possuía associado a si um conjunto de outras informações, que constituem as dimensões do Data Warehouse. Esta informação armazenada no Data Warehouse constitui informação histórica pois estas informações poderão sofrer alterações ao longo do tempo. Se mum determinado instante do tempo temos a ocorrência de um fato para um elemento $Y$, temos como descobrir o estado de $\mathrm{Y}$ neste instante do tempo. Porém se não temos a ocorrência de um fato, não temos como recuperar a informação histórica para $Y$ no instante desejado. Poderíamos obter os dados dos registros anterior e posterior a este instante, porém não conseguiremos determinar o estado de Y no instante desejado. Para recuperarmos este tipo de informação teríamos que ter uma Base de Dados Histórica independente do Data Warehouse tradicional.

Se no Data Warehouse armazenamos informação Histórica e se numa base de dados Histórica também ocorre o armazenamento de dados histórico então porque não integrarmos essas duas propostas em uma única proposta, de maneira a aproveitarmos os principais recursos de cada uma destas soluções. Esta é nosşa proposta, a criação do Data Warehouse Temporal (DWT) que será utilizado para responder as;consultas analíticas que precisam de um argumento histórico de modo 
a proporcionar o armazenamento de informações históricas que poderão ser obtidas com maior facilidade. Vale relembrar aqui que as consultas sobre o Data Warehouse compreendem a análise sobre um grande conjunto de dados enquanto que as consultas na Base de Dados Histórica tradicionalmente são pontuais, compreendem um ou poucos registros.

Outro instante importante que deve ser considerado é que para se obter o Data Warehouse a partir das informações existentes hoje na maioria dos sistemas o dado tem que passar por grandes transformações. Muitas vezes essa transformação não é possível ser realizada em tempo hábil. Algumas vezes esta transfołmação não é feita de maneira correta obtendo-se dados inconsistentes que gerarão informações incorretas que poderão comprometer todo o sistema de análise. 


\subsection{Aspectos Gerais}

Como já foi explicado o modelo Data Warehouse Temporal tem como principal função aproximar os paradigmas de Banco de Dados Histórico e o paradigma de Data Warehouse.

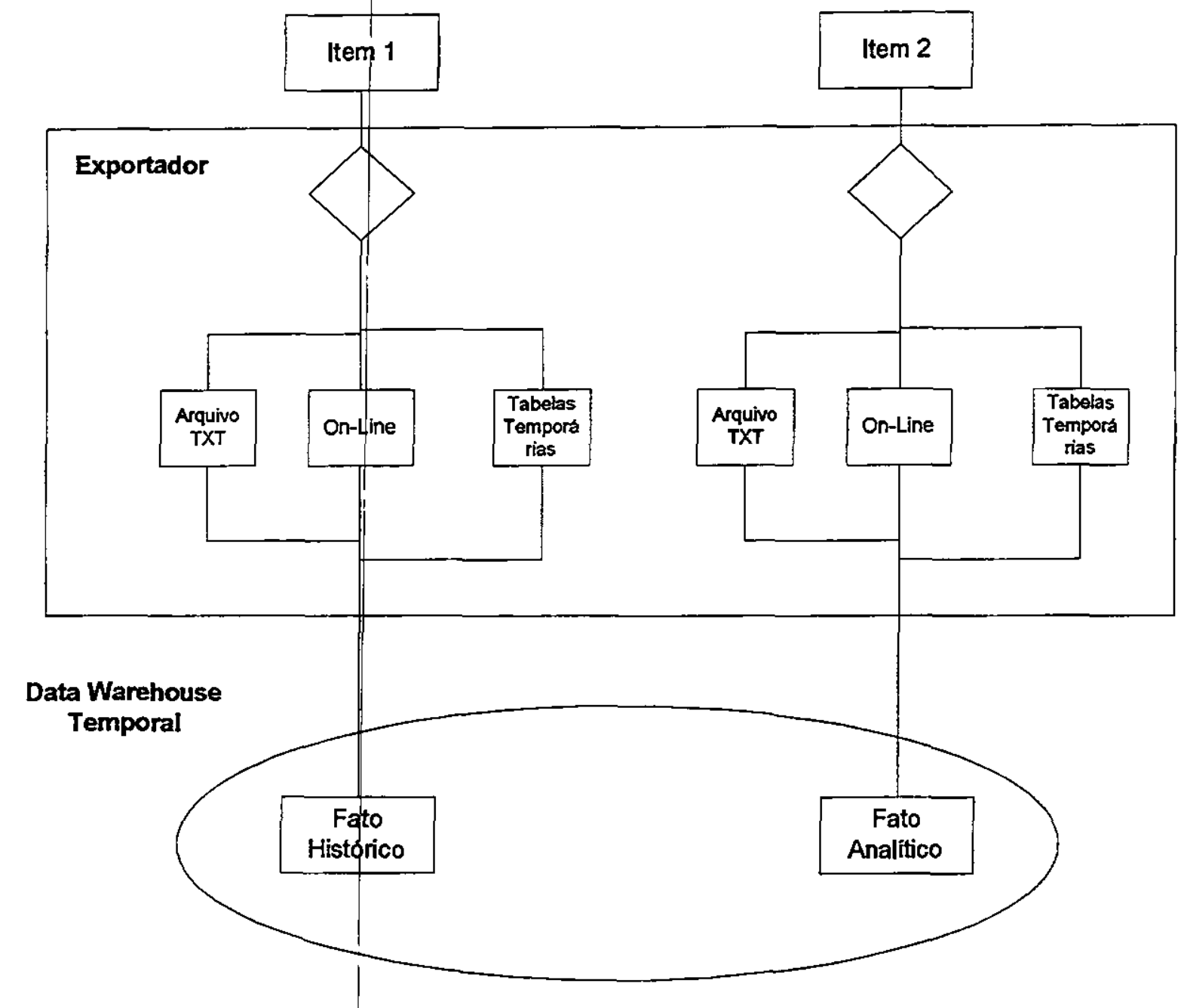

Figura 3.1 - Modelagem do Sistema Transacional e Analítico

Na figura 3.1 podemos identificar os itens 1 e 2 , onde o item 1 contém toda a informação corrente (OLTP) necessária ao sisterha, enquanto que o item 2 contém a informação analítica do sistema a ser analisado. Estes itens são encontrados na maioria dos sistemas atuais. A partir destes itens é que iremos construir e povoar o DWT.

$\mathrm{Na}$ parte inferior da figura temos o modelo do Data Warehouse Temporal (DWT) que é compreendido pelos itens Fato Histórico (FH) e Fato Analítico (FA). 
Fato Histórico é responsável pelo armazenamento da Base de Dados Histórica do sistema enquanto que Fato Analítico é responsável pelo armazenamento dos dados analíticos do sistema. Tanto FH quanto FA tem estrutura diferenciada de Base de Dados Histórica e do Data Warehouse tradicional, isto ocorre para que possamos integrar ambas as soluções em uma única solução, iremos apresentar tais estruturas em seguida.

\subsection{Exportador}

O item Exportador é respónsável pela passagem dos itens 1 e 2 para o DWT. Este item é de grande importância para o sistema. Ele será responsável pela extração da informação, extração esta que precisa ser muito bem executada de maneira a garantir a integridade dos dados. Além da integridade dos dados este item tem como parâmetro de medida o tempo necessário para fazer tal extração. Se o tempo for grande pode ser que a informação obtida não seja mais útil. Outra importante observação a ser feita quando o Exportador poderá estar em execução. Se o Exportador consumir muito recurso (memória, processador), se bloquear tabelas, então é aconselhável que não concorra com o sistema quando este estiver em uso, em suma deve-se avaliar quando este item poderá estar em funcionamento ou não.

O Exportador pode atualizar o FH e o FA das maneiras descritas abaixo:

\subsubsection{Atualização On-line}

A atualização pode set feita On-line, ou seja, a medida que o dado é inserido no sistema corrente (item 1 e 2) 0 dado também é inserido no DWT. A grande vantagem desta abordagem é a de que $\rho$ DWT não ficará desatualizado com o sistema corrente. O tempo de defasagem será nulo. A desvantagem é que o Exportador concorrerá com o sistema corrente, podendo causar uma lentidão indesejável. Esta abordagem é pouco adotada, pois geralmente - Exportador necessita de uma quantidade razoável de recursos. Além disso, devemos considerar também que o uso do sistema pode aumentar a medida que ele se mostra estável, confiável. Muitas vezes este aumento do uso do sistema não é acompanhado pelo aumento de recursos de máquina. Para que o Exportador pudesse funcionar com atualização On-line, os 
recursos teriam que ser maiores, gerando mais custos, o que poderia inviabilizar o sucesso do projeto em decorrência de outra solução mais barata.

\subsubsection{Atualização via arquivos TXT}

Geração de um arquivo txt de saída que posteriormente será exportado para o DWT onde será dada a carga dos dádos.

Quando não há necessidade de se ter os dados do DWT On-Line pode-se adotar esta abordagem, onde as atualizações não ocorrem registro a registro, mas sim por lotes, por conjuntos de registros que são atualizados de tempos em tempos (atualizações podem ser diárias, semanais). Adotaremos aqui a nomenclatura $\boldsymbol{d}+\boldsymbol{x}$ para indicar o tempo de defasagem dos dados, onde $\mathrm{x}$ indica o número de dias de defasagem. Dada uma data $\mathrm{d}$ temos que a defasagem de atualização do dado será de $\mathrm{x}$ dias.

Esta abordagem não mantém os dados atualizados $(d+0)$, porém muitas vezes não há necessidade de se ter os dados síncronos. A vantagem desta abordagem é a de que não concorre com o sistemaj isto pode ser decisivo num sistema, visto que os recursos de máquina poderão ser menores, diminuindo os custos do projeto.

\subsubsection{Atualização via tabelas temporárias}

Geração de tabelas temporárias que posteriormente serão exportadas para o DWT onde será feita a atualização dos dados.

Semelhante a abordagem anterior, com as mesmas vantagens e desvantagens, porém os dados ao invés de serem armazenados num arquivo TXT serão armazenados primeiramente numa tabela temporária. Esta tabela poderá armazenar tanto o conjunto de dados a serem exportados para o DWT como também os identificadores correspondentes as tais alterações. A alteração de um parâmetro $\mathrm{X}$ poderia implicar na exportação de um conjunto de dados $\mathrm{Y} e$ não somente do parâmetro X. Se formos consultar os outros parâmetros de $\mathrm{Y}$ estaremos concorrendo com o sistema, o que não é desejado para esta abordagem. Desta maneira 
armazenaríamos somente o identificador para o registro que sofreu alteração em $\mathrm{X}$, para
posteriormente obtermos os dados associados a ele, no caso $\mathrm{Y}$.

\subsubsection{Uma combinação das soluções apresentadas (configurável)}

Uma solução mais sofisticada seria aquela onde poderíamos configurar a solução a ser adotada de acordo com as necessidades e com o acompanhamento do sistema. Uma primeira divisão que poderiamos fazer seria a separação na política de atualização entre o Fato Histórico e o Fato Analítico. Tradicionalmente o dados analíticos pode apresentar uma defasagem maior que dados históricos. Vamos ver em seguida que o DWT nos dá grande flexibilidade e independência entre fatos históricos e analíticos, permitindo-nos adotar políticas diferentes de atualização para cada uma delas, visto que são independentes entre si. Existem dados, principalmente Históricos, que têm maior importância que putros dados e portanto necessitam de uma atualização mais dinâmica, então poderíamos realizar uma outra divisão de acordo com o conjunto de dados que está sendo tratado. Outra divisão ainda a ser adotada é com relação a horário e datas. Em horários de menor utilização do sistema poderia ser adotada a política On-line enquanto que em horários de pico poderia adotar-se a política de atualização em lotes. De acordo com a data também poderia realizar outra divisão, de acordo com o sistema a utilização dos mesmos nos finais de semana tende a ser menor ou maior que o usual. Existem dados que precisam estar atualizados para uma determinada data (mensal, anual), neste caso devemos garantir que os dados nesta data estarão com $\mathrm{d}+0$. Desta maneira pode-se adotar uma solução viável ao sistema e caso o sistema sofra alterações no decorrer do tempo, a política de atualização pode ser alterada para atender aos novos requisitos devido a sua grande flexibilidade.

De acordo com o sistema ęn análise existem muitas considerações que devem ser feitas, a melhor solução para um sistema nem sempre é a melhor solução para outro sistema. 


\subsection{Porção Analítica}

Nos sistemas tradicionais temos que a tabela de Fatos do Data Warehouse é composta pelos fatos a serem analisados e as chaves para as respectivas dimensões que constituem o Data Warehouse.

No DWT a Tabela de Fatos é composta somente dos fatos e de uma chave W. Esta chave pode ser gerada ou pode ser adotada uma chave do próprio sistema (quando este possuir).

As dimensões do Data Warehouse tradicional correspondem ao estado do fato num determinado instante do tempo, nada mais são do informações históricas num instante do tempo. Desta maneira temos que no DWT as informações referentes as dimensões se encontrarão armazenadas nos Fatos Histórico, repositório de dados responsável pelo armazenamento de informação histórica do sistema. Esta é a grande diferença entre o Data Warehouse tradicional e o DWT.

A estrutura básica dos Fatos Histórico é semelhante a estrutura de Banco de Dados Histórica e é através da chave $\mathrm{W}$, presente tanto no Fato Analítico quanto no Fato Histórico é que faremos a ligação entre estes dois paradigmas.

No modelo DWT temos que os dados ficam armazenados de maneira bem independentes uma da outra, como realmente açontece no mundo real. As atualizações do FH e do FA geralmente ocorrem em momentos diferentes, ou seja, a alteração de um fato histórico não implica na alteração e/ou inserção de um dado analítico e vice-versa.

Como dissemos os dados analíticos são independentes dos dados históricos, isto se reflete na maneira como os dados sầo tratados. Num Data Warehouse tradicional temos que uma alteração nos dados históricos pode se refletir no DW. Isto nos mostra que na abordagem tradicional o grau de dependência entre ambos os dados é grande. No modelo DWT este grau de dependência é pequeno. A única ligação existente entre dados analíticos e dados históricos são as chaves, porém esta não deve ser alterada. Esse é umas das principais motivações para utilização de chaves geradas e não chaves do sistema, pois assim garantimos que as chaves nunca sofrerão alterações, algo que o sistema muitas vezes não pode garantir. 
Além disso, temos que usualmente sistemas mantêm as informações em seus bancos de dados organizados desta maneira, informações históricas armazenadas em um conjunto de dados e informações de análise armazenadas em outro conjunto de dados. Este fator é muito importante visto que a grande maioria das empresas que pretendem implantar Data Warehouse em seus sistemas desejam que todos os dados que já possuem em mãos possam ser aproveitados e convertidos em conhecimento. Esta passagem de dados muitas vezes é inviável num DW tradicional, pois exige um esforço muito grande já para o DWT esta passagem se toma bem mais suave e menos custosa, garantindo uma maior integridade dos dados. A passagem de dados de um sistema usual para o Data Warehouse é uma das maiores dificuldades apontadas na área. Muitas vezes as pessoas que desenvolveram o sistema já não pertencem mais as corporações, a documentação não está bem feita, detalhes importantes são esquecidos e outros pormenores que impossibilitam a transformação segura dos dados. Deseja-se então que os dados possam ser aproveitados com o menor qusto de transformação possível, porém o Data Warehouse tradicional é dificilmente adaptável a uma nova configuração, de maneira que os dados possam ser aproveitados. DWT surge também para suprir esta necessidade, já que a transformação que os dados terão que sofrer serão menores, visto que o DWT é mais flexível a alterações do que o DW tradicional.

O Data Warehouse Temporal é um modelo onde temos total integração entre dados históricos e dados analíticos garantindo assim uma maior confiabilidade da informação, uma melhor organização dos dados. Porém este modelo apresenta uma desvantagem, é menos eficiente.

Devido a sua organização estrutural sempre há a necessidade de se realizar pelo menos uma junção, entre a FA e a FH. Além disso, podem ser necessárias a realização de junções para se obter um conjunto de informações do $\mathrm{FH}$, de acordo com a organização do mesmo. Eștas junções são desnecessárias no DW tradicional visto que toda a informação necessária encontra-se localizada na tabela de Fatos, além disso, o DW tradicional utiliza-se de indices bitmap, o que evita a necessidade de junçळ̋es entre a Tabela de Fatos e as dimensões do modelo. Para minimizar este problema propomos a seguinte distribuição dos dados: quebra em nível fisico e por domínio. 


\subsection{Quebra em nível físico}

Antes de iniciarmos este tópico vale lembrar que o $\mathrm{FH}$ não foi construído único e exclusivamente para atender as necessidades do FA. O FH deve atender as necessidades do FA, mas mais que isso deve ser útil para responder a toda questão que trate de dados históricos, independentes destes dados serem utilizados ou nấo pelo $\mathrm{FA}$.

Consideramos que os itens b e c são formas de visões materializadas do Data Warehouse Temporal. Entretanto definimos os respectivos conceitos de Fato Histórico Global, Fato Histórico Parcial-Dimensional-Independente e Fato Histórico Parcial-Dimensional-Semi-Dependente para um melhor entendimento.

Para melhorar a performance do modelo DWT podemos realizar uma quebra semântica em nivel fisico das tabelas de $\mathrm{FH}$, de acordo com alguns parâmetros vistos a seguir:

\subsubsection{Fato Histórico Global (FHG)}

Nesta abordagem temos que todos os dados relevantes a FA (dados referentes as dimensões, na abordagem clássica do DW) ficarão armazenadas numa mesma tabela. Ou seja, toda vez que uma alteração for feita em algum desses atributos uma nova inserção se fará nesta tabela alterando-se $o(s)$ atributo(s) necessários e mantendo-se os valores dos atributos restantes. Esta técnica é vantajosa, pois temos todos os atributos relevantes a FA numa mesma tabela, desta maneira eliminamos a necessidade de se realizar junções na FH. Todos os dados de que precisamos para a FA encontram-se nesta tabela. A desvantagem desta abordagem é a replicação dos dados, visto que qualquer alteração de um dos atributos corresponde a replicação de todos os outros atributos (aqueles que não sofreram alteração). Desta maneira temos que esta tabela tende a crescer rapidamente e além disso temos também que cada registro desta tabela provavelmente será grande, já que poderá conterlum grande número de atributos. 


\subsubsection{Fato Histórico Parcial-Dimensional-Independente (FHPDI)}

Nesta abordagem temos que todas dimensões relevantes a FA ficarão armazenadas em tabelas independentes umas das outras, ou seja, toda vez que uma alteração for feita em algum desses atributos uma nova inserção se fará nas tabelas necessárias alterando-se o(s) atributo(s) necessários. Os atributos que não sofrerem alteração não terão valores inseridos em suas respectivas tabelas. Esta abordagem deve ser considerada pois muitas consultas focam em um único atributo, desconsiderando os demais, neste caso esta solução é melhor. Esta solução é melhor para estes casos, pois o número de registros da tabela para o atributo considerado será menor do que no caso do FHG, pois os valores serão inseridos na tabela somente se o atributo considerado sofrer alteração, ao contrário do que acontece no FHG. Além disso, os registros referentes ao FHG são maiores do que no FHPDI. Isto ocorre, pois enquanto que no FHG temos todos os atributos relevantes ao FA no FHPDI temos somente o atributo considerado. Como o número de registros do FHG é maior do que no FHPDI temos que a busca sobre o FHG será mais demorada visto que terá que percorrer um número maior de registros. Sendo os registros do FHG maiores do que no FHPDI temos que uma maior quantidade de registros poderão ser carregados para a memória na abordagem do FHPDI em relação ao FHG, favorecendo assim a consulta sobre o FHPDI. A grande desvantagem desta abordagem é quando se deseja realizar uma busca envolvendo mais de um atributo, pois neste caso será necessária a realização de ao menos uma junção, o que pode sobrecarregar uma consulta. Neste caso temos que geralmente o FHG tem desempenho superior ao FHPDI.

3.4.3 Fato Histórico Parcial-Dimensional-Semi-Dependente (FHPDSd)

Uma observação que podemos realizar em Fato Histórico Parcial-Dimensional-Independente é que alguns atributos estão intrinsecamente ligados a outros, ou seja, dado uma consulta que envolva o atributo A, a probabilidade de que esta consulta ou uma próxima consulta envolva também o atributo é muito grande.

Desta maneira podemos adotar a mesma abordagem adotada para Fato Histórico ParcialDimensional-Independente com o diferencial que quando os atributos tiverem forte grau de dependência podemos uni-los numa mesma tabela. 
As vantagens desta abordagem em relação a FHG são as mesmas apresentadas para FHPDI. A desvantagem em relação a FHPDI é que as tabelas do FHPDSd serão um pouco maiores. Porém a grande vantagem é quando se deseja realizar uma busca envolvendo mais de um atributo, e os atributos se encontram presentes em FHPDSd. Neste caso a busca não será realizada na FHG e muito menos na FHPDI, já que será necessário ao menos uma junção para se obter a resposta para esta abordagem. Usaremos o FHPDSd, já que os atributos envolvidos se encontram numa mesma tabela. As seleções relativas as consultas geralmente envolvem um conjunto de atributos, atributos estes que possuem relação entre si.

Outra importante observação a ser feita é a de que não precisamos adotar exclusivamente uma única solução (FHG, FHPDI e FHPDSd). Devemos sim combinar estas soluções de maneira a obtermos com isso uma melhor performance de nosso sistema. A idéia inicial é a de que tenhamos sempre um Fato Histórico Global, para que possamos responder a qualquer consulta e algumas ou várias Fato Histórico Parcial-Dimensional, de acordo com a necessidade das consultas que se aplicarão sobre a FA. Um grande desafio neste instante consiste justamente da identificação de quais atributos são independentes e quais atributos são semi-dependentes e com quais atributos os mesmos se encontram relacionados. Se este levantamento for feito erroneamente criaremos FHPDI e FHPDSd de maneira falha, sendo que a resposta para certas consultas poderão se tornar lentas. Consultas envolvendo mais de um atributo provavelmente irão consultar a FHG ao invés da FHPDSd pois não existîrá tabela relacionando os atributos desejados, desta maneira iremos sobrecarregar a FHG degradando a performance das consultas que as utilizam. Se este levantamento for feito cotretamente temos as condições ideais para a construção de um repositório de dados mais eficiente.

A implementação de FHPDI e FHPDSd pode ser feita através da criação de visões materializadas. 
Exemplo:

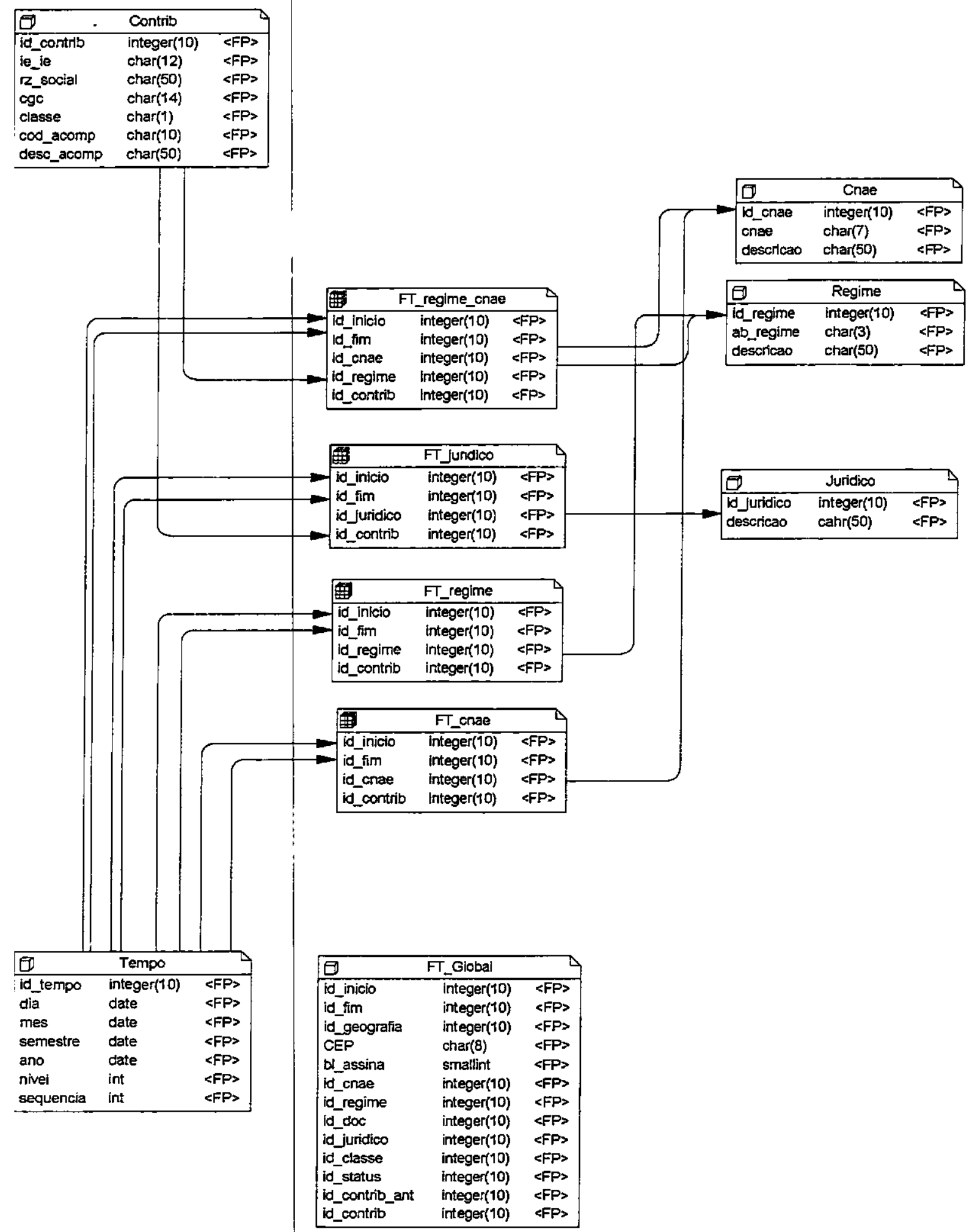

Figura 3.2 - Exemplificação dos conceitos de FHG, FHPDI e FHPDSd 
Dada a figura 3.2 pode-se identificar:

- FT_Global: Fato Histórico Global;

- FT_regime: Fato Histórico Parcial-Dimensional-Independente;

- FT_cnae: Fato Históricd Parcial-Dimensional-Independente;

- FT juridico: Fato Histótico Parcial-Dimensional-Independente;

- FT_regime_cnae: Fato Histórico Parcial-Dimensional-Semi-Dependente;

Dada a consulta: Deseja-se saber a somatória do fato analítico A onde o Regime de Apuração for Microempresa para o ano de 2000. A consulta dada pode ser obtida a partir de: FT_Global, FT_regime e FT_regime_cnae. A melhor solução é data por FT_regime pois esta tabela possui um número de registros infẹrior ou igual (na pior das hipóteses) a FT_Global e FT_regime_cnae. Microempresa, CNAE entre 50.000-00 a 59.999-99 para o ano de 2000. A consulta pode ser obtida a partir de: FT_Global, FT_regime_cnae e FT_regime + FT_cnae. FT_regime_cnae tende a possuir menos registros que FT_Global, logo tem desempenho superior a FT_Global. Para que se possa utilizar FT_regime e FT_cnae é necessário a aplicação de uma junção entre estas duas tabelas de fato, o que encarece o processo de seleção. Em FT_regime_cnae não é necessário a aplicação desta junção, ldgo ela possui desempenho superior a utlização de FT_regime em conjunto com FT_cnae.

Dada a consulta: Deseja-se saber a somatória do fato analítico A onde Regime de Apuração for Microempresa, tipo jurídico for Associação para o ano de 2000. Temos duas soluções principais: FT_Global e FT_juridico em conjunto com FT_regime. FT_Global tende a possuir desempenho superior pois em FT_Global não existe a necessidade de se realizar a junção enquanto que se utilizarmos FT_regime e FT juridico ocorre a necessidade de se realizar tal junção. Esta junção tende a possuir custo elevado inviabilizando assim a solução onde ocorre a utilização de FT_regime em conjunto com FT_juridico. 


\subsection{Quebra de FH por domínio - FHn}

Uma outra quebra que podemos realizar, diz respeito aos valores do domínio que os atributos poderão assumir. Dado um atributo $\mathrm{A}$ podemos determinar seu domínio e com isso criar uma tabela para cada valor do domínio. Dada uma condição que selecione somente um dos conjuntos de domínios do atributo $\mathrm{A}$ já saberemos quais tabelas iremos utilizar. Denominaremos estas tabelas como sendo FHn, onde n representa o número de valores existentes dentro do domínio do atributo desejado. Desta maneira teremos $n$ tabelas, onde cada tabela compreenderá um valor do domínio dado. Teriamos a seguinte notação:

$\mathrm{FHn}=\mathrm{FHI} \mathrm{U} \ldots \mathrm{U}$ FHa $\mathrm{U} \mid \ldots \mathrm{FHn}, \mathrm{com} 1<=\mathrm{a}<=\mathrm{n}$.

Dado $\mathrm{n}$ possíveis valores para o atributo considerado, teríamos $\mathrm{n}$ tabelas.

Existem valores do domínio que possuem tratamentos semelhantes. Freqüentemente aparecem juntos em uma consulta. Ex: dada uma consulta que precise percorrer os dados para o valor $\mathrm{X}$ do domínio a probabilidade que a mesma consulta também precise percorrer os dados para o valor $\mathrm{Y}$ do mesmo domínio são grandes. Neste caso podemos juntar a FHx (referentes ao valor X) e a FHy (referentes ao valor Y) em uma mesma FH. Desta maneira teríamos que:

$\mathrm{FHn}=\mathrm{FH} 1 \mathrm{U} \ldots . \mathrm{U}$ FHa $\mathrm{U} \ldots \mathrm{FHm}, \mathrm{com} 1<=\mathrm{a}<=\mathrm{m}$ e $\mathrm{m}<=\mathrm{n}$.

Dado n possíveis valores para o atributo considerado, teriamos $m$ tabelas. Onde $m$ é menor ou igual a n. Se m menor que n então houve uma junção de FHs de valores diferentes em uma mesma FH.

Expandindo o conceito podemos ter uma quebra por domínio para cada um dos atributos considerados. Nos casos anteriores vimos somente a quebra por domínio relativo a um único atributo. Desta maneira teríamos a seguinte notação:

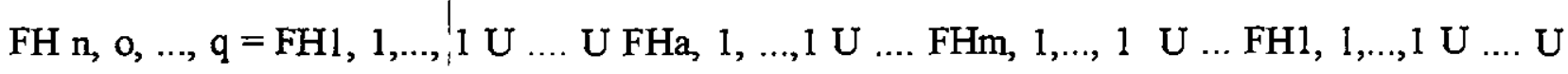

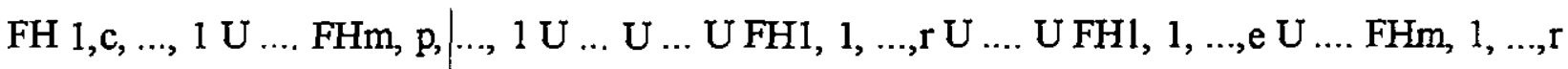


com $1<=a<=m$ e $\mathrm{m}<=$ n, $1<=\mathrm{c}<=$ p e $o<=$ p, $1<=$ e $<=$ q e $\mathrm{r}<=\mathrm{q}$.

Podemos dizer que o elemento FHx,y,z corresponde a tabela que representa o valor $\mathrm{x}$ para para $\mathrm{O}$ atributo A e valor y para 0 atributo B e valor $z$ para o atributo $C$. Sendo que valor $x$, valor y e valor $z$ podem ser compostos, ou seja, podem representar mais de um valor, pois desejou-se agregá-los numa mesma tabela visando um melhor desempenho.

Esta implementação não é possivel de se realizar utilizando-se índices, esta implementação deverá usar a criação de tabelas.

Vimos duas técnicas visando uma melhor distribuição dos dados, estas técnicas não só podem mas devem ser utilizadas em conjunto para a obtenção de um melhor desempenho. Poderíamos ter a seguinte configuração:

$\mathrm{FH}=\mathrm{FHx}, \mathrm{y}, \mathrm{z} \mathrm{U} \mathrm{FHw}, \mathrm{s}, \ldots \mathrm{U}$ Fho,p,q

$\mathrm{x}=$ valores $(\mathrm{a}, \mathrm{b}, \mathrm{c})$ do domínio $\mathrm{M}$.

$\mathrm{y}=$ valores (d) do domínio $\mathrm{N}$.

$z=$ valores $(e, f)$ do domínio $R$.

$\mathrm{w}=$ valores $(\mathrm{g})$ do domínio $\mathrm{M}$.

$\mathrm{s}=$ valores $(\mathrm{h}, \mathrm{i})$ do domínio $\mathrm{N}$.

$o=$ valores $(j)$ do domínio $M$.

$\mathrm{p}=$ valores $(\mathrm{k})$ do domínio $\mathrm{N}$.

$q=$ valores (l) do domínio $R$.

FHx $, y, z=$ FHPDI $x$ U FHPDSd $y, z$.

$\mathrm{FHw}, \mathrm{s}=\mathrm{FHG}$ w,s

Fho,p,q = FHG o,p,q U FHPDI p

Note que existe um grande número de combinações possíveis, o segredo está em justamente conhecer o sistema a ser desenvolvido para que se possa adotar a configuração mais adequada. 


\subsection{Especialização/Composição}

Especialização (E) - podendo ser total/parcial e disjunta/sobreposta

Composição (C)

Hierarquia $(\mathrm{H})$

Modelos

M-1: modelo não apresenta E,C e H. (modelo padrão do Data Warehouse).

M-2: modelo apresenta E. (dois níveis - principal + especializável)

M-3: modelo apresenta $C$. (dois niveis - principal + composição)

M-4: modelo apresenta 1 nível de $\mathrm{E}$ de 1 nível de $\mathrm{C}$ (3 niveis)

M-5: modelo apresenta HE (hierarquia de especialização)

M-6: modelo apresenta HC (hierarquia de composição)

M-7: modelo apresenta HEC (hierarquia de especialização e composição)

Como a tabela de fatos poderia ser mapeada:

M-1

- D-01: modelo padrão.

M-2

- D-02: somente nível superior da E. Neste caso perderíamos as informações relacionadas ao nivel inferior da especialização.

- D-03: somente níveis inferiores da E. Podemos ou não recuperar os valores dos níveis superiores. Caso haja descontos no nível superior este valor pode não ser recuperado. Quando especialização sobreponivel temos que somar os diversos valores obtidos para recuperar o valor do nível superior (isto quando for possivel, sem descontos, por ex.). Se especialização parcial dados serão perdidos no nivel superior.

- D-04: ambos os níveis serão mapeados.

M-3

- D-05: somente nivel superior da composição. 
- D-06: somente nível inferior da composição. Pode-se ou não recuperar o valor de nivel superior. Com a adição de descontos sem que haja uma padronização é impossivel recuperar os valores de nível superior. Existe a necessidade de sumarizar os diversos valores da composição para se obter o valor do nivel superior. Pode ser ainda que a composição não seja obrigatória (como em especialização parcial).

- D-07: ambos os niveis serão mapeados.

M-4

- D-08: somente nível superior da especialização (1 - número de níveis mapeados)

- D-09: somente nível superior da composição (1)

- D-10: somente nivel inferior da especialização (1)

- D-11: somente nível inferior da composição (1)

- D-12: somente nivel principal e relativo a especialização (2)

- D-13: somente nível principal e relativo a composição (2)

- D-14: todos os níveis (3)

M-5

- D-15: somente 1 nível da especialização (primeiro ou último)

- D-16: 2 a n-1 níveis da éspecialização

- D-17: todos os níveis da especialização

M-6

- D-18: somente 1 nível da composição

- D-19: 2 a n-1 níveis da composição

- D-20: todos os níveis da composição

M-7

- D-21: somente 1 nível da hierarquia de especialização

- D-22: somente 1 nivel da hierarquia de composição

- D-23: 2 a nE-1 niveis da hierarquia de especialização (se ordenados) 
- D-24: todos os níveis da hierarquia de especialização (se ordenados)

- D-25: 2 a nC-1 níveis da hierarquia de composição (se ordenados)

- D-26: todos os níveis da hierarquia de composição (se ordenados)

- D-27: 2 a n-1 níveis da hierarquia de especialização/composição

- D-28: todos os níveis da hierarquia de especialização/composição

\begin{tabular}{|c|c|c|c|c|c|c|}
\hline 10\% & thosinge & 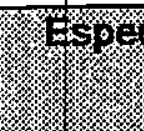 & 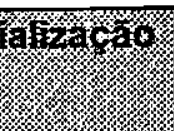 & (1) & 51630 & 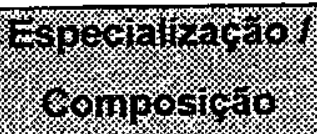 \\
\hline & V & (6) & 4 & (1) & S & \\
\hline$\sqrt{19}$ & D-01 & & & & & \\
\hline א. & & $\begin{array}{l}\mathrm{D}-02 \\
\mathrm{D}-03\end{array}$ & $\overline{D-04}$ & & & \\
\hline . 13 & & & & $\begin{array}{l}\mathrm{D}-05 \\
\mathrm{D}-06\end{array}$ & $\overline{D-07}$ & \\
\hline V. & & $\begin{array}{l}\text { D-08 } \\
D-10\end{array}$ & $D-12$ & $\begin{array}{l}\text { D-09 } \\
\text { D-11 }\end{array}$ & D-13 & D-14 \\
\hline . & & $\overline{D-15}$ & $\begin{array}{l}\text { D-16 } \\
\text { D-17 }\end{array}$ & & & \\
\hline 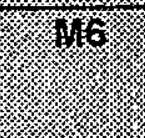 & & & & D-18 & $\begin{array}{l}\text { D-19 } \\
\text { D-20 }\end{array}$ & \\
\hline (1) & & $D-21$ & $\begin{array}{l}\text { D-23 } \\
\text { D-24 }\end{array}$ & D-22 & $\begin{array}{l}\mathrm{D}-25 \\
\mathrm{D}-26\end{array}$ & $\begin{array}{l}\text { D-27 } \\
\text { D-28 }\end{array}$ \\
\hline
\end{tabular}

Tabela 3.1 - Abstrações

Observações:

- Composição: algumas vezes o fato do nível superior é a somatória dos valores do nível inferior + valor $x$ Constante.

- O mesmo vale para especialização. Note que na especialização disjunta temos que a somatória é o próprio valor, já que o pai possui um único filho. 


\subsection{Tratamento de alterações ocorridas nas tabelas de dimensão}

Temos que pequenas alterações podem ser provocadas nas tabelas de dimensão de um DW tradicional. Dr. Kimball propõe três diferentes tipos de tratamento para estes casos. Como exemplo utilizaremos a dimensão Geografia. Adotaremos o município de Miracema do Norte, que já pertenceu ao Estado de Goiás e hoje pertence ao estado de Tocantins. A dimensão Geografia adotada aparece na figura a seguir.

\begin{tabular}{|lll|}
\hline \multicolumn{3}{|c|}{ Geografia } \\
\hline id_geografia & integer(10) & $<\mathrm{FP}>$ \\
cidade & char(30) & $<\mathrm{FP}>$ \\
estado & char(30) & $<\mathrm{FP}>$ \\
pais & char(30) & $<\mathrm{FP}>$ \\
nivel & int & $<\mathrm{FP}>$ \\
\hline
\end{tabular}

Figura 3.3 - Dimensão Geografia

O municipio de Miracema do Norte aparece como sendo a tupla a seguir:

(1,Miracema do Norte, Goiás, Brasil, 1)

Neste caso estamos considerando o periodo anterior a criação do Estado de Tocantins.

A seguir descrevemos os trệs tipos apresentados por Kimball:

\subsubsection{Tipo 1}

Nesta solução os atributos são sobrescritos, perdendo assim o histórico da tabela de dimensão. Por não armazenar dados hịstóricos temos que a dimensão não terá crescimento expressivo. Esta solução é a mais simples apresentada por Kimball.

Neste exemplo alterariamos a tupla considerada obtendo o seguinte resultado:

(1,Miracema do Norte, Tocantins, Brasil, 1)

Ou seja, os fatos que antes/apontavam para o município de Miracema do Norte como sendo do Estado de Goiás agora apontam para o mesmo município porém pertencente ao estado de Tocantins, perdendo, desta forma todos os dados históricos e causando uma certa inconsistência. 
Tomemos como exemplo um fato que ocorreu no ano de 1980. Este fato tem como representante na dimensão geografia o estado de Tocantins, porém em 1980 o estado de Tocantins não existia.

\subsubsection{Tipo 2}

Nesta solução um novo registro é criado. Essencialmente esta solução nos permite criar snapshots de valores em instantes no tempo. Isto nos permite armazenar toda a informação histórica que acaba por introduzir um nivel de complexidade para o DW que pode não ser justificada. Esta abordagem é atualmente a mais usada. Para o exemplo dado teríamos as seguintes tuplas:

(1,Miracema do Norte, Gołás, Brasil, 1)

(1000,Miracema do Norte, Tocantins, Brasil, 1)

Os fatos que antes apontavam para a primeira tupla continuam a apontar para a mesma, as tuplas que forem inseridas após a criação do estado de Tocantins devem possuir id_geografia $=1000$ e não mais 1. A partir da dảta de criação do Estado de Tocantins nenhuma tupla deverá apontar mais a tupla 1, referente ao estado de Goiás. Desta maneira não causamos inconsistências como visto acima, referente ao ano de 1980. Porém esta abordagem não nos permite recuperar a história de determinado dado, ou seja, não existe um atributo que nos indique se determinado valor é ou não corrente. Além disso, não existe um parâmetro que nos indique qual a origem de determinado dado. Suponha que Miracema do Norte mude seu nome para Amparo. Teremos a seguinte configuração:

(1000,Miracema do Norte, Tocantins, Brasil, 1)

(5000,Amparo, Tocantins, Brasil, 1)

Não existe um atributo que faça a ligação entre estas tuplas, que diga que Amparo anteriormente se chamava Miracema do Norte ou vice-versa.

\subsubsection{Tipo 3}

Esta solução surgiu para atender as necessidades que não estavam sendo atendidas pela solução anterior. Visa atender a necessidade de dizer qual é o dado corrente ou não e de efetivamente 
armazenar todas as mudanças históricas, permitindo a criação de uma ligação entre os registros. Para atender esta necessidade atributos adicionais são necessários.

Poderíamos ter a seguinte configuração para a dimensão Geografia.

\begin{tabular}{|lll|}
\hline \multicolumn{3}{|c|}{ Geografia } \\
\hline id_geografia & integer(10) & <FPs \\
cidade & char(30) & $<F P>$ \\
estado & char(30) & $<F P>$ \\
pais & char(30) & $<F P>$ \\
nivel & int & $<F P>$ \\
id_origem & integer(10) & $<F P>$ \\
id_dtalt & integer(10) & $<F P>$ \\
\hline
\end{tabular}

Figura 3.4 - Dimensão Geografia - Tratamento Histórico

Neste caso teríamos a seguinte tupla para representar o município de Miracema do Norte:

(1,Miracema do Norte, Goilás, Brasil, 1, 0, NULL)

Adotamos que se id_origem $=0$ então dado originário da dimensão. Poderíamos adotar também que se id_dtalt=0 então dado é corrente (data de alteração).

Desta forma obteríamos as seguintes tuplas:

(1,Miracema do Norte, Gojás, Brasil, 1, 0, 01/01/1990)

(1000,Miracema do Norte, Goiás, Brasil, 1, 1, NULL)

Desta maneira conseguimos recuperar as informações históricas de determinada dimensão.

Uma pequena modificação|sugerida sobre esta solução seria a criação de uma nova tabela para o atributo mas factível de soffrer alteração. Suponha a dimensão a seguir:

\begin{tabular}{|c|c|c|}
\hline \multicolumn{3}{|c|}{ Cliente } \\
\hline id_cliente & integer(10) & $\langle F P\rangle$ \\
\hline estado_civil & int & $\langle F P\rangle$ \\
\hline id_ctnasc & integer(10) & $<F P\rangle$ \\
\hline sexo & int & $\langle F P\rangle$ \\
\hline nivel & int & $\langle F P\rangle$ \\
\hline id_origem & integer(10) & $\langle F P\rangle$ \\
\hline id_dtalt & integer(10) & $\langle F P\rangle$ \\
\hline
\end{tabular}

Figura 3.5 - Dimensão Cliente 
Temos que estado_civil é um dado que pode sofrer alterações enquanto que data de nascimento (id_dtnasc) e sexo (sexo) sã ter a seguinte representação:

\begin{tabular}{|l|ll|}
\hline & & \\
\hline & Cliente & \\
\hline id_cliente & integer(10) & <FP> \\
id_dtnasc & integer(10) & <FP> \\
sexo & int & <FP> \\
id_origem & integer(10) & <FP> \\
id_ctalt & integer(10) & <FP> \\
\hline
\end{tabular}

\begin{tabular}{|lll|}
\hline & Civil & \\
\hline id_cliente & integer(10) & <FP \\
estado_civil & int & <FP> \\
id_dtalt & integer(10) & <FP> \\
\hline
\end{tabular}

Figura 3.6 - Tratamento Histórico de Dimensões - Data de alteração

Na figura 3.5 os dados id_origem e id_dtalt foram mantidos na tabela de dimensão cliente pois em casos extremos poderiamos ter uma mudança de sexo. Caso este tipo de mudança de sexo não seja representada pelo modelo os atributos id_origem e id_dtalt poderiam ser retirados da dimensão Cliente. A tabela Civil estaria ligada logicamente a tabela Cliente pelo atributo id_cliente.

Outra observação a ser feita é referente a períodos de tempo. Numa consulta que se objetiva conhecer as vendas para clientes casados e para clientes solteiros no ano de 1997. No exemplo acima teríamos que recuperar a primeira tupla anterior a 1997 para determinado cliente. Em seguida recuperar as tuplas iseguintes até que a id_dtalt seja maior que 1997. Suponha que para o cliente 1 e 2 tenhamos as seguintes entradas:

$(1,3,01 / 01 / 1996)-3$ é viúyo

$(1,2,01 / 12 / 1996)-2$ é casado

$(1,4,01 / 09 / 1997)-4$ é divorciado

$(1,2$, NULL $)-2$ é casado

$(2,1,01 / 09 / 1995)-1$ é solteiro

$(2,2, N U L L)-1$ é casado

Neste exemplo devemos recuperar e tratar as seguintes tuplas:

$(1,2,01 / 12 / 1996)-2$ é casado

$(1,4,01 / 09 / 1997)-4$ é divorciado

( 1,2 , NULL) - 2 é casado

$(2,1,01 / 09 / 1995)-1$ é sollteiro 
Obtemos para cliente 1 que no período de 01/01/1997 a 01/09/1997 ele era divorciado e que do período de 01/09/1997 a 3/1/12/1997 ele era casado. Para cliente 2 teríamos que ele era casado durante todo o ano de 1997 . Note que foram necessárias a recuperação de 5 linhas para se chegar ao resultado desejado.

A extensão a ser feita é a inclusão de duas datas para o tratamento de dados históricos, data de início (id_dtinicio) de validade de determinado dado e data de término (id_dtfim) da validade do dado. A seguir o esquema que representa esta abordagem:

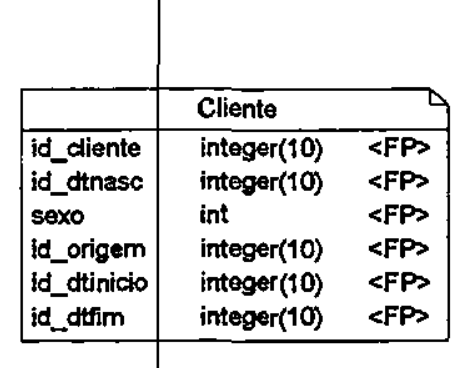

\begin{tabular}{|lll|}
\hline & Civil & \\
\hline id_cliente & integer(10) & <FP \\
estado_civil & int & <FP> \\
id_dtinicio & integer(10) & <FP> \\
id_dtfim & integer(10) & <FP> \\
\hline
\end{tabular}

Figura 3.7 - Tratamento Histórico de Dimensões - Intervalo de Tempo

Desta forma teríamos:

$(1,3,01 / 01 / 1995,01 / 01 / 1996)-3$ é viúvo

$(1,3,01 / 01 / 1996,01 / 12 / 1996)$ - 2 é casado

$(1,2,01 / 12 / 1996,01 / 09 / 1997)-4$ é divorciado

$(1,4,01 / 09 / 1997$, NULL $)-2$ é casado

(2, 1,01/01/1990, 01/09/1995) - 1 é solteiro

$(2,2,01 / 09 / 1995$, NULL $)-1$ é casado

Neste exemplo devemos recuperar e tratar as seguintes tuplas:

$(1,2,01 / 12 / 1996,01 / 09 / 1997)-4$ é divorciado

$(1,4,01 / 09 / 1997, \mathrm{NULL})-2$ é casado

$(2,2,01 / 09 / 1995, \mathrm{NULL})-1$ é casado

O número de tuplas a serem tratadas diminuiu em 2, referentes ao número de clientes considerados, isso acontece pois no caso de termos somente uma data sempre precisamos 
recuperar uma tupla a mais para cada cliente considerado, para sabermos a data final de validade da informação. Desta maneira temos que o número de tuplas da primeira solução recuperará $x+n$ tuplas enquanto que a segunda abordagem recupera somente $\mathrm{x}$ tuplas, para o caso de $\mathrm{n}$ clientes.

Outra vantagem desta abordagem é que possuimos a data de início de validade da primeira tupla enquanto que na abordagem anterior não armazenamos este tipo de informação, pois será armazenado a data de alteração da informação e não do início de sua validade. 


\section{Capítulo 4}

\section{Monitor de Consultas}

Neste capítulo será visto as possíveis seleções que podem ser aplicadas sobre o Data Warehouse Temporal e as alternativas para cada uma delas. Cada alternativa possui associado a si um custo de operação que precisa ser muito bem dimensionado.

Em seguida serão apresentados aspectos lógicos de uma ferramenta que terá a capacidade de considerar os parâmetros de uma consulta para criar diferentes estruturas de consultas SQL para cada modelo físico de dados armazenados no Data Warehouse. Apresentamos aqui as três propostas segundo Kimball além da nossa proposta, de Data Warehouse Temporal (DWT).

Também apresentaremos nesse capitulo as algumas alternativas para representação das abstrações de composição e agregação nos modelos lógicos de Data Warehouse.

\subsection{Considerações Gerais sobre Data Warehouse Temporal}

A primeira importante observação a ser feita é a de que podem existir várias configurações referentes ao Data Warehouse Temporal: fatos analíticos que não estão em FH. Estas dimensões não constituem informação de dados cadastrais, mas sim um outro tipo de informação que chamaremos de informação exclusiva ao FA. Um exemplo disso pode ser dado utilizando o pagamento da GIA, que pode ser realizado, em diferentes bancos. Deseja-se que a informação em que banco foi paga a GIA seja transportada para o Data Warehouse. Esta informação não faz parte dos dados cadastrais do contribuinte, porém a mesma deve ser transportada ao DWT, mas precisamente na FA, da mesma forma que num DW tradicional. 
Desta maneira temos que as consultas que se deseja realizar sobre o DWT podem compreender tanto as dimensões existentes em FH quanto em FA.

Se as consultas que forem realizadas se utilizarem somente das dimensões referente a data de entrega da GIA e dimensões exclusivas a FA então temos que esta consulta não precisará se utilizar de FH. Desta maneira temos que consultas deste gênero, denominadas Consultas FA, se utilizarão somente da FA não precisando consultar a FH. Consultas que se utilizam da FH serão denominadas de Consultas FH. Consultas que são FA e FH simultaneamente, ou seja, que se utilizam de FA e FH serão denominadas Consultas DWT.

\subsection{Consultas FH}

Consultas que se utilizam de dados da $\mathrm{FH}$ são o alvo principal de estudo do monitor. Dada a condição de seleção e de agrupamento da consulta temos que analisar se existe uma agregação na FH que contenha somente estes parâmetros referentes a FH. Caso exista esta agregação então ela será utilizada para atender a consulta. No caso de existir tal agregação denominaremos esta consulta como sendo Consulta FH agregação completa caso contrário denominaremos como Consulta $\mathrm{FH}$ agregação parcial.

\subsubsection{Consultas Temporais}

Consulta temporal é aquela que se utiliza dos dados da FH, toda Consulta FH é também uma consulta temporal. Consulta Temporal é aquela que precisa agregar a informação o período de sua validade, como veremos no exemplo abaixo. Consultas ditas temporais não aparecem num DW tradicional.

Imagine que se deseja conhecer o valor total pago na GIA pelas empresas no ano de 1999 referentes ao regime de apuração RPA. O recolhimento para empresas RPA é feito mensalmente, ou seja, se num determinado mês a empresa pertencia ao regime RPA então deve entrar GIA referente àquele mês. Existem regimes de apuração onde não há recolhimento de GIA, onde este recolhimento é mensal, semestral, anual. 
Devemos percorrer a FH a procura de empresas que no ano de 1999 pertenceram ao regime RPA. Porém esta não é uma informação completa, ou seja, se a empresa A pertenceu ao regime RPA no mês de janeiro isso não quer dizer que as GIAs entregues por ela nos meses subsequentes são relativos a sua condição de RPA. Ou seja, para um DWT com consultas temporais temos que a informação necessária diz respeito a quem atende a necessidade imposta e dentro de qual periodo. Sendo que o periodo a ser analisado corresponde ao imposto pela consulta temporal. Esta é uma importante observação pois toda informação levará agregada a si o período de sua validade o que acarreta numa degradação de desempenho.

\subsubsection{Agrupamento}

Numa consulta padrão, onde não há a existência de agrupamentos, temos que a informação será constituída pela chave primária, responsável pela ligação entre FH e FA além do período de sua validade. Caso haja agrupamentos na consulta então fará parte da informação a chave primária, sua validade e os parâmetros do agrupamento, para que se possa obter o resultado esperado. Exemplo: deseja conhecer o valor pago pela GIA agrupados por Regime de Apuração, então precisaremos ter a chave primária, para realizar a ligação entre FH e FA, o período de validade de tal dado (Consulta temporal) além do Regime de Apuração válido no período, para que a agregação possa ser feita corretamente.

\subsubsection{Tratamento de Hierarquia}

O tratamento de hierarquia pode ser feito de maneira semelhante ao dado no DW tradicional. Para a dimensão Geografia poderíamos Ter:

\begin{tabular}{|lll|}
\hline & Geografia & \\
\hline id_geografia & integer(10) & $<$ FP> \\
municipio & char(50) & $<\mathrm{FP}>$ \\
pf & char(50) & $<\mathrm{FP}>$ \\
if & char(50) & $<\mathrm{FP}>$ \\
drt & char(50) & $<\mathrm{FP}>$ \\
nivel & int & $<\mathrm{FP}>$ \\
\hline
\end{tabular}

Figura 4.1 - Dimensão Geografia 
O tratamento dado para a dimensão geografia neste caso é o mesmo dado no DW tradicional. O atributo nível seria utilizado para indicar o nível da informação. Nível 1 corresponde a municipiopf, nivel 2 a inspetoria fiscal (if) e nível 3 a delegacia (drt). Desta maneira poderiamos Ter também o modelo snowflake:

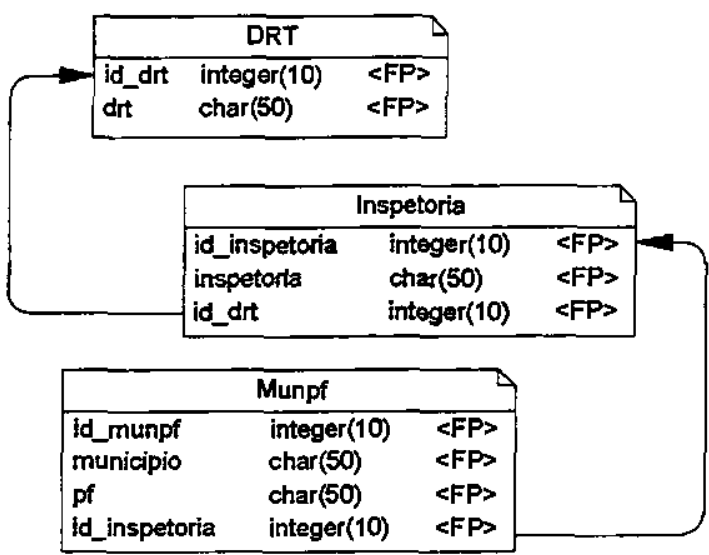

Figura 4.2 - Hierarquia de dimensões

Tratamento dado a esta agregação e a mesma do DW tradicional. Um adendo que podemos utilizar é o período de validade da informação, ou seja, existe a possibilidade de que um elemento de nível 1 passe a pertencer a outro elemento de nível 2 a partir de determinada data, o mesmo acontecendo para elementos de nível 2 em relação ao nível 3. Além disso temos a possibilidade de que elementos de nível 3 deixem de existir. Estas alterações geralmente acontecem com baixa freqüência, muitas vezes não sendo mapeada para o DW. Desta maneira teríamos as seguintes dimensões: 


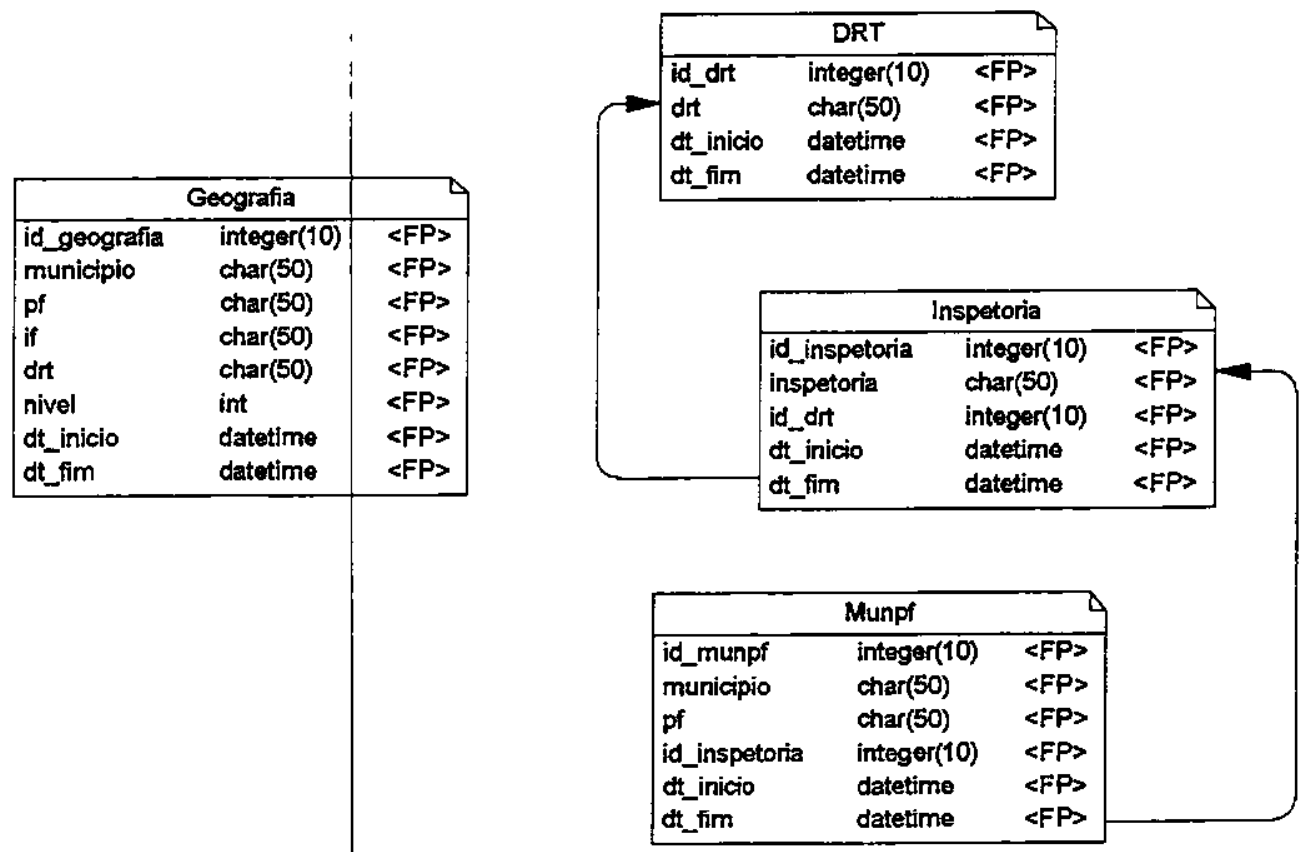

Figura 4.3 - Histórico - Dimensão Geografia

\subsubsection{Consultas FH agregação completa}

O primeiro passo consiste em identificar a agregação que atende as necessidades da consulta. Desta maneira obtemos toda informação desejada juntamente com seu período de validade. Este subconjunto de dados, resultante da Consulta $\mathrm{FH}$ atendendo aos parâmetros passados pela consulta desejada, receberá o nome de Resultado FH.

\subsubsection{Consultas FH agregação parcial}

Primeiramente devemos analisar as seguintes alternativas para determinar sobre quais tabelas deveremos percorrer para a 'obtenção dos dados necessários.

- Levantar qual a tabela de menor granulalidade que atende a consulta desejada (FHPI ou FGPSd), ou seja, que possua todos os parâmetros da consulta. Na pior hipótese teremos que a tabela FHG atenderá a necessidade, caso ela exista.

- Levantar quais conjuntos de tabelas podem atender as pesquisas desejadas.

Feito este levantamento inicial vamos analisar quais deles nos é menos custoso. O custo é medido pelo tempo médio gasto para que se realize a consulta desejada. Para determinar o custo da consulta desejada deve-se considerar: 
- Custo para percorrer: número de registros a serem analisados nas tabelas desejadas, quanto menor for o número de registros menor será este custo.

- Utilização paralela: quantas consultas estão percorrendo a tabela no momento em que se deseja realizar a consulta, quanto maior for este número, maior será o custo para se percorrer a tabela desejada. Suponha que quase toda consulta direcione para a FHG, logo a FHG ficará sobrecarregada, tendo um desempenho de busca inferior as outras tabelas.

- Custo da junção este custo corresponde a necessidade de se unir buscas que foram realizadas em tabelas separadas, ou seja, determinação do periodo que atende a consulta desejada. Suponha que desejamos saber quais empresas pertenceram ao regime ME e CNAE 53.400-01 no ano de 1999. Dada a agregação A que possui dados históricos referentes a regime verificamos que a empresa $W$ pertenceu ao regime ME deste 01/1999 até 09/1999. Dada a agregação $B$ verificamos que W possui CNAE 53.400-01 desde 03/1999. Logo devemos realizar a junção destes dois resultados onde obteremos como resposta que a empresa $W$ atendeu a consulta desejada no periodo de 03/1999 a 09/1999. O algoritmo para obtenção destes resultados será apresentado ainda neste capitulo.

Determinar a consulta de menor custo total e realizá-la, obtendo assim o Resultado FH.

\subsection{Consultas FA}

As Consultas FA funcionam da mesma maneira que num DW tradicional, através da utilização de indices bitmap.

Neste ponto faremos uma importante observação relacionada as agregações de especialização e composição. O Data Warehouse não possui uma padronização para tratamentos de consultas destes dois tipos de agregação. Já estudamos quais são as possíveis soluções para cada um destes casos no capítulo 3. O monịtor deve ter a capacidade para saber quais junções serão necessárias ou quais valores para o atribito nível ele deverá considerar para determinada pesquisa.

O mais importante para que as consultas FA sejam realizadas com sucesso é a adoção do melhor modelo para atender estas consultas. Parâmetros como Obrigatoriedade (Descendente e/ou 
Ascendente), Quantidade (Restrita ou Livre) e Compartilhamento são parâmetros que nos ajudarão a adotar a melhor solução.

Feita a consulta FA iremos obter um subconjunto que denominaremos aqui de Resultado FA.

\subsection{Resultado FH x Resultado FA}

Para a obtenção do resultado final do DWT precisamos realizar a interseção entre o Resultado FH e o Resultado FA.

Desta maneira devemos fazer a junção do Resultado FH com o Resultado FA. O processo para obtenção do resultado desejado através deste processo de junção é complexo resultando com isso num custo elevado. Devido ao alto custo este passo precisa ser cuidadosamente avaliado.

Para minimizar o problemá relacionado entre a junção do Fato Histórico e do Fato Analítico propomos a criação e manutenção dos Índices Histórico-Analítico.

\subsection{1 Índices Histórico-Analítico}

A consulta que envolve a junção entre tabelas contendo grande quantidade de tuplas tradicionalmente tende a possuir baixo desempenho. Como o número de tuplas envolvidas tanto na Fato Histórico quanto na Fato Analítico pode ser grande, então pode-se ter um baixo desempenho.

Índices Histórico-Analítico foram criados justamente para minimizar o custo deste tipo de junção. Estes índices possuem um maior custo de mamutenção / criação se comparados aos índices tradicionais, porém possuem custo inferior no momento da realização da consulta.

Tais índices são possiveis de serem criados devido a estrutura estática de armazenamento de fatos do Data Warehouse. Este tipo de índice é inviável no ambiente transacional devido ao alto número de alterações que taís ambientes sofrem. 
A criação dos Índices Hístórico-Analítico é dividida em duas etapas principais: criação e manutenção de listas em Fato Histórico e criação do vetor bitmap HistoAnalítico.

1) Criação e manutenção de listas em Fato Histórico

Para cada elemento pertencente ao Fato Histórico cria-se uma lista contendo os Fatos Analíticos associados.

Cada inserção em Fato Analítico corresponde também a inserção de sua posição relativa ao Data Warehouse na lista do Fato Histórico correspondente. Esta lista conterá a posição relativa ao Data Warehouse, do mesmo modo que os índices bitmap. Como exemplo suponha que temos o seguinte índice bitmap para uma determinada característica:

00010111100

Se uma nova tupla é inserida em FA então temos que esta tupla assumirá a última posição dos índices bitmap, ou seja, a posição relativa ao DW será igual a 12. Então numa determinada lista do $\mathrm{FH}$ associado será inserido o valor 12 referente a esta tupla.

Desta maneira temos que toda tupla em Fato Analítico será mapeada ao seu correspondente na Fato Histórico.

2) Construção do vetor bitmap HistoAnalitico

O vetor bitmap HistoAnalitico possui o mesmo tamanho e compreende as mesmas tuplas que os indices bitmap referentes ao Fato Analítico.

Os passos para a criação do vetor são mostrados a seguir:

2.1) Cria-se o vetor com todos valores iguais a zero;

2.2) Cria-se um cursor contendo todos os Fatos Históricos pré-selecionados (de acordo com a consulta dada); 
2.3) Seleciona-se a lista do Fato Histórico selecionado. Para cada valor da lista atribui-se o valor 1 a posição correspondente no vetor bitmap HistoAnalítico. Como o armazenamento na lista é fisico temos que se o elemento 6 pertence a lista então o sexto bit do vetor terá valor 1 .

2.4) O passo 2.3 é executado até o término das listas pré-selecionadas.

Em seguida realiza-se a junção entre o Fato Histórico e o Fato Analítico com a utilização do vetor bitmap HistoAnalítico. Note que a operação de junção, após a criação do vetor, apresenta custo insignificante dada que esta operação é realizada pelo Data Warehouse de maneira bem eficiente. Se em Fatos Analíticos temos $\mathrm{X}$ pré-condições o Data Warehouse fará $\mathrm{X}+1$ cruzamentos de índices bitmap ao invés de $\mathrm{X}$ cruzamentos.

O custo da utilização destes índices é identificado na criação / manutenção das listas associadas. O processo de carga da Fato Analítico terá um custo adicional onde será necessário relacionar cada Fato Analítico ao correspondente na Fato Histórico. Além disso, temos que considerar também o custo para a criacão do vetor bitmap HistoAnalítico. Porém, se avaliarmos este custo comparado ao custo de se realizar a junção pela maneira tradicional temos que o desempenho dos Índices Histórico-Analítico tende a ser superior.

Uma outra opção seria a realização da junção para posteriormente realizarmos a seleção na FA baseada nas dimensões exclusivas e na dimensão temporal, porém esta abordagem é pouco aconselhada já que esta seleção é realizada com bom desempenho devido a presença de índices bitmap, além disso estariambs sobrecarregando ainda mais a junção, ponto chave de desempenho do sistema. 


\subsection{Aspectos para a Geração das consultas}

Dada uma consulta genérica, por exemplo:

Selecione os campos $<\mathrm{A}>$ onde $<\mathrm{C}>$ agrupados por $<\mathrm{D}>$ sendo que $<\mathrm{E}>$ ordenados por $<\mathrm{F}>$.

Temos que os parâmetros $\mathrm{em}<\mathrm{A}>$ correspondem a dados que podem estar tanto na tabela de fatos quanto nas tabelas de'dimensão. Geralmente os dados que se desejam selecionar na tabela de fatos encontram-se agregados a alguma função.

$\mathrm{O}$ elemento $<\mathrm{C}>$ refere-se as condições que se deseja impor sobre cada linha da consulta. $\mathrm{O}$ elemento $<\mathrm{D}>$ refere-se como os dados serão agrupados e o elemento $<\mathrm{E}>$ refere-se as condiçб̄es que se deseja impor sobre o agrupamento. É importante notar a diferença entre $<\mathrm{C}>$ e $<\mathrm{E}>$. Enquanto as condições em $<\mathrm{C}>$ referem-se a cada dado particular, as condições em $<\mathrm{E}>$ referemse ao grupo que foi obtid $\phi$ a partir do agrupamento de cada dado particular. $O$ elemento $<F>$ refere-se a maneira como os dados serão ordenados para a uma melhor visualização.

\section{Exemplo:}

Um dado de grande importância para a Secretaria da Fazenda refere-se ao Regime de Apuração pois é ele que determina quanto e como uma empresa deve pagar de ICMS. Uma consulta que se deseja fazer é o valor arrecadado de IMCS para cada tipo de regime de apuração. Temos então:

Selecione regime de apuração, soma do ICMS pago onde ano for 2000 agrupados por regime de apuração sendo que a soma do ICMS pago for maior que $\mathrm{R} \$ 0,00$ ordenados pelo valor de ICMS.

Esta consulta retornará umá tabela onde temos cada regime e o valor pago de ICMS durante todo o ano de 2000. A condição maior que R $\$ 0,00$ foi utilizada simplesmente para não mostrar dados de regimes de apuração que já não existem para o ano de 2000. O resultado apresentará os dados ordenados pelo valor pago de acordo com a instrução que foi passada pela consulta. 
O resultado obtido da execução da consulta seria:

\begin{tabular}{|c|c|}
\hline 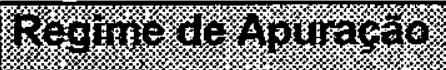 & Marogomo \\
\hline $\mathrm{ME}$ & $400.000,00$ \\
\hline EPPA & $500.000,00$ \\
\hline EPPB & $500.000,00$ \\
\hline RES & $1.000 .000,00$ \\
\hline $\mathrm{RPA}$ & $9.000 .000,00$ \\
\hline
\end{tabular}

Tabela 4.1 - Consulta típica num Data Warehouse

Nesta consulta podemos identificar cada um dos elementos:

$<\mathrm{A}>$ - regime de apuração e valor do ICMS pago (os dados que fazem parte da tabela).

$<\mathrm{C}>$ - ano igual a 2000.

$<\mathrm{D}>$ - regime de apuração.

$<\mathrm{E}>$ - valor de ICMS pago maior que $\mathrm{R} \$ 0,00$.

$<$ F $>$ - valor pago de ICMS

Além disso, existe um elemento subtendido nesta consulta. O elemento $<\mathrm{B}>$. Este elemento é utilizado para indicar onde as informações serão obtidas. No exemplo dado os dados podem estar dispostos de diferentes maneiras, o elemento $<\mathrm{B}>$ que nos diz onde cada informação deve ser obtida. O elemento $<\mathrm{B}>$ é representado pelas tabelas que são necessárias para que a consulta possa ser realizada.

\subsubsection{Alternativas para representação dos dados em DW}

A seguir uma análise das quatro propostas para a estrutura do DW. Será feita uma análise baseada nas tabelas de fato e de dimensão padrão, ou seja, não será levada em consideração a existência ou não de tabelas de visão, com dados ou tabelas agregados.

O objetivo aqui é demonstrar que é possivel criar uma ferramenta de consulta que consiga gerar o SQL equivalente para cada uma das abordagens existentes e/ou propostas. Já foi visto no inicio do trabalho (capitulo 2) quais são os recursos existentes (tabelas de visão, agregações etc) para a melhoria do desempenho das consultas no DW. Além disso, vimos também quais recursos que 
poderiam ser utilizados para a melhoria de desempenho no DWT, como as FHPSd, FHPI (capítulo 3).

Os aspectos relativos ao DWT merecem uma análise para se determinar em qual agregação deveremos realizar a busca, para o DW. Tais pontos já foram apontados no trabalho (capítulo 3). Com esta análise podermos determinar qual é a agregação que será utilizada.

\subsubsection{Proposta 1 e 2 do Dr. Kimball}

Primeiramente analisaremos a proposta 1 e 2 de Kimball, ambas produzirão o mesmo SQL pois ambas tem a mesma estrutura quanto ao DW. A consulta relativa a ambas propostas consiste na junção da tabela de fatos com as tabelas de dimensão, junção essa que pode ser facilitada com a utilização dos índices de junção. O SQL equivalente a uma consulta genérica é:

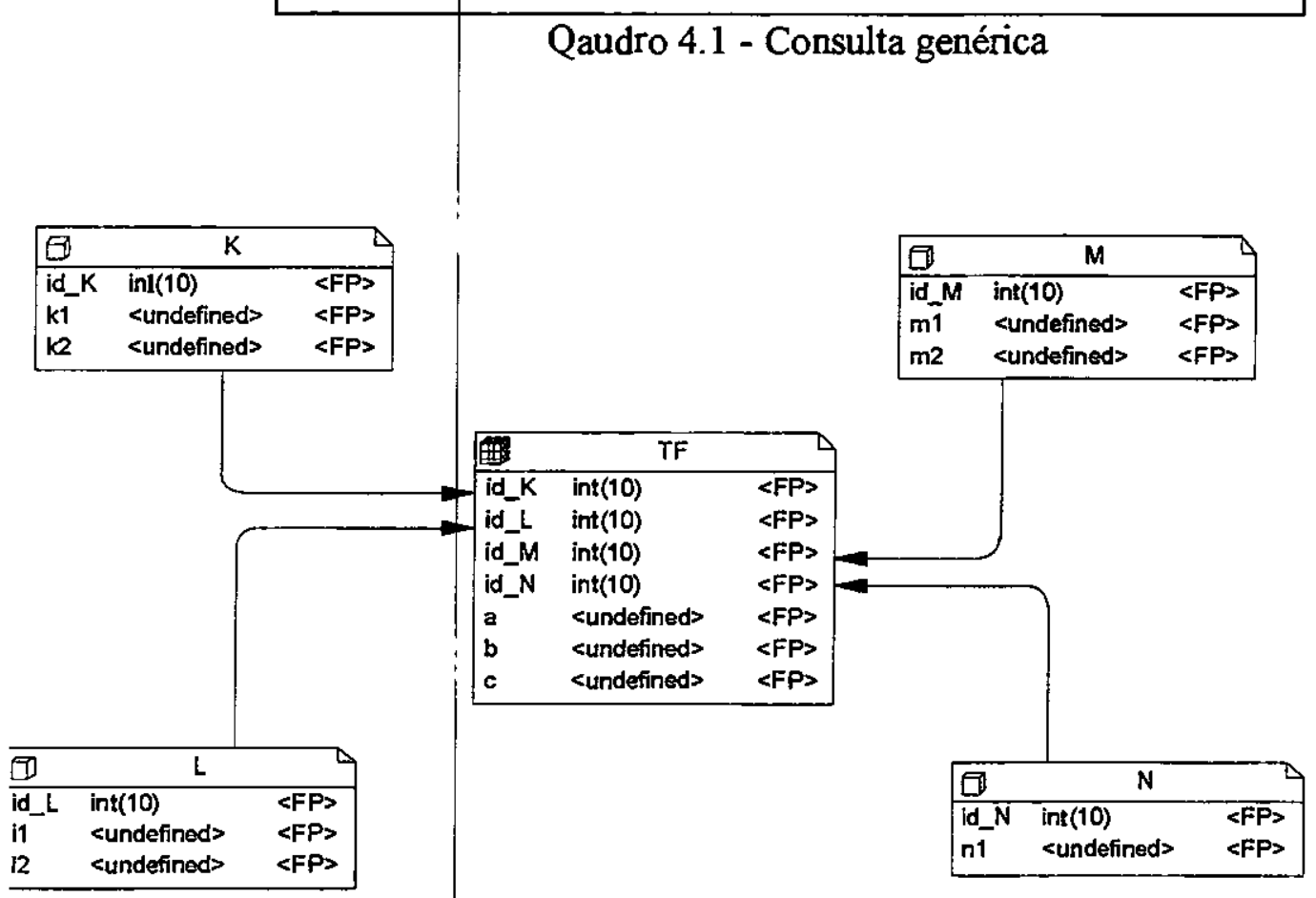

Select $f(T F . a), f(T F . b), K$.valor from $T F, K, L, M$

where TF.id_K=K.id_K and TF.id_L $=L . i d \_L$

and L.id_jalor in $(x, y, z)$ and TF.id_M $M=$ M.id_M

and $M$ between $(w, k)$ group by K.id_K, K.valor

having $f($ TF.a) $>$ e order by $f(T F . a)$

Qaudro 4.1 - Consulta genérica

Figura 4.4 - Modelo Data Warehouse exemplo 
$\mathrm{Na}$ consulta padrão o elemento TF corresponde a Tabela de Fatos enquanto que os elementos $\mathrm{K}$, $\mathrm{L}$ e $\mathrm{M}$ correspondem as tabelas de dimensão. Os id_X (onde $\mathrm{X}$ representa $\mathrm{K}, \mathrm{L}$ e $\mathrm{M}$ ) referem-se ao atributo de ligação entre a TF e K, L e M, note que este atributo de ligação é chave para a proposta analisada.

Esta consulta é padrão dentro do DW onde:

- $f(T F . a), f(T F . b), A$. valor $\mid$ corresponde ao elemento $<\mathrm{A}>$ da consulta genérica;

-TF.id_K=K.id_K and TF.id_L $L=L . i d \_L$ and L.id_valor in $(x, y, z)$ and TF.id_M $=$ M.id_M and $M$ between $(w, k)$ corresponde ao elemento $<\mathrm{C}>$ da consulta genérica

- K.id_K, K.valor corresponde ao elemento $<\mathrm{D}>$ da consulta genérica.

- $T F, K, L, M$ representando o elemento $<\mathrm{B}>$, que é a maneira pela qual as informações são obtidas. As tabelas envolvidas na consulta. Observe que a tabela $\mathrm{N}$ não foi utilizada.

- $f(T F . a)>e$ representando o elemento $<\mathrm{E}>$, uma condição relativa ao agrupamento.

- $f(T F . a)$ representando o elemento $<\mathrm{F}>$, referente a ordenação desejada.

Um atributo muito comum ao DW é aquele que se refere ao período de tempo e que se assemelha ao atributo $\mathrm{C}$ da consulta padrão. Dada a consulta genérica os elementos $\mathrm{em}\langle\mathrm{A}>$ são traduzidos para 1 , os elementos em $<C>$ são traduzidos para 2 , não se esquecendo de adicionar os TF_id_X $=X$.id_X, para que se realize a junção de maneira correta e os elementos de $\langle\mathrm{D}>$ são traduzidos para 3. Note o aparecimento do elemento K.id_K em $\langle\mathrm{D}\rangle$, isso ocorre pois podem existir dois atributos com mesmo valor (cidades com mesmo nome, em estados diferentes) porém o id_K nos garante a unicidade do valor (atributo chave). Os elementos em $\langle\mathrm{B}>$ abrangem sempre a TF e todas as tabelas de dimensão envolvidas, que podem ser obtidas a partir dos elementos de $\langle A\rangle$ e de $\langle\mathrm{C}\rangle$, ou seja, dada a seleção e as condições identificar em quais tabelas tais atributos estão localizados. $O$ elemento $\langle E\rangle$ refere-se somente a uma seleção sobre os agrupamentos surgidos. É utilizado para que somente os agrupamentos de maior expressão apareceram para o usuário 
Esta abordagem é tradicional e largamente utilizada pelas diferentes ferramentas disponíveis hoje no mercado.

\subsubsection{Unicidade}

Suponha uma consulta onde se deseja conhecer o valor do fato A para o ano de 1999 e mais uma série de condições, agrupadas pelo valor do atributo $\mathrm{K}$. Suponha agora que um determinado dado possuía o valor Q para $\mathrm{K}$ até $06 / 1999$ e valor $\mathrm{R}$ a partir de $06 / 1999$. Um exemplo do atributo $\mathrm{K}$ pode se tratar, por exemplo, do nome de determinada cidade ou produto. A cidade de Amparo trocou seu nome para Arcadas, a pasta dental que antes se chamava Kolynos trocou seu nome para Sorriso. Se a consulta deseja avaliar as vendas de determinado produto agrupadas por cidade é natural que Amparo e Arcadas sejam tratadas como sendo uma mesma cidade, pois as vendas do produto não devem ser alteradas pela mudança do nome do município. Neste caso temos unicidade verdadeira, as cidades serão tratadas como sendo a mesma. $O$ mesmo não deve ocorrer para a alteração no nome do produto pasta de dente. Kolynos era campeã de vendas, Sorriso, apesar de possuir a mesma composição química de sua antecessora, não deve ser tratada como sendo o mesmo produto. A alteração do nome do produto influiu diretamente na venda do produto (estamos considerando que os fatos estão associados a venda do produto). Não se pode tratar o produto Kolynos e Sorriso como o mesmo pois comercialmente falando eles não o são. $O$ fabricante sabia que com a alteração do nome do produto ele perderia parte de seus clientes, que a venda iria cair, que toda um novo marketing do novo produto teria que ser criado. Neste caso, onde os produtos são tratados diferentemente, temos unicidade falsa.

Unicidade: verdadeira (setado em 1) quando o dado é tratado como sendo único caso contrário (setado em 0) este dado recebe tratamento como sendo não único (unicidade falsa). $O$ atributo Unicidade sempre é verdadeira para a proposta 1 de Kimball enquanto que para a proposta 2 sempre será falsa.

\subsubsection{Proposta 3 (Kimball)}

Nesta proposta temos uma pequena diferença em relação a abordagem anterior, o aparecimento e tratamento de dados histónicos nas tabelas de dimensão. A abordagem anterior se mostra 
relativamente ineficaz, pelo fato de seus dados serem estáticos, e ainda não terem uma estrutura de apoio direto a dados históricos.

Do ponto de vista do SQL a ser construido esta abordagem se diferencia da anterior referente ao elemento $<\mathrm{C}>$ e uma pequena modificação em $<\mathrm{D}>$ pode ser necessária.

Para unicidade falsa o tratamento é o mesmo adotado que para as abordagens 1 e 2 . Em $<\mathrm{A}>$ consideraremos sempre o valor atual para a seleção (id_dtfinal=NULL).

Caso o atributo que tenha dados históricos ( $K$, no exemplo) apareça em $<A>$ é desejável que ambos os valores que ele assumiu apareçam na consulta, trazendo inclusive o periodo de validade de cada informação, em se considerando unicidade verdadeira.

Outra importante observação a ser feita relaciona-se com o elemento $<\mathrm{C}>$. Dada uma condição sobre um atributo que já tenha sofrido alterações deve-se avaliar a partir de quando a informação presente em $<\mathrm{C}>$ é válida.

Exemplo: selecione soma (vendas) para o produto Sorriso no ano de 1999. Os dados a serem recuperados da Tabela de Fatos não devem compreender o período de 01/01//1999 a 31/05/1999, pois neste período o nome do produto era Kolynos e não Sorriso.

Para que todo este tratamento de data possa ser feito é necessário que os parâmetros relativos a data sejam tratados. Desta maneira temos o seguinte SQL:

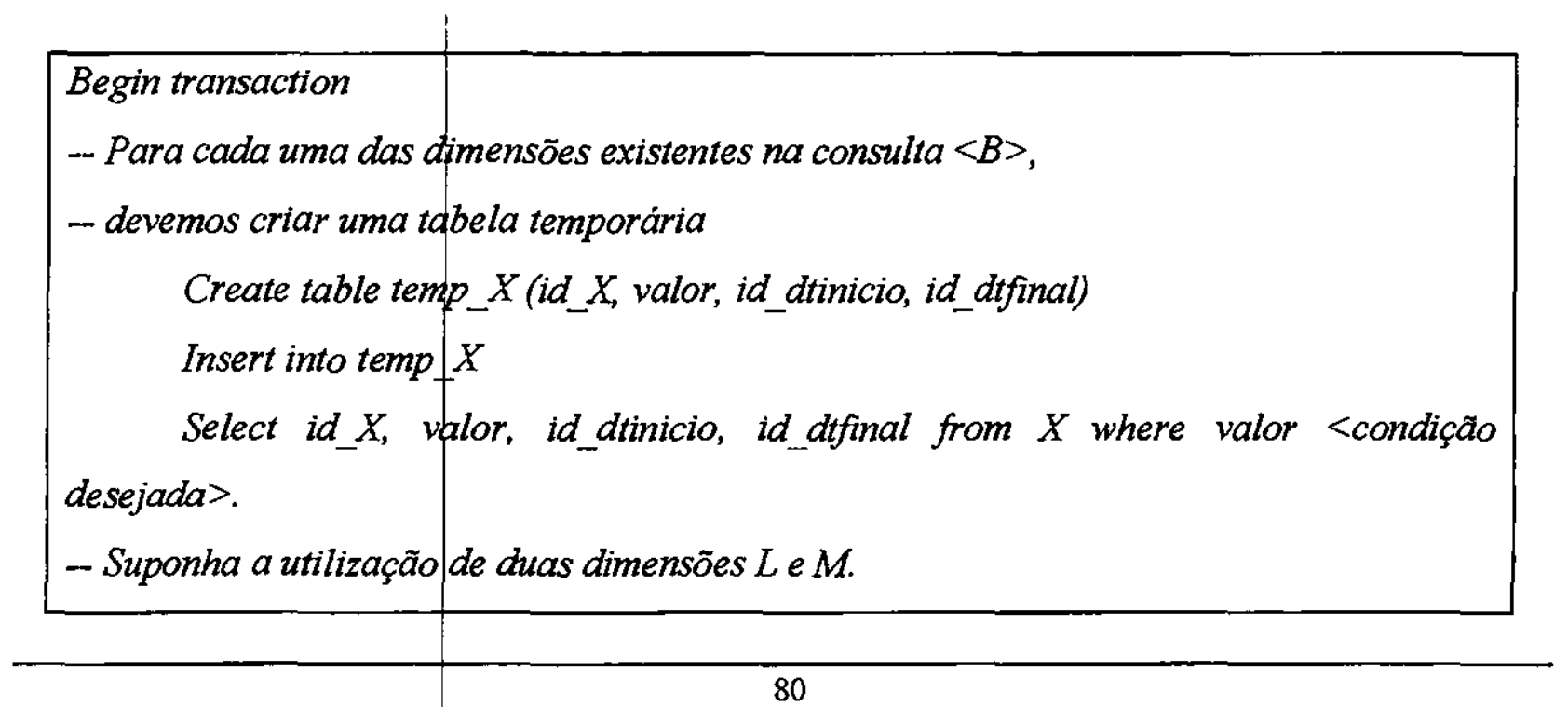



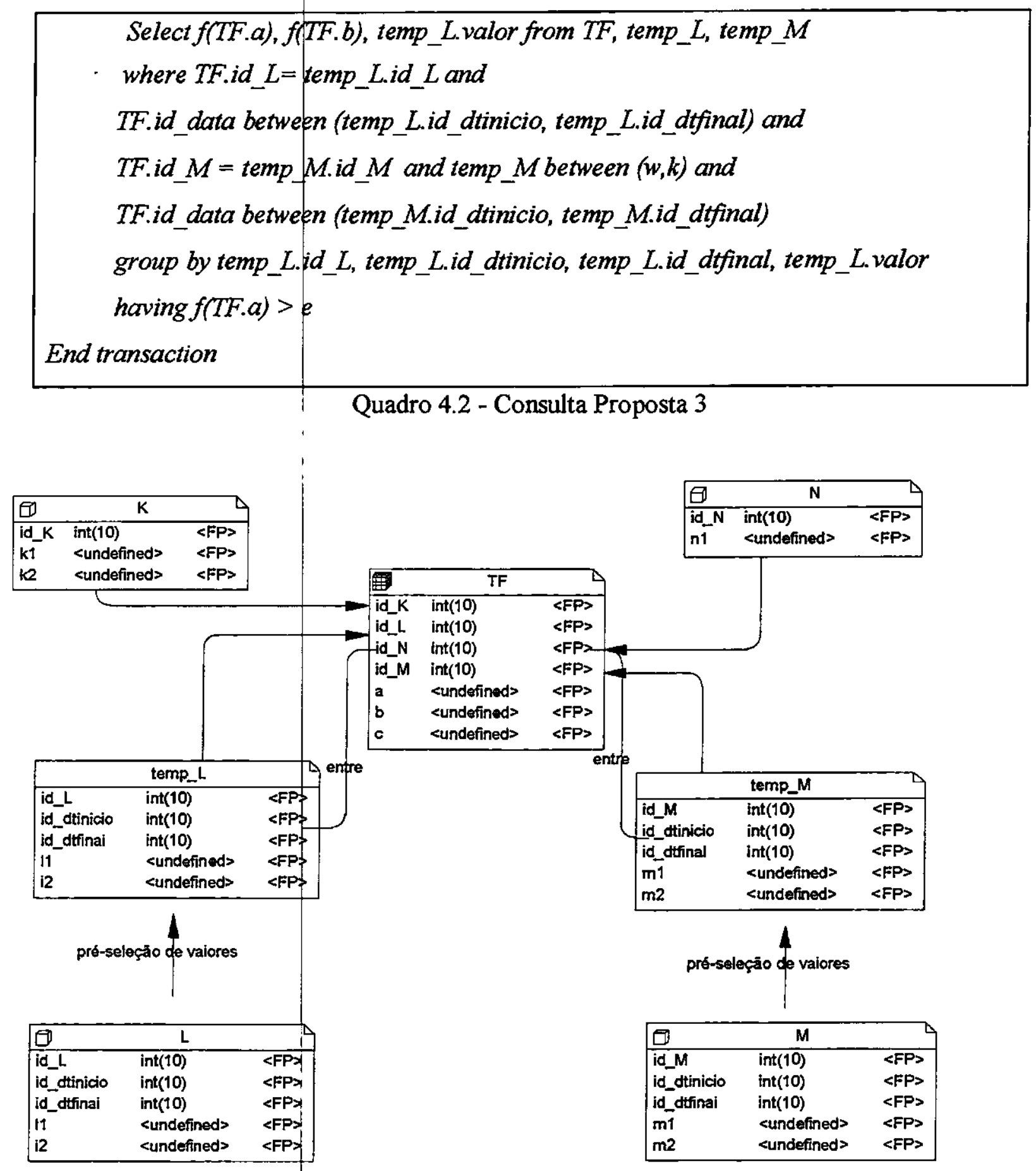

Figura 4.5 Criação de tabelas temporárias para tratamento histórico

Onde id_N na figura 4.2 corresponde a dimensão temporal.

Vemos agora que o atributo id_X não é mais chave mas sim o conjunto id_X, id_dtinicio e id_dtfinal. Logo precisamos destes parâmetros para a realização das operações desejadas. No exemplo acima criamos tabelas temporárias para responder as consultas desejadas e para um 
melhor entendimento do procedimento, note porém que a criação das mesmas não são necessárias, sendo que a jun ção poderia ser realizada diretamente.

Para a resolução do problema relativo a datas houve o surgimento da condição extra TF.id_ data between (temp_X.id_dtinicio, temp_X.id_dtfinal), desta maneira garantimos a unicidade da informação, além disso precisamos garantir a unicidade também no agrupamento, onde o mesmo é feito pelo atributo chave, consistindo agora do id_X e dos campos relativos a data.

\subsubsection{Proposta 4-Data Warehouse Temporal}

Incorpora as alterações da proposta 3 para o tratamento de dados históricos, porém aplicadas agora, num Data Warehouse Temporal. Num DWT temos o tratamento de histórico tanto nas dimensões do FH como na própria FH. Vale lembrar que num DWT uma junção adicional é necessária, entre a TF e a FHI.

O primeiro passo desta abo-dagem é semelhante a adotada para a proposta 3 , sendo que a saída do resultado é redirecionada para uma nova tabela temporária, a temp_FH. 


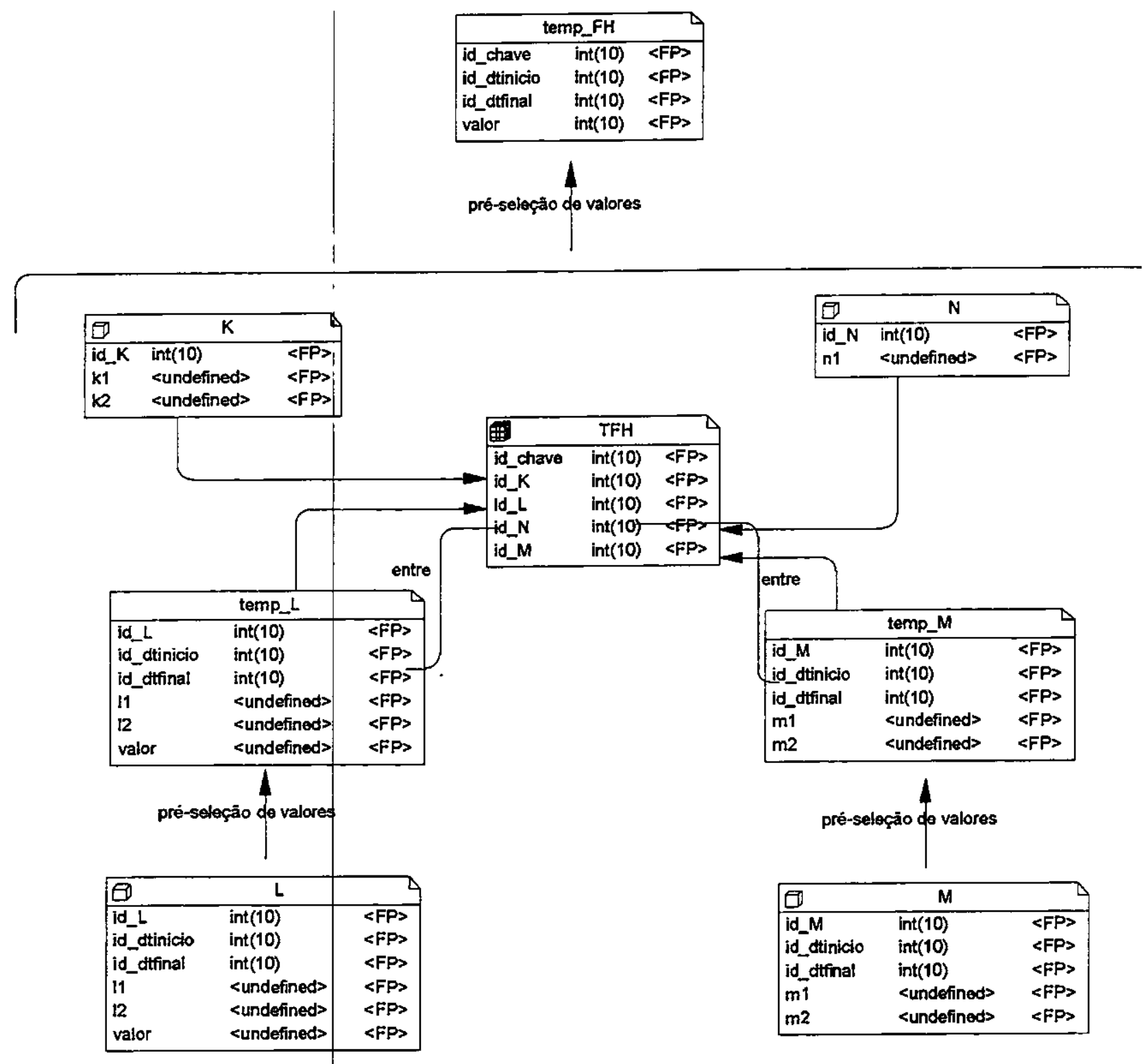

Figura 4.6 - Tratamento dado ao Data Warehouse Histórico

O segundo passo é idêntico ao primeiro passo da abordagem 3, onde a temp_FH atuará agora como uma das dimensões da solução.

A solução para o problema apontado pode ser resumida como sendo a dupla aplicação da proposta 3 , com a criação de uma tabela temporária.

A maior dificuldade desta abordagem consiste na obtenção do período de validade da informação já que tanto as tabelas de dimensão quanto a TFH possuem periodos de validade da informação. Neste caso devemos fazer a junção entre a TFH e as FH para obtenção do período de validade de 
cada conjunto de informações. Podemos ter as seguintes configurações para o período considerado. Suponha a seguinte pesquisa para as considerações a seguir.

Deseja-se conhecer o valor pago de GIA relativo ao ano de 1999 agrupados pelo regime de apuração, a seguir as ocorrências que podemos obter:

1) Todo o periodo tanto para TFH quanto para FH. Ou seja, durante todo o ano de 1999 não houve alteraçð̃es tanto para o a dimensão considerada quanto para a TFH considerada. Ou seja, a dimensão regime de apuração não sofreu nenhuma alteração e nem o contribuinte analisado sofreu alteraçăo de Regime de apuração no ano de 1999.

2) Em somente uma consideração. Houve alterações somente na TFH ou então na dimensão FH considerada. Desta maneira teríamos tantas linhas quanto forem o número de alterações ocorridas no período + 1. Ex: suponha que o contribuinte tenha trocado de regime três vezes, gerando os períodos de 01/99 a 03/99, 04/99 a 07/99 e 08/99 a 10/99 e de 11/99 a 12/99. Neste caso teríamos quatro entradas provenientes da junção, relativos ao período de 01/99 a 03/99, 04/99 a 07/99 e 08/99 a 10/99 e de 11/99 a 12/99. Neste caso o número de entradas relativos a junção é o mesmo número de entradas na TFH( ou FH), abrangendo inclusive o mesmo período.

3) Houve alterações em ambas as tabelas, na TFH e na FH. Neste caso devemos realizar uma análise da intersecção destes periodos:

4.6 Iguais. Ou seja, quando da alteração do dado na $T F H$ houve também a respectiva alteração na FH e vịce-versa. Neste caso o periodo considerado não é alterado e o número de linhas provenientes da junção se mantém iguais a qualquer uma das tabelas.

4.7 Intercaladas. Ocorreram alterações em momentos diferentes de período. Ex: a FH resultou em dois períodos relativos a 01/99 a 07/99 (dado A) e 08/99 a 12/99 (dado B) enquanto que a TFH resultou em dois períodos relativos a 01/99 a 9/99 (dado C) e 10/99 a 12/99 (dado D). O resultado desta junção deve ser:

- 01/99 a 07/99 - dado A, C;

- 08/99 a 09/99 - dado B, C;

- $10 / 99$ a $12 / 99$ - dado B, D. 
Uma importante observaçẩo a ser feita considerando a consulta exemplo é a de que o ano considerado (1999) é uma referência, ou seja, também deve ser considerado como parâmetro da consulta, como periodo a ser analisado. Desta maneira temos os períodos relativos a dados históricos da dimensão, a dados da TFH e a dados referentes ao período que se deseja fazer a consulta.

Considere a seguinte linha de alterações:

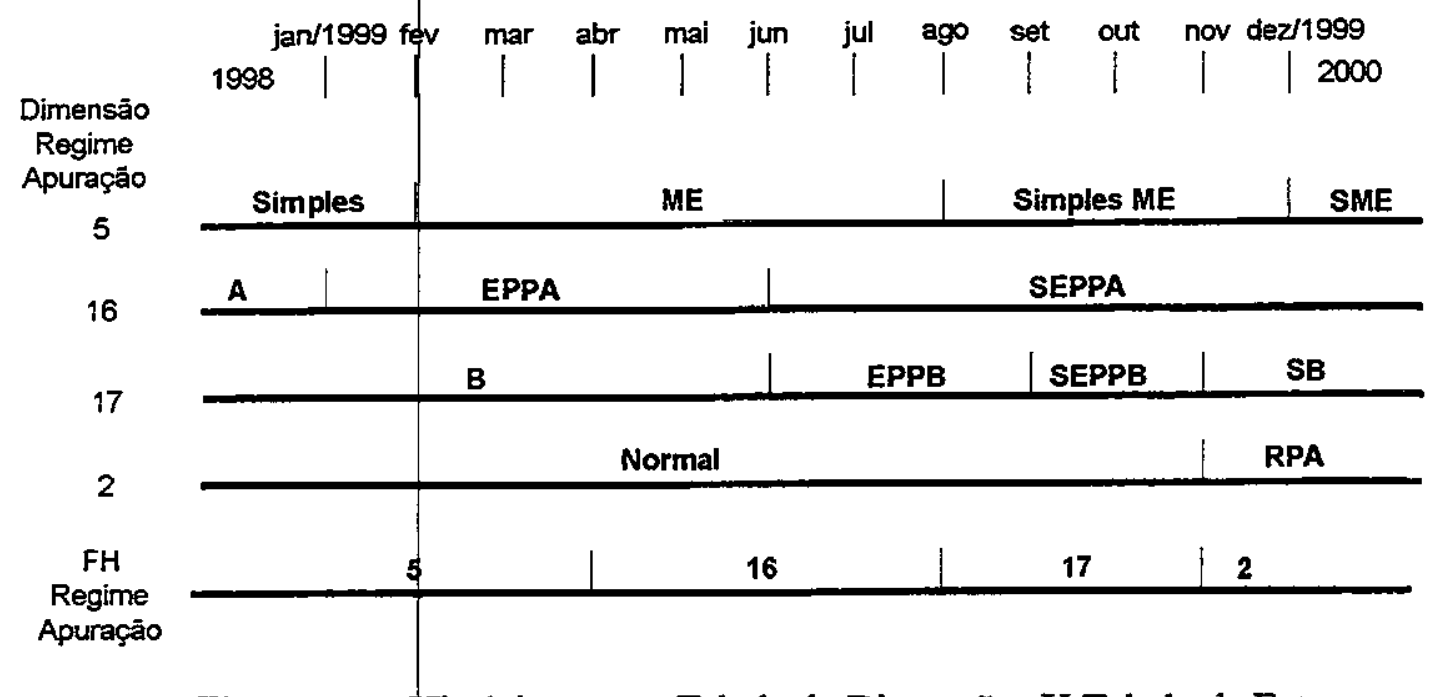

Figura 4.7 - Histórico entre Tabela de Dimensões X Tabela de Fatos

O SQL equivalente se tornaria:

\section{Begin transaction}

Para cada uma das dimensões existentes na consulta $<\mathrm{B}>$ (tanto em FH quanto em FA) devemos criar uma tabela temporária.

Create table temp_X (id_X, valor, id_dtinicio, id_dtfinal)

Insert into temp_X

Select id_X,valor, id_dtinicio, id_dtfinal from $X$ where valor <condição desejada> and id_dtinicio < par_final e id_dtfinal > par_inicial.

\section{Quadro 4.3 - Consulta DWT - passo I}

Outra alteração que pode ser feita neste passo é relativo ao período. No exemplo considerado desejamos avaliar o ano de 1999. Então para a dimensão tempo podemos fazer a seguinte adaptação. Para toda data na tabela temporária onde a data de início seja inferior ao ano 
de 1999, substituiremos |por 01/1999 e para toda data final superior ao ano de 1999 substituiremos por 12/1999. Desta maneira conseguimos fazer com que o intervalo de tempo considerado seja balizado já neste passo. A seleção and id_dtinicio < par_final e id_dtfinal > par_inicial nos garante que somente dados relativos ao periodo desejado serão selecionados, onde par_inicial refere-se a data inicial e par_final a data final considerada.

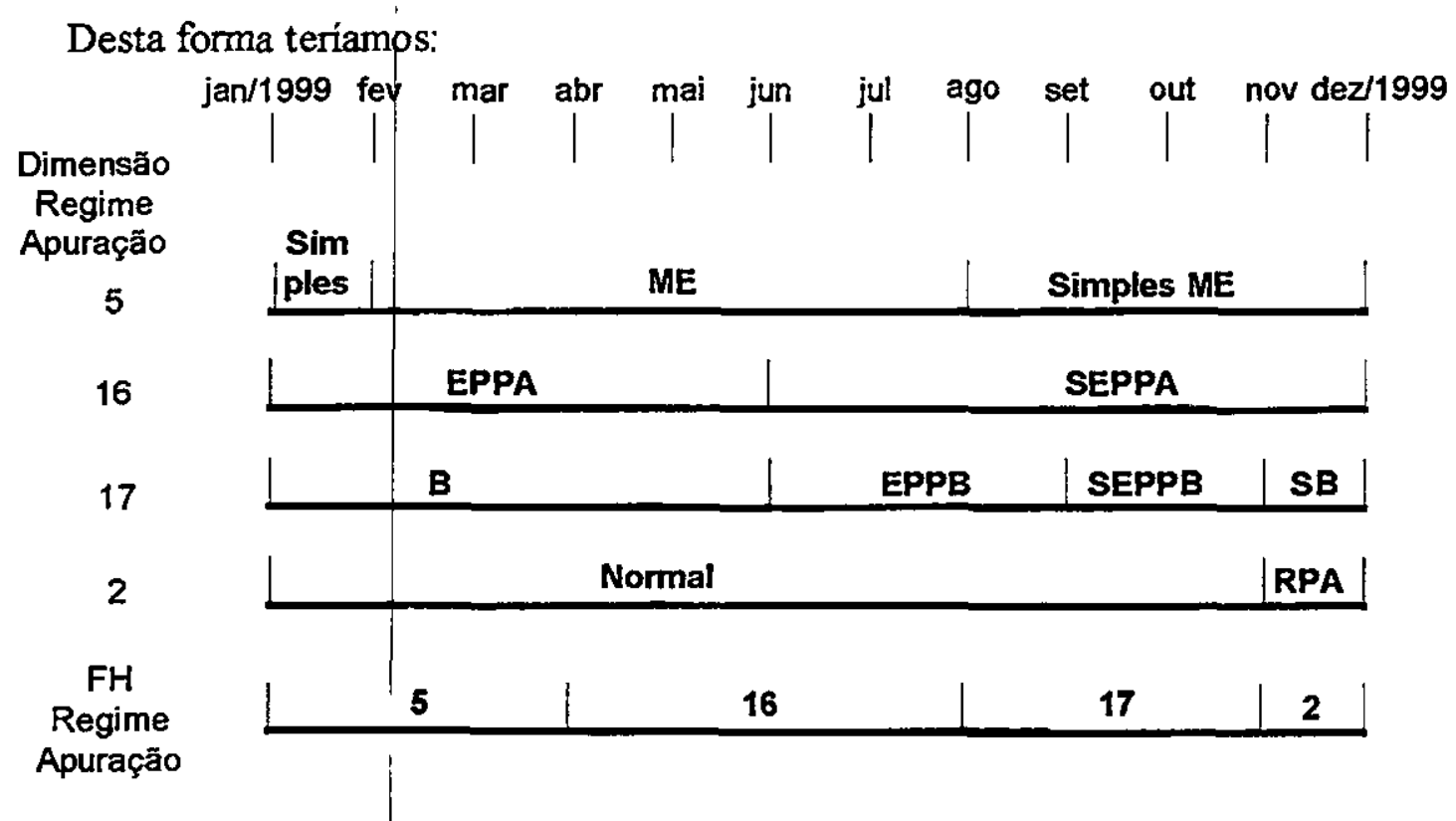

Figura 4.8 - Tratamento de Períodos de Data

Iremos construir outra tabela temporária relativa a $\mathrm{TFH}$, somente a título de uma explicação mais clara dos conceitos, sendo que a mesma seleção poderia ser obtida a partir da junção. 


Create table temp_TFH
(id_chave, id_dtinicio, id_dtfinal, id_dimensoesFA)
insert into temp_TFH
select id_chave, id_dtinicio, id_dtfinal, id_dimensoesFA
from TFH where and id_dtinicio < par_final e id_dtfinal > par_inicial
Iremos considerar somente em TFH os dados referentes ao periodo desejado.
Adaptar datas inicial $\mid$ e final para que assumam valores das datas inicial e final do periodo
considerado (os balizadores femporais).
update temp_TFH set id_dtinicio=id_dtinicial where id_dtinicio < id_dtinicial
update temp_TFH set id_dtfinal $=i d$ - dtfim where id_dtfinal $<i d$ idtfim

\section{Quadro 4.4 - Consulta DWT - passo 2}

Neste ponto temos as TFH e dFH prontas para a realização da junção, cada uma delas abrange somente o período considerado, restringidas pelos balizadores temporais. A junção a ser feita deve considerar os aspectos 1, 2 e 3 levantados anteriormente, de maneira tal a suportar estes três aspectos. A solução encontrada segue o seguinte raciocínio:

1) Primeiramente obtém-se a primeira tupla de cada tabela (TFH e dFH), ordenados pela sua data inicial.

2) Verifica-se qual das datas finais de ambas tuplas é menor. Considera-se como primeiro período àquele que vai desde a maior data inicial até a menor data final. Observe que teoricamente ambas as tuplas possuem mesma data inicial para a primeira tupla mas pode não ser verdade, suponha que o contribuinte começou a operar somente em 05/99, logo o período que vai desde 01/99 a 04/99 não deve ser considerado. 0 mesmo pode ocorter com a data final. Em seguida a tupla que possuir menor data final vai para a próxima tupla. Se ambas tuplas possuírem a mesma data final então ambas irão para a próxima tupla. Gravam-se os dados referentes a ambas tuplas, em se considerando o período obtido.

3) Repete-se o procedimento aplicado em 2, até o final das tuplas. 
O SQL referente a esta opção assumiria a seguinte forma:

Create table temp_FH

(id_chave, id_dtinicio, id_dtfinal, valorl,.., valorm)

select@existe=true

Create cursor cr_TFH for select * from temp_TFH order by id_dtinicio

Open $c r \_T F H$

Next $c r \_T F H$

while@existe=true

begin

If cr_TFH.exists

Select@tfh_chave=cr_TFH.id_chave, @tfh_dtinicio=cr_TFH.id_dtinicio,

@tth_dtfinal $=c r \_T F H . i d \_d t f i n a l, @ t t h \_d i m f a=c r$ TFH.id_dimensoesFA,

@tth_dimensao = @cr_TFH.id_dimensao

else

select@existe=false

if(@existe)

begin

Create cursor cr_FH for select * from temp_dFH where id_dtfim > @tfh_dtinicio and id_dimensao=@tfh_dimensao order by id_dtinicio

Open_cr_FH

end $N$ ext ${ }^{2} F H$

if $c r_{-}$FH.exists

Select@fh_chave=cr_FH.id_chave,@fh_dtinicio=cr_FH.id_dtinicio,

@fh_dtfinal=cr_FH.id_dtfinal, @fh_valor=@ocr_FH.valor

else

select@existe=false

if@existe='true

begin 


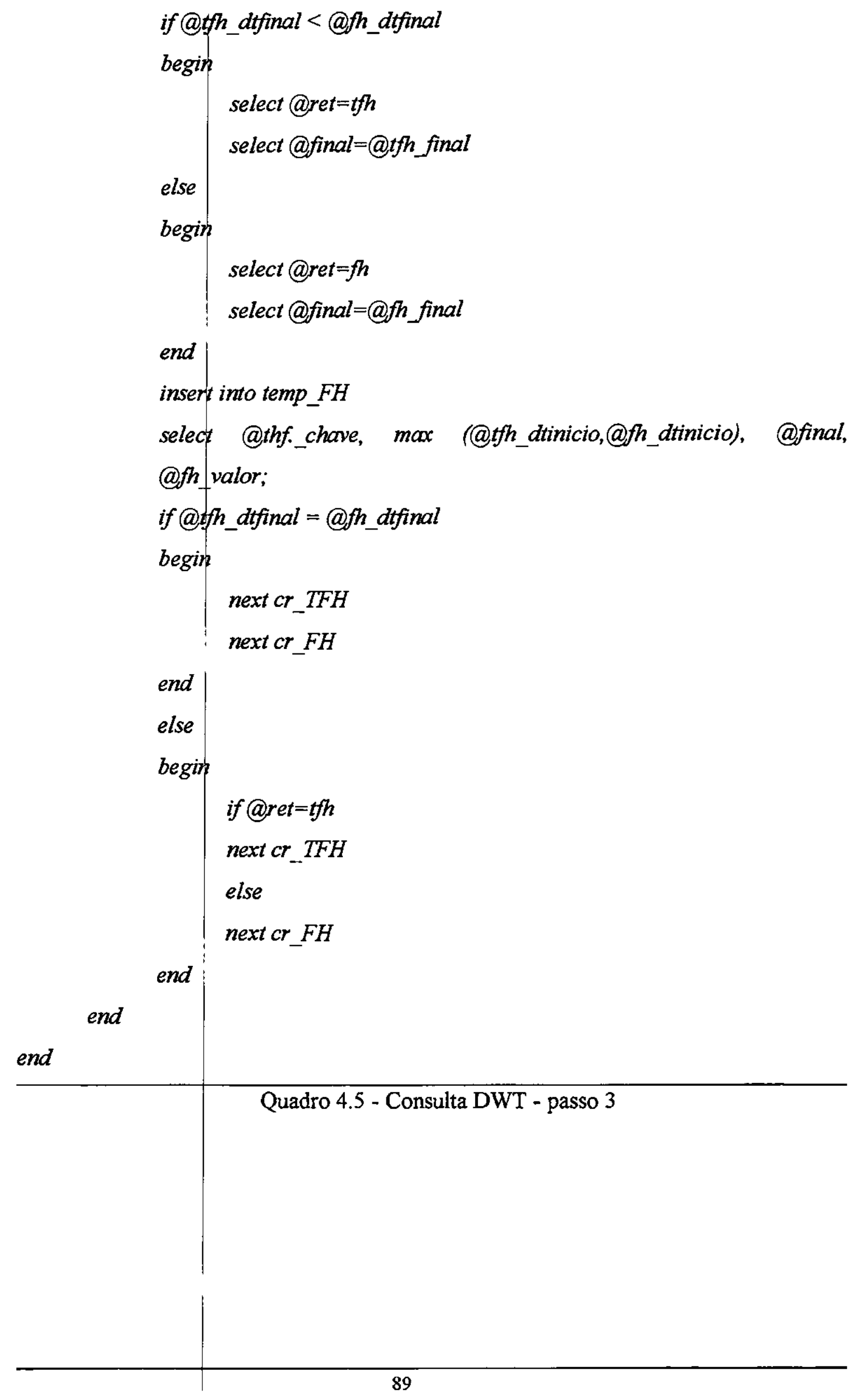


Onde ao final deste processo obteriamos:

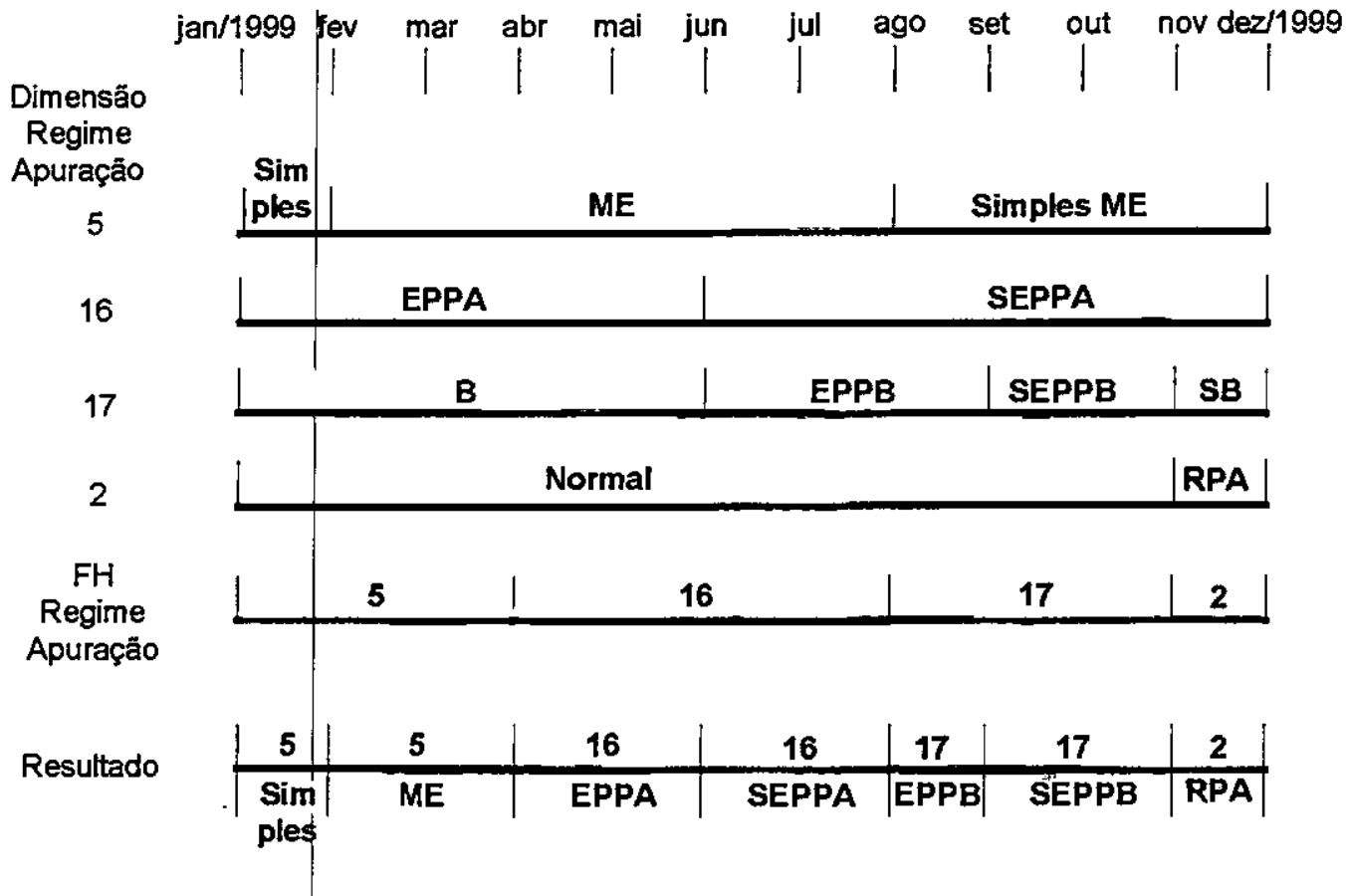

Figura 4.9 - Resultado Final

O passo final consiste da junção da tabela obtida com a TF, gerando assim o resultado desejado.

Select $f(T F . a), f(T F, b)$, temp_FH.valor from $T F$, temp_FH, temp_FAl

where TF.id_dado=temp_FH.id_dado and

TF.id_data between (temp_FH.id_dtinicio, temp_FH.id_dtfinal) and

$T F . i d \_F A l=$ temp」FAI.id_FAI and temp_FAl between $(w, k)$ and

TF.id_data between(temp_FAl.id_dtinicio, temp_FAl.id_dtfinal)

group by temp_FH.id_FH, temp_FH.id_dtinicio,

temp_FH.id_dtfinal. temp_FH.valor

having $f(T F . a)>e$

End transaction

Quadro 4.6 - Consulta DWT - passo final 
Uma importante observação a ser relembrada é aquela que diz respeito ao custo deste passo. Como a quantidade de tuplas envolvidas pode ser grande temos um alto custo que poderia inviabilizar o projeto.

No exemplo mostrado foi considerada uma dimensão, porém extensões para mais dimensões são facilmente obtidas. Uma das maneiras de se fazer isso seria considerar a temp_FH obtida como a nova temp_TFH. Desta maneira poderíamos fazer a junção com uma outra dimensão obtendo assim uma nova temp_FH e assim sucessivamente. A maneira mais eficiente de se fazer isso seria a alteração no código para atender a todas as dimensões desejadas, seguindo-se o mesmo algoritmo.

\subsection{Tratamento das Agregações de Composição / Especialização}

Como já foi visto no capítulo 3 as agregações de especialização / composição possuem diferentes soluções.

Cada uma das possíveis soluções gerará um SQL diferente. Porém é importante notar que todas as soluções envolvem somente a Tabela de Fatos, a estrutura das dimensões se mantém. Foi visto no tópico anterior como gerar SQLs para atender as consultas sobre o DWT, considerando também a possibilidade de alteração nas tabelas de dimensão. A extensão para modelos que possuam agregações de composição e/ou especialização pode ser obtida de maneira simplificada.

Para isso basta substituir a referência a Tabela de Fatos pelos SQLs mostrados a seguir. Note que nenhuma alteração será necessária em outros passos, já que a estrutura para as outras tabelas se mantêm.

\subsubsection{Replicação de Chaves}

Nesta abordagem criam-se tabelas filhos onde a mesma possuirá uma tupla que indique quem é seu pai além de todos os apontadores para as dimensões, tal qual como seu pai. No caso do DWT possuirá também a chave que o liga ao $\mathrm{FH}$.

Deve-se avaliar agora as necessidades da consulta. 
- Consultas independentes necessitam apenas dos dados presentes em algum nível da

- hierarquia. Neste caso assume-se que a $T F=T F x$, onde $x$ indica o nivel hierárquico desejado.

- Consultas dependentes, onde se deseja conhecer dados de mais de m nível hierárquico ou se deseja conhecer dados de um nível hierárquico baseado em algum fato do outro nível hierárquico. Neste caso teríamos que $\mathrm{TF}=\mathrm{TFa} X \mathrm{TFb}$ onde TFa.id_chave $=$ TFb.id_pai além das outras condições normalmente impostas ao DW.

\subsubsection{Sem replicação de chaves}

Nesta abordagem criam-se tabelas filhos onde a mesma possuirá uma tupla que indique quem é seu pai, porém não conterá apontadores para as dimensões presentes na Tabela de Fatos pai. Neste caso uma junção sempre será necessária quando houver referência a alguma dimensão não presente na TF filho. Caso todas as dimensões da seleção encontrem-se presentes na TF filho o processo segue o padrão, onde $\mathrm{TF}=\mathrm{TFx}$. No caso de houver a referência a alguma dimensão não presente na TF filho temos: $\mathrm{TF}=\mathrm{TFa} X \mathrm{TFb}$ onde $\mathrm{TFa}$.id_chave $=\mathrm{TFb}$.id_pai além das outras condições normalmente impostas ao DW.

\subsubsection{Atributo nível}

Adiciona-se o atributo nivel e o atributo id_pai as tuplas. $O$ atributo nível indica em que nível da hierarquia determinado dado se encontra. Se a consulta for independente do nível da hierarquia (como portas para carro ou não) então a consulta segue o padrão, caso a consulta seja dependente do nivel de hierarquia então a consulta toma-se:

$\mathrm{TF}=\mathrm{TF}$ as $\mathrm{TFa}, \mathrm{TF}$ as $\mathrm{TFb}$ onde $\mathrm{TFa} . \mathrm{id} \_$chave $=\mathrm{TFb} . \mathrm{id} \_$pai e TFa.nivel $=1$ e TFb.nivel $=2$, além das outras condições normalmente impostas ao DW.

Desta maneira conseguimos montar uma ferramenta capaz de gerar o SQL independentemente da arquitetura assumida pelo $\mathrm{DW}$, independentemente de haver ou não agregações de especialização e/ou composição e a maneita pela qual foram implementadas. 


\section{Capítulo 5}

\section{Conclusão}

O objetivo desse trabalho foi de levantar as estruturas convencionais para armazenamento histórico de dados tanto no ambiente operacional como no ambiente analítico, de modo a propor uma alternativa para diminuição das dificuldades de sincronismo de dados entre esses ambientes.

No capitulo 2 apresentou-se uma revisão da literatura existente, no capítulo três a proposta de Data Warehouse Temporal(DWT), no quatro as diretrizes para construção de uma ferramenta capaz de criar diferentes |estruturas de consultas SQL para cada modelo fisico de dados armazenados no DWT.

Para validar a proposta desse trabalho, aplicou-se os conceitos, ora apresentados, num estudo de caso da Secretaria de Fazenda do Estado de São Paulo.

No desenvolvimento desse trabalho pode-se ratificar novas necessidades de sincronismo entre os bancos de dados operacionais e os analiticos. Como mostrado em Garcia-Molina(citar), a evolução das análises e al complexidade transacional dos sistemas operacionais está exigindo novas formas de abordagem e criação dos repositórios analíticos de dados. A diminuição do tempo de sincronização entre o dado no sistema operacional e dado no sistema analítico tem sido cada vez mais necessário. 


\subsection{Contribuições do trabalho}

\subsubsection{DWT (FH e FA)}

O conceito de DWT considera a possibilidade de aproximação do paradigma do Banco de Dados Histórico e o de armazenamento em Data Warehouse. As dimensões do Data Warehouse tradicionais correspondem ao estado de um fato num determinado instante do tempo, nada mais são que informações históticas num instante do tempo. Desta maneira temos que no DWT as informações referentes as dimensões se encontrarão armazenadas no fato histórico (FH), repositório de dados responsável pelo armazenamento de informações histórica do sistema. Assim as dimensões assumem um novo valor semântico se tornando fatos históricos.

Essa mudança é substancial. Com a criação do $\mathrm{FH}$ podemos desvincular, sem causar perdas de consistência, os dados históricos, que convencionalmente sempre foram alocados nas dimensões, em novas estruturas de dados que denominamos nesse trabalho de fatos históricos. Isso permite uma flexibilidade enorme para o processo de sincronização de dados entre os ambientes operacionais e analíticos. Como visto no capítulo 4, esse conceito permite que dados cadastrais que convencionalmente são representados em dimensões e que possuem uma periodicidade transacional distinta do fato analítico possam ser sincronizados em tempos distintos do fato analítico principal.

Outra importante contribuição é que esses fatos históricos desvinculados podem ser utilizados por mais de um fato analítico, evitando assim a replicação de dimensões de dados muito comuns na abordagem convencional.

A desvantagem dessa proposta recai na necessidade de junções entre os fatos históricos e analíticos, que podem ser qtimizadas através dos indices histórico-analítico.

Esses índices, que também são uma importante contribuição desse trabalho, diminuem o custo de realização das junções. 


\subsubsection{Monitor de consultas}

Uma outra importante contribuição desse trabalho foi a classificação dos tipos de consultas na estrutura do DWT. Essa classificação tem como objetivo a otimização dos planos de consulta realizadas no DWT. Tal classificação permitiu caraterizar as consultas: ao fato histórico $\mathrm{FH}$ (temporais, agrupamento, hierarquia); ao fato analítico FA e principalmente a junção entre $\mathrm{FH}$ e FA.

Com tal classificação comparou-se a solução DWT com as soluções propostas por Kimball. Apresentou-se também os códigos SQL gerados em cada uma das situações.

\subsection{Futuras pesquisas}

Com a proposta do DWT e a caraterização das consultas apresentadas nesse trabalho pretendemos evoluir com as seguintes frentes de futuras pesquisas:

\subsubsection{Métrica para classificação de transaçōes}

A modelagem de dados para Data Warehouse pauta-se muito ainda nos aspectos estruturais do banco de dados. Assim os problemas são repassados para os processos denominados de carga que tratam o problema de sincronismo de dados de forma homogênea. $O$ tempo e o trabalho em determinadas situações podem inviabilizar a disponibilidade do dado para as consultadas analíticas. Esse problema pode ser minimizado através da criação de uma métrica para capturar os requisitos das transações operacionais e analíticas envolvidas nesses ambientes e a relação entre elas. Tais requisitos devem ser utilizados no projeto fisico de Data Warehouse.

\subsubsection{Alteração dos Algoritmos de Sincronismo}

Os vários algoritmos de sincronismo de dados (Zhuge et. al., 1998) consideram o processo dinâmico de cargas ou estático. $O$ modelo de dados estrutural para isso são visões materializadas ou modelo estrela vistos no 'capitulo 2. O DWT permite a criação de um modelo de dados híbrido tanto na estrutura de dados como no processo de sincronismo dos mesmos entre os ambientes 
operacionais e analíticos. A $\$ s s i m$, como próximos passos podemos analisar possiveis alterações em tais algoritmos de modo a especializar para cada porção de dados do Data Warehouse os processos de sincronismo.

\subsubsection{Monitor de Consultas}

Com as soluções apresentadas no capítulo 4, pode-se implementar um simulador de consultas de modo a conhecer o comportamento das transações analíticas. Esse conhecimento poderá eventualmente ser utilizado para um novo projeto das porções de dados e seus mecanismos de sincronismo do Data Warehouse.

\subsubsection{Indíces Histórico-Analítico}

Com o conceito de Índice Histórico-Analítico pretende-se criar um projeto de implementação de modo que as soluções dos gerenciadores de dados existentes do mercado possam incorporá-lo. A primeira abordagem considera a criação de tais índices fora da estrutura do gerenciador de dados. Com tal implementação é possível compará-la com outras soluções convencionais. Num segundo momento é possível integrar tal solução nos gerenciadores de dados disponíveis. 


\section{Capítulo 6}

\section{Referências Bibliográficas}

(Blakeley et. al., 1986) Blakeley, J.A.; Larson, P.A.; Tompa, F.W. Efficiently Updating Materialized Views. In Proc. ACM SIGMOD Int. Conf. on Management of Data, May 1986, p.61-71.

(Brachman et. al., 1996) Brachman, R.J.; Khabaza, T.; Kloesgen, W.; Simoudis, E. Mining Business Databases. Communications ACM, Special Issue on Data Mining, v.39, n.11, November 1996, p.42-8.

(Carter \& Hamilton, 1998) Carter, C.L.; Hamilton, H.J. Efficient Attribute-Oriented Generalization for Knowledge Discovery from Large Databases. IEEE Transactions on Knowledge and Data Engineering, v.10, n.2, March/April 1998, p.193-208.

(Chaudhuri \& Dayal, 1997) Chaudhuri, S.; Dayal, U. An Overview of Data Warehousing and OLAP Technology. ACM SIGMOD Record,v.26, n.1, March 1997, p.65-74.

(Chaudhuri, 1998) Chaudhuri, S. Data Mining and database systems: where is the intersection?. IEEE Data Engineering, v.21, n. 1, March 1998, p.4-8.

(Chen et. al., 1996) Chen, M-S.; Han, J.; Yu, P.S. Data Mining: An Overview from a Database Perspective. IEEE Transactions on knowledge and Data Engineering, v.8, n.6, December 1996, p.866-83. 
(Chen et. al., 1998) Chen, M-S.; Park, J.S.; Yu, P.S. Efficient Data Mining for Path Traversal Patterns. IEEE Transactions on knowledge and Data Engineering, v.10, n.2, March-April 1998, p.209-221.

(Cheung et. al., 1996) Cheung, D.W.; Ng, V.T.; Fu, A.W.; Fu, Y. Efficient Mining of Association Rules in Distributed Databases. IEEE Transactions on Knowledge and Data Engineering, v.8, n.6, December 1996, p.911-22.

(Colliat, 1996) Colliat, G. Relational and Multidimensional Database Systems. $A C M$ SIGMOD Record, v.25, n.3, September 1996, p.64-9.

(Dar et. al., 1996) Dar, S.; Jagadish, H.; Levy, A.; Srivastava, D. Aswering Queries with Aggregation using Views. In Proc. $22^{N D}$ Int. Conf. on Very Large Data Bases, September de 1996, p.318-29.

(Dey et. al., 1998) Dey, D; Barron, T.M; Saharia, A.N. A Decision Model for Choosing the Optimal Level of Storage in Temporal Databases. IEEE Transactions on Knowledge and Data Engineering, v.10, n.2, March/April 1998, p.297-309.

(Faloutsos et. al., 1995) Faloutsos, C.; Lin, K-I.; FastMap: A Fast Algorithm for Indexing, DataMining and Visualization of Traditional and Multimedia Datasets. ACM SIGMOD Record, v.24, n.2, June 1995, p. 163-74.

(Fayad \& Shapiro, 1996) Fayad, U.; Shapiro, G.P. Data Mining and Knowledge Discovery in Databases: An overview. Communications of the ACM, Special Issue on Data Mining, v.39, n. 11, November 1996, p 27-34.

(Fayad et. al., 1996) Fayad, U.; Haussler, D.; Stolorz, P. Mining Scientific Data. Communications of the ACM, Special Issue on Data Mining, v.39, n.11, November 1996, p.51-7. 
(Gray et. al., 1996) Gray, J.; Helland, P.; ONeil, P.; Shasha, D. The danger of replication and a solution. In Proc. ACM SIGMOD Int. Conf. on Management of Data, June 1996, p.173-182.

(Griffin \& Libkin, 1995) Griffin, T.; Libkin, L. Incremental Maintance of Views with Duplicates. In Proc. ACM SIGMOD Int. Conf. on Management of Data, May 1995, p.328-39.

(Gupta et. al., 1995) Gupta, A.; Harinarayanm, V.; Quass, D. Aggregate Query Processing in Data Warehouses. In Proc. $21^{\text {st }}$ Int. Conf. on Very Large Data Bases, August 1995, p.358-69.

(Hammer et. al., 1995) Hammer, J.; Garcia-Molina, H.; Widom, J.; Labio, W.; Zhuge, Y. The Stanford Data Warehousing Project. In Proc. IEEE Quart. Bull. Data Engineering, v.18, n.2, June 1995, p.41-8.

(Han et. al., 1996) Han, I.; Huang, Y.; Cercone, N.; Fu, Y. Intelligent Query Answering by Knowledge Discovery Techiniques. IEEE Transactions on Knowledge and Data Engineering, v.8, n.3, June 1996, p.373-90.

(Harinarayan et. al., 1996) Harinarayan, V.; Rajaraman, A.; Ullman, J. Implementing Data Cubes Efficiently. ACM SIGMPD Record, v.25, n.2, June 1996, p.205-216.

(Imielinski \& Mannila, 1996) Imielinski, T.; Mannila, H. A Database perspective on Knowledge Discovery. Communications of the ACM, Special Issue on Data Mining, v.39, n.11, November 1996, p.58-64.

(Inmon, 1996) Inmon, W.H. The Data Warehouse and Data Mining. Communications of the ACM, Special Issue on Data Mining, v.39, n.11, November 1996, p.49-50.

(Keim \& Kriegel, 1996) Keim, D.A.; Kriegel, H-P. Visualization Techniques for Mining Large Databases: A Comparison. IEEE Transactions on Knowledge and Data Engineering, v.8, n.6, December 1996, p.923-38. 
(Kimball, 1996) Kimball, R. Aggregate Navigation with (almost) no Metadata. DBMS Online, http://www.dbmsmag.com/9608d54.html, August 1996.

(Orli, 1996) Orli, R.J. Data Extraction, Transformation, and Migration Tools. Kismet Analytic Corporation, http://www.kismeta.com/ex2.html, 1996.

(Orr, 1996) Orr, K. Data Warehousing Technology. The Ken Orr Institute, http://www.kenorrinst.com/warehousing.html, 1996.

(Ozsu \& Valduriez, 1999) Ozsu, M.T; Valduriez, P. Principles of Distributed Database Systems. 2.ed. USA, Prentice Hall, 1999.

(Pacitti et. al., 1998) Pacitti, E.; Simon, E.; De Melo, R. Improving Data Freshness in Lazy Master Schemes. In Proc. $17^{\text {th }}$ Int. Conf. on Distributed Computing Systems, May 1998, p.164-171.

(Ramakrishnan, 1997) Ramakrishnan, Raghu. Database Management Systems. 1.ed. Wiscosin, McGraw-Hill, 1997.

(Rossopoulos, 1998) Rossopoulos, N. Materialized Views and Data Warehouse. ACM SIGMOD Record, v.27, n.1, March 1998, p.21-6.

(Widom, 1995) Widom, J. Research Problems in Data Warehousing. In Proc. $4^{\text {th }}$ Int. Conf. on Information and Knowledge Management, November 1995, p.25-30.

(Zhang et. al., 1996) Zhang, T.; Ramakrishnan, R; Livny, M. BIRCH: An Efficient Data Clustering Method for Yery Large Databases. In ACM SIGMOD Int. Conf. on Management of Data, June 1996, p.103-114.

(Zhuge et. al., 1995) Zhuge, Y.; Garcia-Molina, H.; Hammer, J.; Widom, J. View Maintenance in a Warehousing Environment. ACM SIGMOD Record, v.24, n.2, June 1995, p.316-327. 
(Zhuge et. al. 1998) Zhuge, Y.; Garcia-Molina, H.; Wiener, J. L. Consistency Algorithms for Multi-Source Warehouse View Maintenance. Distributed and Parallel Databases, 1998, p. 740. 


\section{Apêndice A}

ESTUDO DE CASO

\section{Secretaria da Fazenda do Estado de São Paulo (SeFaz)}

Como visto no capítulo 3 a extração e transformaçāo dos dados do ambiente Operacional para o Data Warehouse se constitui em grande dificuldade. A dificuldade é tamanha que muitas vezes o projeto é inviabilizado devido a este problema. Analisaremos a seguir como o Data Warehouse Temporal foi de grande importância para o desenvolvimento do Data Warehouse na Secretaria da Fazenda do Estado de São Paulo.

O procedimento padrão para abertura e alterações de dados cadastrais de empresas anteriores a implantação deste projeto, demoninado Posto Fiscal Eletrônico (PFE), consistia dos seguintes passos:

1) Contribuinte ou Contador responsável se dirigia ao Posto Fiscal (PF) de sua Jurisdição munida de toda documentação necessária para a abertura e/ou alteração dos dados;

2) Fiscais verificam a autenticidade de toda documentação e das informações, como por exemplo, verificar se a empresa encontra-se localizada no endereço informado;

3) Os documentos são enviados para São Paulo para a atualização do cadastro;

4) Dados cadastrais são atualizados por digitadores contratados para isso e documentos são devolvidos aos PFs.

Os dados cadastrais das empresas localizavam-se armazenados em plataforma de Grande Porte.

Com o Posto Fiscal Eletrônico os dados cadastrais das empresas passaram a ser armazenados em plataformas de Pequeno Porte. Esta passagem de dados da plataforma de Grande Porte para Pequeno Porte está sendo feita gradativamente, devido a muitas inconsistências de dados que impossibilitariam a passagem total de dados de uma plataforma para outra. No caso de abertura de uma nova empresa não há problema algum, já que na plataforma de grande porte não possui dados da mesma. Esta passagem ocorre basicamente da seguinte maneira: 
1) $O$ contribuinte ou contador deve solicitar uma senha via PFE, que a enviará pelo Correio ou então diretamente no PF de sua Jurisdição, caso haja maior urgência.

2) O contribuinte ou contador, ao tentar realizar qualquer opção de alteração dos dados cadastrais será qbrigado a fazer o Recadastramento. No Recadastramento os dados serão obtidos da|plataforma de grande porte e o contribuinte será obrigado a informar novos dados que constam somente na nova plataforma, dados esses que são de grande importância paral o Fisco.

3) Feito o Recadastramento o contribuinte terá liberdade para alterar os dados necessários.

Para que o contribuinte possa realizar essas operações ele precisa somente de internet e de um browser que tenha suporte a Java 1.1. Todas as operações são realizadas via Internet. $O$ contribuinte não precisa realizar download de programa algum.

Foi criada uma base de dados na plataforma de pequeno porte semelhante àquela existente na plataforma de grande porte. Foram criados arquivos texto dos dados existentes da plataforma de grande porte para que os mesmos pudessem ser utilizados para a importação na plataforma de pequeno porte.

Este é o escopo geral do Projeto PFE, veremos agora os problemas apresentados para a implantação do DW tradicional e os motivos que nos fizeram optar pelo DWT.

Primeiramente analisaremos a GIA. GIA é um documento importante que envolve pagamento de impostos e que deve ser entregue pelo contribuinte a SeFaz periodicamente. A GIA está diretamente ligada a um atributo da empresa que é conhecido como Regime de Apuração. Este atributo que nos diz quanto a empresa deve pagar, a peridiocidade de entrega da GIA. Um exemplo, se a empresa pertence ao Regime de Apuração de MicroEmpresa os impostos que ela deve pagar são menores do que se pertencesse ao Regime de Apuração RPA.

Dois grandes problemas encontrados para o desenvolvimento do DW tradicional foram os já supracitados: transformação dos dados e atualização do DW. 
A transformação dos dados do ambiente Operacional para o DW era inviável. As dificuldades apontadas pela equipe que deveria extrair tais dados eram muitas. Por ser um sistema antigo, que passou por muitas transformações no decorrer dos anos, que envolveu um grande número de programadores, existiam muitas particularidades que poucos conheciam e que poderiam vir a provocar inconsistências importantes de dados. A informação de que dispunham eram basicamente o histórico de dados das informações mais relevantes, como Regime de Apuração e dados relativos a GIA, quando foi entregue e valor pago.

Outro problema é que muitas vezes as atualizações necessárias não eram feitas no cadastro. Alguns documentos eram esquecidos, outros perdidos, digitadores que por erro ou preguiça entravam com informações incorretas. Isto provocava o seguinte efeito colateral, o contribuinte então entregava a GIA como se fosse ME, porém no cadastro constava ainda como RPA, por exemplo. Desta maneira teríamos no Data Warehouse uma informação incorreta, ou seja, o valor da GIA deste contribuinte referia-se ao Regime de Apuração ME e não RPA. Feita a atualização no Histórico de Regime, como faríamos para que essa alteração se refletisse no DW. Teríamos que criar um processo para que toda alteração de Histórico se refletisse no DW, causando um trabalho extra.

A solução encontrada para este problema foi o desenvolvimento do DWT. Desta maneira o esforço gasto para a passagem dos dados foi bem suavizado. As tabelas de dimensão foram representadas pelas tabelas históricas que o grande porte já possuia. Elas constam basicamente das seguintes informações, Inscrição Estadual, data inicio, data fim e a informação desejada.

O modelo é apresentado a seguir. Mudanças tiveram que ser feitas, criação de chaves geradas, criação de FHP, criação da dimensão Tempo e adaptação das outras tabelas para o suporte de datas utilizando a dimensão Tempo (id_inicio e id_fim), porém todas estas alterações são relativamente simples se comparado com as alterações necessárias para se obter o DW tradicional. $O$ esforço computacional para que estas alterações possam ser realizadas no conceito tradicional é grande. 


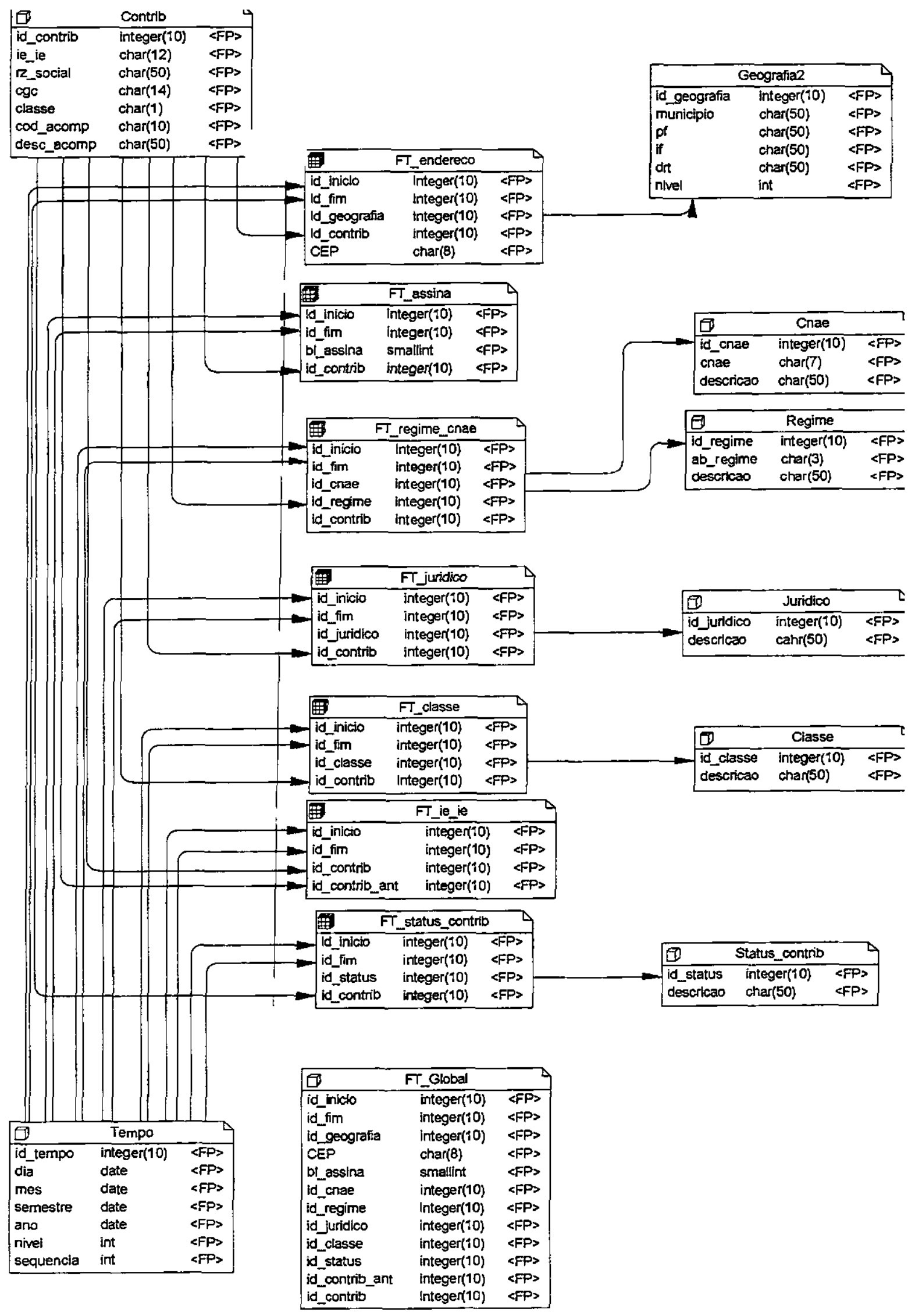


A figura anterior mostra o modelo de FH. Note que no modelo acima temos uma FHG, uma FHPSd e algumas FHPI. Somente para não poluir o modelo as chaves primárias da FHG não aparecem ligadas a suas respectivas chaves nas dimensões.

A seguir temos o modelo de FA da GIA.

\section{GIA}

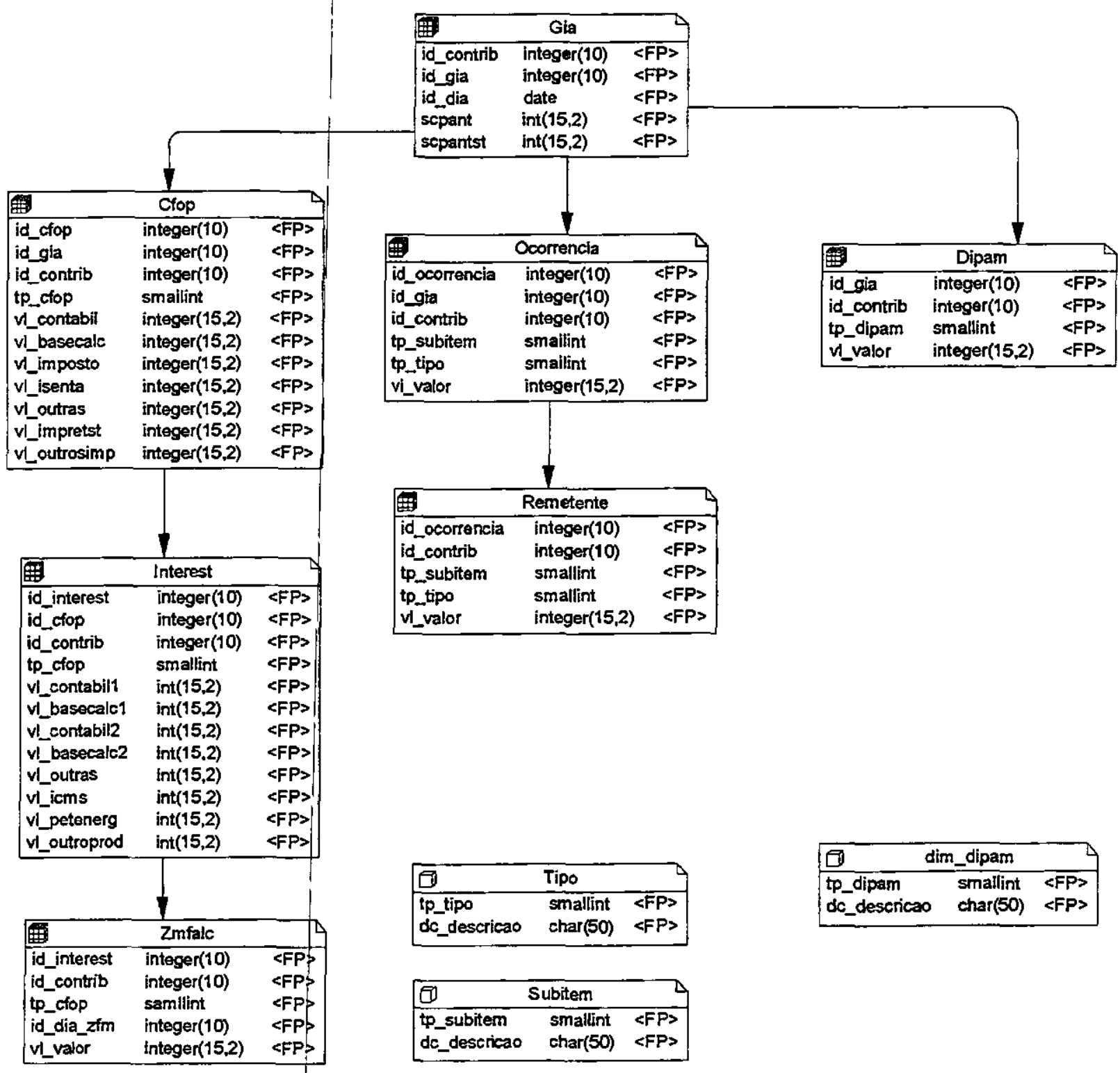

\begin{tabular}{|lll|}
\hline 1] & dim_cfop & \\
\hline tp_cfop & smallint & <FP $>$ \\
de_descricao & char(50) & $<F P>$ \\
\hline
\end{tabular}

Nesta figura não ligamos as tabelas de dimensão correpondentes a seus fatos. Foi dito que as dimensões estariam localizadas no histórico, porém as dimensões que aparecem acima são na 
realidade tabelas de look-up, ou seja, não são informações cadastrais do contribuinte;-são-tabelas estáticas, são informações restritas a própria tabela de fatos, informaç̄̄es essas que não se alteram. Neste caso foi adotada a política de se replicar os ids e dimensões correpondentes, pois as buscas são bem localizadas em cada uma das Tabelas de Fato. Em cada uma das tabelas de fato temos o atributo id_contrib, que serve para ligar as Tabelas de Fato ao FH.

A tabela de dimensões Geografia será subdividida pela dimensão Posto Fiscal. Além disso a FHPI FT_regime_cnae será subdivida pelo Regime de Apuração em:

- Simples - sendo os regimes que compõem o Simples, ME, EPPA e EPPB;

- RPA - composto pelos regimes RPA e RPA-ST;

- Regime de Estimatiya - composto pelos regimes RES e RES-ST;

- Outros - composto/pelos regimes restantes.

Existem milhares de donsiderações a serem feitas sobre Data Warehouse. Não existe nenhum modelo de Data Warehouse que atenda perfeitamente a todas as necessidades. Devemos analisar informações que se deseja extrair a elas. Esta análise déve ser feita tendo como base as consultas e atender satisfatoriamente as necessidades, pode conduzir por un modelo falho, que não consiga trabalho que se fez sobre ele ao fracasso, principalmente no projto de Data Warehouse e todo o - queffange a extração de dados. 